\begin{abstract}
UNIVERSIDADE DE SÃO PAULO
INSTITUTO DE FÍSICA DE SÃO CARLOS

INSTITUTO DE QUÍMICA DE SÃO CARLOS

ESCOLA DE ENGENHARIA DE SÃO CARLOS

GRUPO DE POLÍMEROS BERNHARD GROSS
\end{abstract}

MIKE MELO DO VALE

Guias de onda poliméricos para sensoriamento óptico e conversão de comprimento de onda 

MIKE MELO DO VALE

\section{Guias de onda poliméricos para sensoriamento óptico e conversão de comprimento de onda}

Dissertação apresentada ao Programa de Pós-Graduação Interunidades em Ciência e Engenharia de Materiais, da Universidade de São Paulo, para obtenção do título de Mestre em Ciência e Engenharia de Materiais.

Área de Concentração: Desenvolvimento, Caracterização e Aplicação dos Materiais.

Orientador: Prof. Dr. Francisco Eduardo Gontijo Guimarães

SÃO CARLOS 
AUTORIZO A REPRODUÇÃO E DIVULGAÇÃO TOTAL OU PARCIAL DESTE TRABALHO, POR QUALQUER MEIO CONVENCIONAL OU ELETRÔNICO, PARA FINS DE ESTUDO E PESQUISA, DESDE QUE CITADA A FONTE.

Do Vale, Mike Melo.

Guias de onda poliméricos para sensoriamento óptico e conversão de comprimento de onda /Mike Melo do Vale; orientador Francisco Eduardo Gontijo Guimarães. São Carlos, 2010.

$102 \mathrm{p}$.

Dissertação (Mestrado - Programa de Pós-Graduação Interunidades em Ciência e Engenharia de Materiais. Área de Concentração:

Desenvolvimento, Caracterização e Aplicação de Materiais) - Escola de Engenharia de São Carlos, Instituto de Física de São Carlos, Instituto de Química de São Carlos da Universidade de São Paulo.

1. Guias de onda. 2. Conversores de comprimento de onda. 3. Biossensores ópticos. 4. Polímeros luminescentes. I.Título. 


\section{FOLHA DE APROVAÇÄO}

Mike Melo do Vale
Dissertação apresentada ao Programa de Pós-Graduação em Ciência e Engenharia de Materiais da Universidade de São Paulo para obtenção do título de Mestre em Ciência e Engenharia de Materiais.
Área de Concentração: Desenvolvimento, Caracterização e Aplicaçăo de Materiais.

Aprovado(a) em 14.06.2010

\section{Comissão Julgadora}

Prof(a). Dr(a). Francisco Eduardo Gontijo Guitparães Instituição: IFSC/USP Assinatura
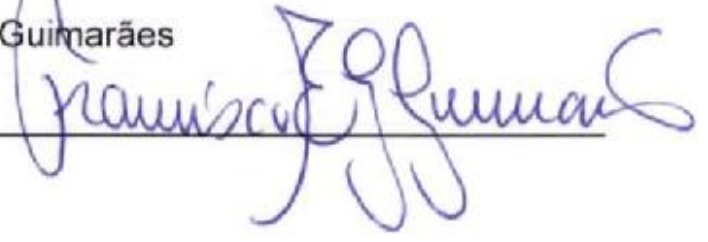

Prof(a). Dr(a). Ernesto Chaves Pereira de Souza

Instituição: UFSCar

Assinatura

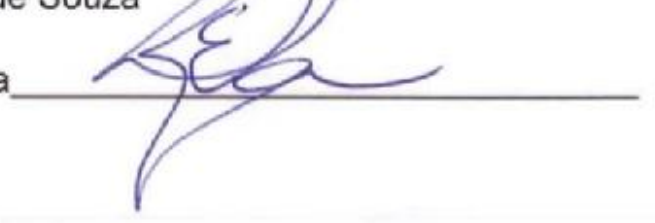

Prof(a). Dr(a). Valtencir Zucolotto

Instituição: IFSC/USP

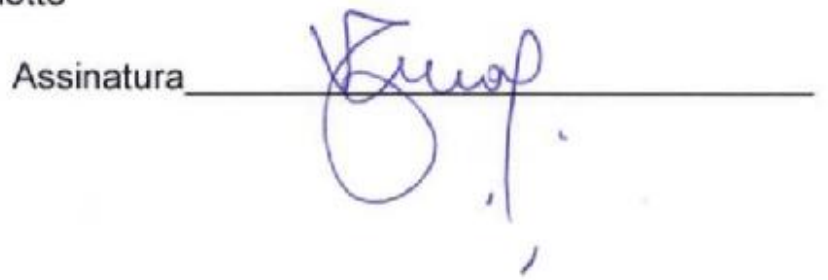



Dedico este trabalho a meu pai, Antonio Carlos Machado do Vale, por sua batalha dia após dia, honestidade, generosidade, a sua contagiante e incrível alegria de sempre. Muito obrigado! 



\section{A G RA D E C I M E N T OS}

$\checkmark$ Primeiramente ao Prof. Dr. Francisco Eduardo Gontijo Guimarães por sua orientação e preciosos ensinamentos, por entender as dificuldades e possuir o discernimento necessário para sempre permitir um novo começo. Agradecer a toda e qualquer importante ajuda que me foi oferecida. Muito obrigado, sempre!

$\checkmark$ Ao Prof. Dr. Helder Nunes da Cunha e ao Prof. Dr. Célio Aécio Borges da Universidade Federal do Piauí-UFPI, por terem influência direta em minha escolha de estar aqui. Obrigado pela amizade e confiança.

$\checkmark$ Ao Prof. Dr. Roberto Mendonça Faria pelo suporte financeiro que supriu as primeiras necessidades de um recém chegado em São Carlos. Nunca esquecerei!

$\checkmark$ A minha família. Meus pais Antonio Carlos Machado do Vale e Iva Melo Pereira do Vale pela vida, por todas as ações em cada um dos momentos que passamos juntos, pelos ensinamentos, conversas, tristezas, por cada "sim" e cada "não", pois estes constituíram as bases de minha formação como ser humano. A minha irmã, Adria Melo do Vale, por toda luta em sua vida, coragem e determinação, por ser exemplo de quão responsável uma pessoa deva ser com seus afazeres. Aos avós e tios em Piripiri-PI, por sua simplicidade e carinho de sempre. Amo vocês hoje como vou amar sempre. Obrigado por existirem!

Agradecer a uma pessoa sem igual que faz parte da minha vida, Emanuele Alves Araújo, por todos os dias de minha vida em que sorri a seu lado, que sorri a distância, cada momento de paz, por tudo que aprendi, por cada lágrima que via escorrer em seu rosto em nossas despedidas, por cada "te adoro", cada abraço aconchegante, todas as simples ligações, por tudo que somos hoje, que seremos amanhã. Sempre lembrarei!

Aos amigos Alexandre, Washington e Manoel por todos os momentos de descontração e seriedade, por me mostrarem como entender a diferença entre as necessidades de cada um sob um teto. Ao "Voshington" pela simplicidade da vida. Ao "MCV" pela alegria de viver, superação.Ao "maguim”, por todas as e reflexões a respeito de vários assuntos, por todo o tempo que nos conhecemos, por sempre ser amigo, por ser um educador nato, por ser um idealista, e se Henry Ford estiver correto: Um idealista é uma pessoa que ajuda os 
outros a prosperar. Então, o Piauí tem muita sorte de ter/ser os sonhos de alguém como você, obrigado por tudo, sorte meu velho amigo!

$\checkmark$ Aos meus amigos de graduação (SEFUFPI), que hoje se encontram na PUC-RJ, UFMG, USP-SP, USP-SC e alguns já de volta a nossa maravilhosa Teresina-PI. Aos velhos tempos sempre guardarei boas recordações e aos dias que virão desejo que retornem à nossa terra, não somente por nossa amizade, sobretudo pelo potencial de cada um de vocês, ajudando a erguer a sociedade que sonhamos em viver.

$\checkmark$ Aos colegas do Grupo de Polímeros Bernhard Gross, aos amigos Rodrigo Pagliai, Yurica e em especial aos amigos da sala 20A: Angelo, Cris, Kleber, Moema e Nirton pela amizade, por cada dia dentro e fora da USP.

$\checkmark$ Aos que fazem parte do "grupo de alunos do Prof. Francisco": Borrero (Borrerito), Haroldo, Fernando, Danilo, Regina, Victor e os demais, obrigado por tantas boas conversas dentro e fora da USP.

$\checkmark$ Aos colegas do Piauí no IQSC, em especial aos "parceiros" Adriano e Orlando, por todos os momentos de descontração nos finais de semana, fazendo com que São Carlos ganhasse ares de Teresina por alguns instantes, dizer que é sempre muito bom quando nos reunimos.

$\checkmark$ No grupo de polímeros a Dr. Débora Balogh, pelo auxílio no lab. de química, pois se o mesmo ainda se encontra em pé e seus utilizadores ainda podem voltar para casa sem sentir nada de anormal, deve-se agradecer a esta pessoa. A Níbio, Bertho, Ademir pelo apoio técnico.

$\checkmark$ No grupo de semicondutores aos técnicos Carlos e Aroldo pelo apoio técnico.

$\checkmark$ Na Pós-Graduação gostaria de deixar meu muito obrigado a Silvio César, Victor Barioto e Samira Italiano por toda a calma e ajuda ao longo dos anos que estive aqui.

$\checkmark$ Muito obrigado a todos os funcionários da biblioteca do IFSC, em especial a Mara e Cris por toda a ajuda prestada.

$\checkmark$ A USP, ao IFSC, a CAPES e em especial ao CNPq pelo apoio financeiro. 
...você deve ficar apenas com aquilo que lutou para ter, pois aquilo que conquistou com luta é seu... Antonio Carlos Machado do Vale ...que para todas as coisas efêmeras que a vida nos proporciona, ao menos para algumas devemos nos permitir a distração... 



\section{R E S U M O}

DO VALE, M. M. Guias de onda poliméricos para sensoriamento óptico e conversão de comprimento de onda. 2010. 102 p. Dissertação (Mestrado em Ciência e Engenharia de Materiais) - Instituto de Física de São Carlos, Instituto de Química de São Carlos, Escola de Engenharia de São Carlos, Universidade de São Paulo, São Paulo, 2010.

O objetivo de pesquisa deste trabalho foi estudar guias de onda planares constituídos por uma blenda polimérica composta por uma matriz transparente de polimetacrilato (PMMA) e polímeros emissores de luz em baixa concentração para atuarem como material absorverdor e emissor de luz em uma larga faixa espectral. Devido aos processos luminescentes nestes sistemas planares surgem características interessantes do ponto de vista de sua aplicação em dispositivos opto-eletrônicos, sensores e em possíveis concentradores de comprimento de onda. Os dispositivos foram caracterizados de acordo com suas características de absorbância, emissão e excitação. No presente trabalho, nós demonstramos o funcionamento de guias de onda planares produzidos a partir de blendas poliméricas contendo diferentes polímeros luminescentes diluídos em uma matriz de PMMA. Estes materiais foram dissolvidos em tolueno e depositados pela técnica 'cast' sobre substratos de vidro contendo filmes metálicos de alumínio. Nessa configuração, a luz incidente de excitação é acoplada ao guia através de sua absorção e conseqüente re-emissão pelos polímeros luminescentes. Foram utilizados cinco polímeros conjugados que possuem sobreposição dos seus espectros de absorção e emissão entre 350 e $600 \mathrm{~nm}$ visando uma ampla faixa de aplicação. Estes guias apresentam um espectro de emissão com características típicas de uma cavidade do tipo Fabri-Perot, com linhas extremamente estreitas $(3 \mathrm{~nm})$ e altamente polarizadas na direção paralela (modo TE) e perpendicular (TM) ao plano do guia de onda. A emissão destes guias é fortemente dependente de sua geometria e do índice de refração efetivo. Os mesmos filmes poliméricos, porém mais espessos $(30 \mu \mathrm{m})$, foram utilizados como conversores de comprimento de onda visando aplicação em conversores solares luminescentes (Luminescence Solar Converters, ou LSCs). O uso de baixas concentrações das moléculas utilizadas foi necessário para evitar possíveis formações de agregados quando altas concentrações de PMMA são utilizadas na preparação dos filmes. A metalização de uma das faces planares possibilitou o aumento da eficiência de converssão dos comprimentos de onda nos LSCs. Estes foram analisados em termos de suas emissões laterais (ao longo do plano) e normal (perpendicular ao plano). Neste sistema, a luz absorvida é convertida em luz de baixo comprimento de onda e alta pureza espectral através de processos de reabsorção, relaxação interna e re-emissão que ocorrem ao longo do plano do LSC. A eficiência de conversão e as perdas em função da concentração polimérica na matriz foram estudadas para os LSCs preparados neste trabalho. O escape dos fótons nas interfaces para ângulos menores que o ângulo crítico $\left(\theta_{c}=\operatorname{sem}^{-1}(1 / n)\right)$ e processos de transferência de energia em LSCs com alta concentração polimérica devem ser otimizados para sua aplicação como dispositivos. Com o presente trabalho, esperamos promover um controle mais eficaz dos processos radiativos, bem como aumentar a eficiência do confinamento da radiação nos guias e a interação da luz guiada com o ambiente em torno desses dispositivos. Apesar da enorme versatilidade para aplicações optoeletrônicas, alguns aspectos fundamentais relacionados à preparação e física destas estruturas ainda representa um grande desafio.

Palavras-chave: Guias de onda. Conversores de comprimento de onda. Biossensores ópticos. Polímeros luminescentes. 



\section{A B S T R A C T}

DO VALE, M. M. Polymeric based waveguides for optical biosensor and wavelength conversion. 2010. 102 p Dissertação (Mestrado em Ciência e Engenharia de Materiais) Instituto de Física de São Carlos, Instituto de Química de São Carlos, Escola de Engenharia de São Carlos, Universidade de São Paulo, São Paulo, 2010.

The main goal of this work is the production and the study of planar wave guides based on a polymeric blend composed of light emitting polymers embedded in a transparent polymetacrilate (PMMA) matrix. The function of these light emitting polymers is to absorb a broad spectrum of light and re-emit it along the wave guide. Interesting features arise from the luminescent process along these planar systems. Therefore this system can be applied as optoelectronics devices, sensors and also in wavelength converters. The devices were studied in terms of its absorption, emission and excitation characteristics. As a result of this work, we expect to promote a more efficient control of the radiactive process inside of devices, to improve their guiding performance and to establish the conditions for light interaction with the surround environment. Although they represent a versatile option to optoelectronic applications, some fundamental aspects regarding production and physical understanding still not fully understood. Planar wave guides were formed by using blends with different luminescent polymers embedded in a PMMA matrix. Films of these materials dissolved in toluene were deposited by casting the polymethacrylate solution on a glass substrate containing a reflective aluminum layer. Using this configuration, the incident excitation light is coupled to the wave guide by its absorption and then re-emitted by the luminescent polymers. Five different conjugated polymers with an overlap in their absorption and emission spectrum from $350 \mathrm{~nm}$ to $600 \mathrm{~nm}$ were used. This overlapping was required to increase the range of application. These wave guides show a light emission spectrum with characteristics similar to the Fabri-Perot cavity, where very narrow peaks and highly polarized emission in both TE and TM modes were observed. In addition, the emission is strongly dependent on its geometry and the effective refraction index. In other hand, thicker polymeric guides $(30 \mu \mathrm{m})$ were used as luminescence solar converters (LSCs). The optimal concentration of conjugated polymers has to be very low in order to avoid the formation of aggregates since high PMMA concentrations have to be used in the LSC preparation. The study of such LSCs was carried out by measuring the lateral and the normal emissions of the guide. The total polymeric luminescence is fully converted to light of low wavelength for the case of lateral emission. This process does not depend on the excitation wavelength. The conversion efficiency was increased by evaporating metals on one planar face of the LSC. In this structure, light is absorbed and then converted to a shorter wavelength with high spectral pureness through re-absorption, relaxation and re-emission processes occurring along the LSC plane. The conversion efficiency and the losses along the converter were studied as a function of the polymeric concentration. In order to optimize these structures, a full understand the process of energy transfer and photon leakage through the interfaces for angles smaller than the critical angle $\left(\theta_{\mathrm{c}}=\operatorname{sem}^{-1}(1 / \mathrm{n})\right)$ is necessary for using LSCs as devices.

Keywords: Waveguides. Wavelength converters. Optical biosensors. Luminescent polymers. 



\section{LISTA DE F I G URAS}

Figura 1 - Representação dos orbitais moleculares $\pi$ e $\sigma$ formados entre dois átomos de carbono $\mathrm{sp}^{2}$

Figura 2 - A parte superior da figura mostra um esquema da formação da banda quando os níveis de energia estão muito próximos. A parte inferior da figura mostra as bandas de valência e de condução dos três tipos de materiais classificados de acordo com a teoria de bandas.

Figura 3 - Diagrama e ilustração dos processos óticos em polímeros conjugados e das posições relativas para os espectros de absorção, fluorescência e fosforescência.

Figura 4 - Sobreposição do espectro de absorção de uma molécula aceptora pelo espectro de emissão de uma molécula doadora.

Figura 5 - Processos responsáveis pela transferência do estado excitado entre moléculas: os processos de reabsorção, relaxação interna e re-emissão e os processos de transferência de energia do tipo Förster.

Figura 6 - Mecanismo Förster de transferência de energia. Um estado inicial $D^{*}$ transfere energia de forma não radiativa para um estado $A^{*}$ e então retorna para o estado fundamental $D$.

Figura 7 - Destaque para os modos TE e TM na propagação de uma onda eletromagnética no interior de um guia.

Figura 8 - (a) Representação do guia de onda obtido para os estudos de emissão lateral neste trabalho. (b) Visão lateral do guia constituído por três meios distintos: ar, meio 1 e meio 2 com seus respectivos índices de refração $\mathrm{n}_{\mathrm{ar}}, \mathrm{n}_{1}$ e $\mathrm{n}_{2}$. (c) Esboço de como ocorrem reflexões e transmissões em interfaces com diferentes índices de refração.

Figura 9 - Trajetórias de múltiplos raios de luz entre duas superfícies semitransparentes. Cálculos que levam em conta a diferença entre dois sucessivos raios podem ser usados para encontra a intensidade da luz transmitida $(\mathrm{T})$ e da luz refletida $(\mathrm{R})$. Esta função mostra o comportamento espacial das franjas de interferência em um experimento de múltiplos feixes como o interferômetro de Fabry-Perot.

Figura 10 - (a) Esquematização do processo de interferência entre dois feixes consecutivos no limite $\theta \sim \theta$. Os cálculos necessários para se obter a diferença de fase existente em tal sistema podem ser realizados através das informações geométricas apresentadas nesta figura. (b) Diferença de fase gerada por uma diferença de caminho.

Figura 11 - Representação da Airy function para a distribuição de intensidades para diferentes valores da refletância $R$. 
Figura 12 - Ilustração do princípio de funcionamento dos sensores ópticos a partir de guias de onda luminescentes.

Figura 13 - O conceito de conversores de comprimento de onda

Figura 14 - Esquema original proposto em 1976 por W. H. Weber e John Lambe para um "Luminescent Solar Collector" ou LSC

Figura 15 - "Planar Solar Concentrator" ou PSC. A luz solar incide sobre a face superior e uma fração é aprisionada dentro da espessura "D". Está fração pode tanto escapar (A) como pode ser guiada por reflexões (B).

Figura 16 - Substrato de vidro contendo superfícies refletoras de alumínio. (a) padrão visto por cima indicando largura e comprimento. (b) vista lateral indicando a espessura de $200 \mathrm{~nm}$ e largura da metalização de $3 \mathrm{~mm}$.

Figura 17 - Espectros de absorbância de cada polímero utilizado, todos em solução de PMMA em tolueno a $40 \mathrm{~g} / \mathrm{l}$.

Figura 18 - Polímeros conjugados diluídos a $0,5 \mathrm{~g} / \mathrm{l}$ em tolueno foram utilizados em apenas alguns microlitros (aproximadamente 30 microlitros na solução precursora de PMMA) resultando em uma nova solução, chamada de solução polimérica.

Figura 19 - Representação das amostras com e sem metalizações obtidas por "casting" da solução polimérica em substratos de vidro com e sem metalização. (a) para guia de ondas, (b) e (c) para LSCs.

Figura 20 - Configuração do sistema para medidas laterais dos guias de onda.

Figura 21 - Esquema do aparato experimental para medida da emissão lateral nos LSCs. A posição de incidência da luz sobre os LSCs foi variada por meio do aparato esquematizado acima através de passos micrométricos.

Figura 22 - Na parte inferior podem ser vistas as curvas de absorbância de cada polímero utilizado, todos em solução de PMMA em tolueno. Deslocados, na parte superior, são mostrados para comparação os espectros da solução de PMMA contendo todos os polímeros (círculos pretos) e da soma de cada espectro em separado da parte inferior (tracejado).

Figura 23 - Na parte inferior podem ser vistas as curvas de emissão de cada polímero utilizado, todos em solução PMMA. Na parte superior pode ser visto o espectro de todos os polímeros em uma mesma solução de PMMA. 
Figura 24 - Na parte inferior podem ser vistas as curvas de Excitação de cada polímero utilizado, todos em solução PMMA. Na parte superior pode ser visto o espectro de todos os polímeros em uma mesma solução de PMMA.

Figura 25 - (a) Modo TE e TM de guia de onda contendo material polimérico emissor de luz. O espectro da emissão normal (sem efeito de guia de onda) é mostrado para comparação. (b) Razão das intensidades do modo TE e do modo TM

Figura 26 - Dependência da emissão lateral com a espessura do filme polimérico do guia de onda.

Figura 27 - Simulação da emissão lateral para diferentes espessuras e fator de qualidade (a) $\Delta=10 \mathrm{~nm}$ e (b) $\Delta=40 \mathrm{~nm}$ de um guia de onda

Figura 28 - (a) representação esquemática do LSC sem interface metálica, (b) posicionamento da fibra óptica em relação ao concentrador, (c) destacando-sr a emissão lateral característica da SP utilizada.

Figura 29 - (a) Emissão lateral em função da distância $d$ para os concentradores: $\operatorname{LSC}_{\mathrm{SM}}(4,4,4,3,5)$, $\operatorname{LSC}_{S M}(6,6,6,5,7)$ e $\operatorname{LSC}_{\mathrm{SM}}(8,8,8,6,10)$, juntamente com a absorção do $\operatorname{LSC}_{\mathrm{SM}}$ $(6,6,6,5,7)$ e absorção do MEH-PPV em filme. (b) Coordenadas CEI em um diagrama cromático 1931 respectivamente em vermelho (quadrado), preto (círculo) e azul (triângulo). A distância da luz incidente aumenta com relação ao maior caminho ótico da esquerda para a direita.

Figura 30 - (a) representação esquemática do $\mathrm{LSC}_{\mathrm{CM}}$ avançado, (b) e (c) destacam a emissão lateral característica da SP utilizada para o $\operatorname{LSC}_{\mathrm{CM}}(6,6,6,5,7)$.

Figura 31 - (a) Espectros de luminescência em função da distância lateral d da saída do guia. (b) Espectros de luminescência dos cinco polímeros que compõe o conversor de comprimento de ondas que emitem em uma vasta região espectral.(c) Emissão lateral para um conversor evidenciando a distância $d$ de excitação. (d) Representação do conversor em que uma luz incidente Deslocamento das coordenadas CIE em um diagrama cromático 1931 para $\operatorname{LSC}_{\mathrm{CM}}(4,4,4,3,5), \mathrm{LSC}_{\mathrm{CM}}$ $(6,6,6,5,7)$ e $\operatorname{LSC}_{\mathrm{CM}}(8,8,8,6,10)$ respectivamente em vermelho (quadrado), preto (círculo) e azul (triângulo). A distância da luz incidente aumenta com relação ao maior caminho ótico da esquerda para a direita. (Colocar ponto inicial e final $\mathrm{d}=\mathrm{o} \mathrm{e}$ $\mathrm{d}=12 \mathrm{~mm}$ no diagrama $\mathrm{CIE}$ )

Figura 32 - Dependência da intensidade da luminescência medida em $630 \mathrm{~nm}$ em função da posição da luz de excitação $d$ em relação à saída dos LSCs de mais baixa e mais alta concentrações, ou seja, $\operatorname{LSC}_{\mathrm{CM}}(4,4,4,3,5)$ e $\operatorname{LSC}_{\mathrm{CM}}(8,8,8,6,10)$.

Figura 33 - Coordenadas CEI em um diagrama cromático 1931 para $\operatorname{LSC}_{\mathrm{CM}}(8,8,8,6,10)$ e $\operatorname{LSC}_{\text {SM }}(8,8,8,6,10)$ respectivamente em azul (círculo) e vermelho (quadrado). 
Figura 34 - Intensidade normalizada da luminescência lateral com a variação do comprimento de onda de excitação para o $\operatorname{LSC}_{S \mathrm{M}}(8,8,8,6,10)$ comparada com o espectro de absorbância da solução.

Figura 35 - Caráter de conversão para o $\operatorname{LSC}_{\mathrm{CM}}(8,8,8,6,10)$ observado através da emissão lateral com a incidência de luz branca na superfície do dispositivo em comparação com a emissão normal para o mesmo.

Figura 36 - Coordenadas CEI para a emissão normal para os $\operatorname{LSC}_{\mathrm{CM}}(12), \operatorname{LSC}_{\mathrm{CM}}(12,12)$, $\operatorname{LSC}_{\mathrm{CM}}(12,12,8), \operatorname{LSC}_{\mathrm{CM}}(1,1,1), \operatorname{LSC}_{\mathrm{CM}}(2,2,2)$ e $\operatorname{LSC}_{\mathrm{CM}}(4,4,4)$ (pontos coloridos). Os pontos brancos de $\mathrm{A}$ a $\mathrm{E}$ correspondem às coordenadas no diagrama $\mathrm{CIE}$ obtidos de espectros obtidos a partir de soluções de tolueno contendo um único polímero.

Figura 37 - Caminho livre do fóton nos LSCs estudados na Figura 36. As espessuras desses dispositivos são de $30 \mu \mathrm{m}$.

Figura 38 - (a) Emissão normal com a variação da concentração em cinco LSCs. (b) Representa a área integrada dos espectros de (a) em função da concentração polimérica nos LSCs.

Figura 39 - (a) Coordenadas CEI em um diagrama cromático 1931 para $\operatorname{LSC}_{\mathrm{CM}}(12)$, $\mathrm{LSC}_{\mathrm{CM}}(12,12)$ e $\operatorname{LSC}_{\mathrm{CM}}(12,12,8)$ respectivamente em preto (quadrado), vermelho (círculo) e azul (triângulo). b) Mudanças espectrais responsáveis pelo deslocamento $\operatorname{LSC}_{\mathrm{CM}}(12)$ no diagrama cromático comparadas em escala logarítmica com o espectro do ADS-329BE em solução. 


\section{LISTA DE TABELAS}

Tabela 1 - Exemplo de monômeros de algumas moléculas de polímeros conjugados com suas respectivas

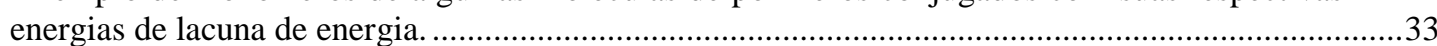

Tabela 2 - Fórmula química e comprimento de onda de emissão dos polímeros conjugados utilizados. 



\section{LISTA DE ABREVIATURAS E SÍMBOLOS}

abs.

Absorção

ADS-108GE

Polímero luminescente, Poli-[(9,9-dioctil-2,7-divinileno-fluorenoleno)alt-co-\{2-methoxi-5-(2-ethilhexiloxi)-1,4-fenileno $\}$ ]

ADS-329BE

Polímero luminescente, Poli(9,9-dioctilfluoreno)

BK7

Vidro

$(\mathbf{C H})_{\mathbf{x}}$

Poliacetileno

CIE 1932

Diagrama de Cor

$\mathbf{E}_{\text {lacuna }}$

Lacuna de Energia (Energia de "Gap")

em.

Emissão

HUMO

Highest Occupied Molecular Orbital

IC

Cruzamento Intersistema

ISC

Cruzamento Intersistema

$L$

Espessura do filme

LAPS-16

Polímero luminescente, Poli(9,9-di-hexilfluorenodiilvinileno-alt-1,4fenilenevinileno)

LBL

Filmes finos

LSC Luminescent Solar Concentrator (Concentrador Solar Luminescente)

$\mathbf{L S C}_{\mathrm{CM}}$

LSC com Metal na interface

$\mathbf{L S C}_{\mathbf{S M}}$

LSC Sem Metal na interface

LUMO

Lowest Unoccupied Molecular Orbital

MEH-PPV

Poli(p-fenileno vinileno) 


\begin{tabular}{|c|c|}
\hline Modo TE & Modo transversal elétrico \\
\hline Modo TM & Modo transversal magnético \\
\hline$n$ & Índice de refração \\
\hline$n_{\mathrm{ar}}$ & Ìndice de refração do ar \\
\hline $\boldsymbol{n}_{\text {ef }}$ & Índice d refração efetivo \\
\hline PANI & Polianilina \\
\hline PEDOT & Polietileno dioxitiofeno \\
\hline PMMA & Poli (metil metacrilato) \\
\hline PPy & Polipirrol \\
\hline PSC & Planar Solar Concentrador \\
\hline $\boldsymbol{R}$ & Intensidade de luz refletida \\
\hline$r$ & Refletância \\
\hline $\mathbf{R}_{\mathbf{0}}$ & Raio de Förster \\
\hline SY & Polímero luminescente, Super Yellow \\
\hline$T$ & Intensidade de luz transmitida \\
\hline$t$ & Transmitância \\
\hline$T_{1}, T_{2}$ & Estados tripletos \\
\hline$\delta$ & Diferença de fase \\
\hline$\Delta \mathbf{I}$ & Alteração da intensidade da emissão \\
\hline$\Delta x$ & Diferença de caminho \\
\hline $\boldsymbol{\theta}_{\mathrm{c}}$ & Ângulo crítico \\
\hline$\lambda$ & Comprimento de onda \\
\hline
\end{tabular}




\section{S U MÁ R I O}

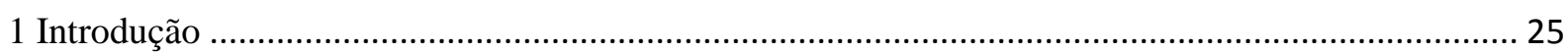

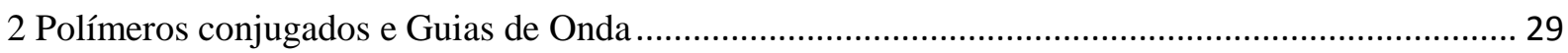

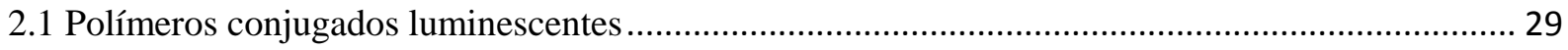

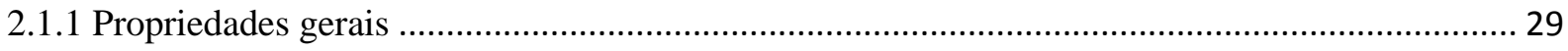

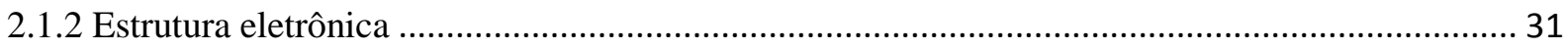

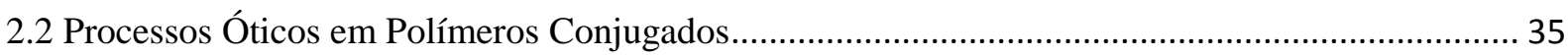

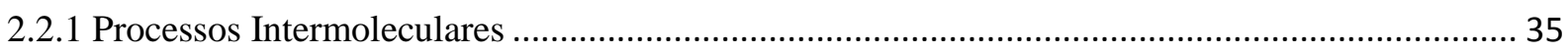

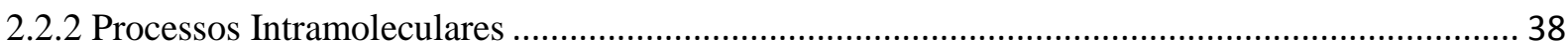

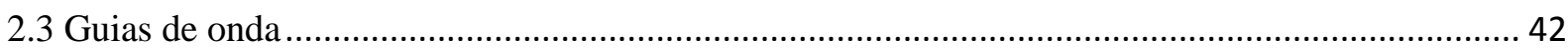

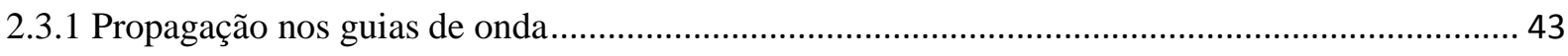

2.3.2 Guias de onda planares multipoliméricos ............................................................................... 44

2.4 Sensores a base de Guias de onda Poliméricos ............................................................................... 50

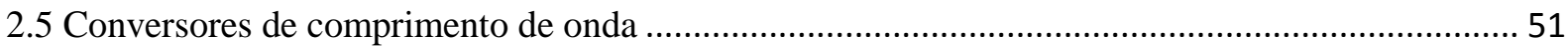

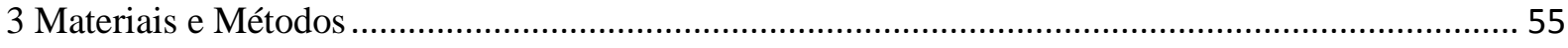

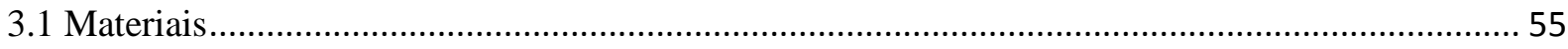

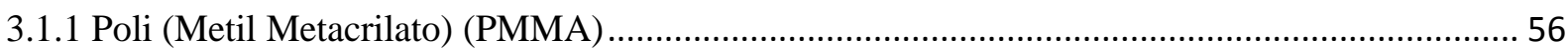

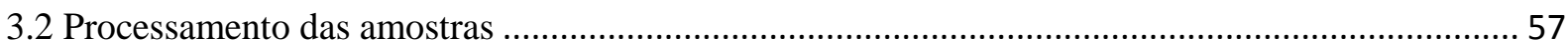

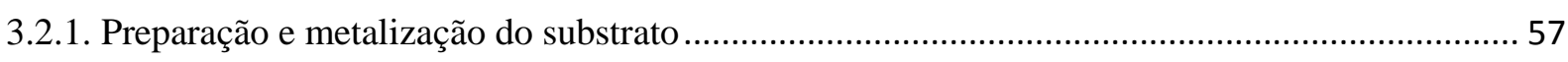

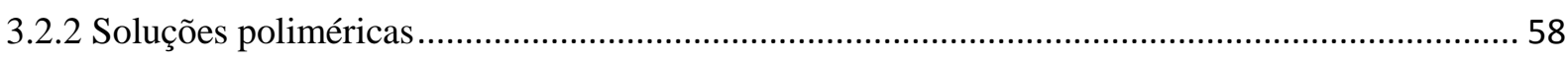

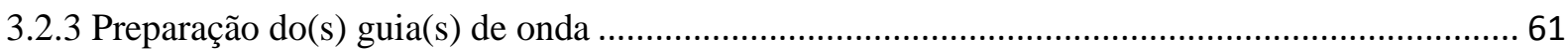

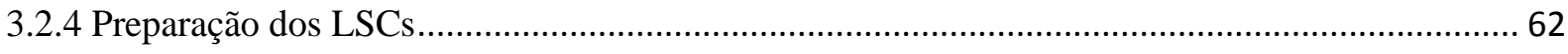

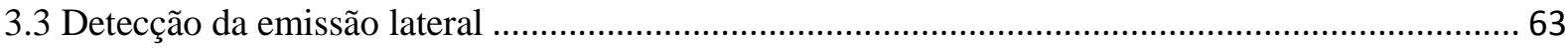

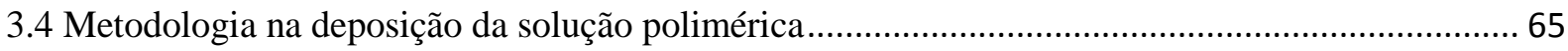

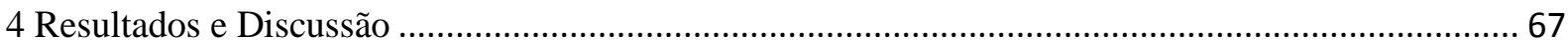

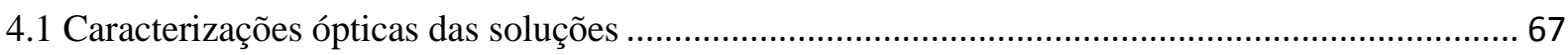

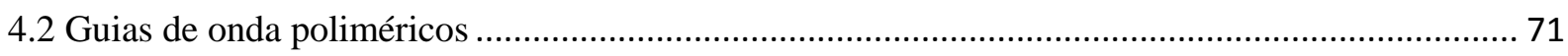

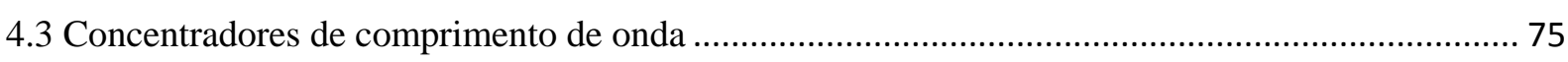

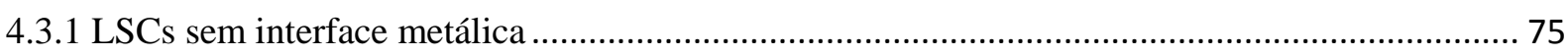

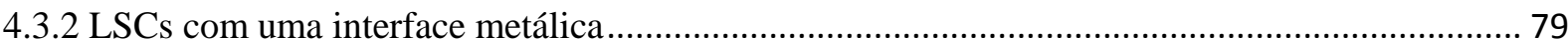

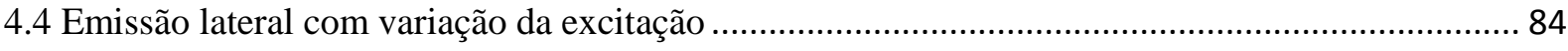

4.5 Caracterização dos LSCs através da emissão normal................................................................... 86 


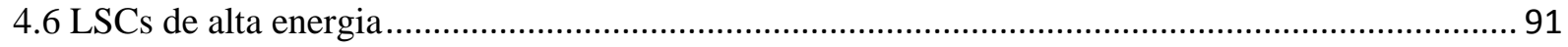

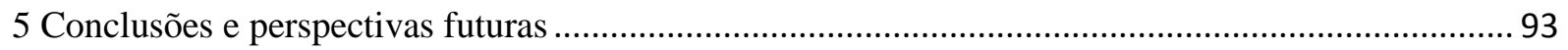

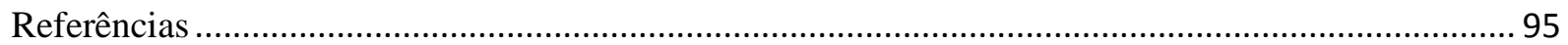




\section{Introdução}

Nas últimas décadas tem ocorrido um crescimento exponencial no número e na faixa de aplicação de dispositivos baseados em diferentes fenômenos óticos relacionados a novos materiais. Em especial, os dispositivos baseados na tecnologia dos guias de onda têm atraído uma crescente atenção devido a sua grande versatilidade e alta sensibilidade nas aplicações $(1-2)$.

Os guias de onda planares vêm ganhando espaço dentre os novos conceitos na tecnologia de concentração e conversão da energia solar introduzidos nas décadas passadas de forma a superar os desafios para o desenvolvimento de métodos responsáveis pela obtenção de energia limpa e que estejam aliados a soluções mais baratas, rápidas e de alguma forma, menos agressivas ao planeta. Uma grande esperança é depositada na energia que vem do sol, fato que mobiliza um número cada vez maior de recursos financeiros e humanos na pesquisa, desenvolvimento e fabricação de dispositivos capazes de converter a luz solar em energia elétrica. Contudo, o rendimento (que se reflete em um alto custo por kwatt/hora implantado* é atualmente baixo (3).

Pesquisas recentes estão direcionadas em buscar melhorias nas células fotovoltaicas, tanto com relação aos processos internos responsáveis pela transformação da energia solar em energia elétrica. Porém, grande esforço tem sido despendido nas etapas que os antecedem a essa transformação através do uso de novos conceitos em concentradores solares (4-7) e de conversão de energia através processos fotofísicos (8-10). Um condensador ou conversor, por exemplo, pode ser exposto à luz de vários comprimentos de onda, absorver completamente a radiação incidente e redirecionar essa energia através de processos ópticos múltiplos dentro de um guia de onda para células solares coletoras.

Por outro lado, os guias de onda encontram também grande aplicação na área de sensores $(2,11,12)$. Sensores óticos baseados em guias de onda planares têm um papel importante quando se requer alta sensibilidade. Aqui se destacam os sensores óticos a base de guias de onda que utilizam efeitos de microcavidades $(13,14)$, de onda evanescente (2) e de interferência $(15,16)$. A importância tecnológica dos sensores advém da ampla variedade de aplicações, dentre as quais se podem citar as atividades de análise e controle nos campos de

\footnotetext{
* $\mathrm{O}$ custo médio em uma termelétrica a gás gira em torno de $\mathrm{R} \$ 0,20$ à 0,28 enquanto é de $\mathrm{R} \$ 2,89$ à 5,78 para
} células solares. 
agricultura e no monitoramento ambiental, bem como nas áreas das engenharias, da medicina, de instrumentação científica, de segurança e da meteorologia.

Assim, esforços têm sido conduzidos para a obtenção de materiais que possam substituir aqueles convencionalmente utilizados como camada ativa nos guias de onda para uso em concentradores solares, conversores de comprimento de onda (6), e sensores (17). Em especial, a utilização de materiais orgânicos, dentre eles os poliméricos, tem-se mostrado bastante atrativa para esse tipo de aplicações devido a gama de propriedades exibidas nesses materiais. Por exemplo, polímeros conjugados são mais baratos, de fácil síntese e manipulação e exibem excelentes propriedades ópticas em termos de absorção e emissão de luz.

O desenvolvimento recente de polímeros semicondutores emissores de luz na região do visível e infravermelho tem aberto oportunidades para o desenvolvimento de conversores solares luminescentes (LSCs) de alta eficiência (4, 5). LSCs são guias de onda planares que consistem de um filme de um material altamente transparente (matriz) dopado com um cromóforo luminescente. Fótons incidentes sobre a matriz são absorvidos, convertidos em radiação de comprimentos de ondas específicos pelas moléculas luminescentes que, depois de guiada até as laterais do guia, é convertida fotovoltaicamente por detectores de última geração. LSCs são mais eficientes que outros coletores, utilizam tanto radiação direta como difusa e convertem energia sem dissipação de calor. A eficiência de um LSC depende das características espectrais dos cromóforos e da matriz. Cálculos mostram que $75 \%$ da luz solar pode ser convertida em tais dispositivos, assumindo índice de refração $n=1,5$ para a matriz $(18,19)$.

Outros dispositivos utilizam o conceito de organizar as moléculas em matrizes hospedeiras porosas e transparentes (8). Os poros com dimensões nanométricas oferecem a possibilidade de serem preenchidos com cromóforos ou moléculas luminescentes. Neste sistema, a excitação luminosa é eficientemente coletada pelas moléculas confinadas nos poros e transportada de forma eficiente ao longo dos mesmos através de processos de transferência de energia, simulando uma fotossíntese artificial (10). Estes materiais compósitos do tipo "hospedeiro/hóspede" com ordem em escala nanométrica oferecem uma nova direção para o controle das propriedades ópticas dos materiais em nível molecular.

Em estudos recentes realizados em nossos laboratórios durante estágio de pósdoutoramento de Francisco Trivinho Strixino (20) foi possível preparar estas estruturas mesoporosas com sucesso. Foi demonstrado que matrizes de alumina porosa transparentes apresentam uma forte luminescência. A emissão de luz na direção paralela ao filme de 
alumina é modificada por moléculas luminescentes depositadas sobre a sua superfície ou dentro dos poros. Foram exploradas questões sobre o efeito da estrutura e ordem da alumina porosa na conformação e ordenamento molecular e nos processos de transferência de energia entre o material poroso para regiões funcionais específicas do material hospedeiro através de distâncias muito maiores que os espaçamentos intermoleculares. Além disso, guias de onda de alumina porosa apresentam propriedades interessantes quando a emissão é observada lateralmente à estrutura. Nesta configuração de emissão lateral, a luminescência adquire características interessantes do ponto de vista de aplicação tecnológica $(3,11)$. É possível observar o efeito cavidade ótica na emissão através dois modos de guia de onda e do forte estreitamento das linhas. A ocorrência de interferência construtiva e destrutiva (cavidade Fabry-Perot) para a luz propagando entre as interfaces metálicas e de ar no filme poroso de alumina gera esses dois modos de propagação paralelo (TE) e perpendicular (TM) de altíssima polarização. A luz emitida apresenta-se como um espectro com bandas estreitas, altamente polarizada, que se distingue da banda larga emitida perpendicularmente ao filme.

Os resultados de Trivinho Strixino (20) com a alumina porosa foram precursores para o presente trabalho. Aqui, todo o esforço foi concentrado na preparação e caracterização de guias de onda planares à base polímeros. O objetivo foi obter as características de um guia de onda luminescente contendo simultaneamente propriedades a) de emissão com as características de uma cavidade Fabri-Perot ou de interferência e b) de um LSC, ou seja, de um conversor de comprimento de onda. A fabricação dos guias de onda difere sensivelmente daquelas apresentadas em alguns trabalhos anteriores (21-23). Com isso, este trabalho visou conciliar uma maneira simples e eficaz reproduzir guias com padrões estruturais e emissões características que permitisse sua aplicação como dispositivos opto-eletrônicos tais como sensores $(2,11,15,24-29)$. O grande diferencial desta atividade é a utilização de um guia de onda planar à base de blenda multipolimérica composta de diferentes polímeros conjugados emissores de luz diluídos em uma matriz opticamente inerte de polimetacrilato e que possuem absorção óptica e emissão em uma larga faixa de comprimentos de onda.

Apesar da enorme versatilidade para aplicações optoeletrônicas, alguns aspectos fundamentais da formação de materiais híbridos (diluição, separação de fase, formação de aglomerados) e da física por trás da construção/otimização de dispositivos baseada neste novo conceito ainda permanecem controversa e pouco entendida. Dominar estes aspectos estruturais e fotofísicos no nível molecular representa um posicionamento estratégico e um desafio para a pesquisa de novos dispositivos à base de materiais orgânicos no país. Este é um 
estudo preliminar que foi direcionado para a obtenção destes dispositivos de maneira reprodutível. Sendo assim, novos horizontes podem ser alcançados por estudos baseados neste trabalho, onde as questões expostas acima poderão ser entendidas e um completo domínio das características finais de tais dispositivos se torne uma realidade.

Parte das dificuldades encontradas foram superadas pela grande facilidade de infraestrutura e caracterização do IFSC. Os filmes foram preparados no Grupo de Polímeros Bernhard Gross do Instituto de Física de São Carlos (IFSC/USP) e a caracterização óptica dos dispositivos híbridas metal/polímero foi realizada tanto no grupo de polímeros quanto no Grupo de Semicondutores do IFSC.

Em função disto, o presente trabalho será apresentado da seguinte forma: Uma breve introdução, inserindo dentro de um contexto os motivos para o desenvolvimento e aplicação dos dispositivos obtidos neste trabalho. O capítulo 2 introduz conceitos fundamentais de polímeros conjugados, obordando principalmente suas propriedades luminescentes. No mesmo capítulo os guias de onda são apresentados de forma rápida e direta para o entendimento básico deste trabalho. Além disso, conceitos relacionados aos concentradores de comprimento de onda e suas aplicação estão presentes no capítulo 2 . O capítulo 3 é dedicado aos materiais utilizados, às metologias aplicadas tanto para a obtenção dos guias e conversores, bem como as técnicas empregadas para as caracterizações dos mesmos. Os resultados e discussões, tanto para guias de onda quanto para concentradores estão apresentados no capítulo 5. O capítulo 6 conclui e direciona o foco para possíveis trabalhos futuros, apresentando uma síntese do que pode ser esclarecido a respeito dos guias e LSCs obtidos neste trabalho. 


\section{Polímeros conjugados e Guias de Onda}

\subsection{Polímeros conjugados luminescentes}

\subsubsection{Propriedades gerais}

Polímeros são moléculas longas cuja estrutura é resultado de processo químico de polimerização de unidades estruturais menores e idênticas chamadas monômeros. O termo grego deriva da fusão do prefixo "poli" (muita) com a palavra "mero" (parte).

A polimerização é a síntese que acontece através de reação de grupos funcionais de monômeros. Na polimerização, o crescimento das moléculas é um processo aleatório. Este crescimento aleatório resulta em uma mistura de macromoléculas com diferentes massas moleculares que pode ser representado por uma função distribuição.

Polímeros, também chamados 'macromoléculas', freqüentemente são compostos de elementos orgânicos como carbono e hidrogênio. Eventualmente, ligados a estes aparecem também oxigênio, nitrogênio, e halogênios. Uma classe de moléculas orgânicas de especial interesse são os compostos orgânicos conjugados, visto que eles apresentam propriedades elétricas, ópticas e mecânicas de interesse. Estes compostos orgânicos geralmente formam uma cadeia principal de átomos de carbono ligados lateralmente por átomos de hidrogênio.

Excluindo aqueles elétrons mais internos que não participam das ligações (elétrons do caroço), se pode distinguir os chamados elétrons $\sigma$ dos elétrons $\pi$ (30,31). Tomando como exemplo uma molécula de poliacetileno, as ligações $\sigma$, unindo um átomo de carbono $\mathrm{C}$ com dois outros átomos $\mathrm{C}$ adjacentes e um de hidrogênio $\mathrm{H}$, são formadas pela combinação linear dos três orbitais atômicos $2 \mathrm{~s}, 2 \mathrm{p}_{\mathrm{x}}, 2 \mathrm{p}_{\mathrm{y}}$ de cada átomo de carbono (30). Estas são chamadas ligações $\sigma$ hibridizadas $s p^{2}$ pois apresentam uma simetria axial em relação ao eixo que passa pelos átomos adjacentes ligantes. Já a ligação $\pi$ é formada pela superposição lateral dos orbitais atômicos $2 p_{z}$ perpendiculares ao plano da molécula $(30,31)$ 


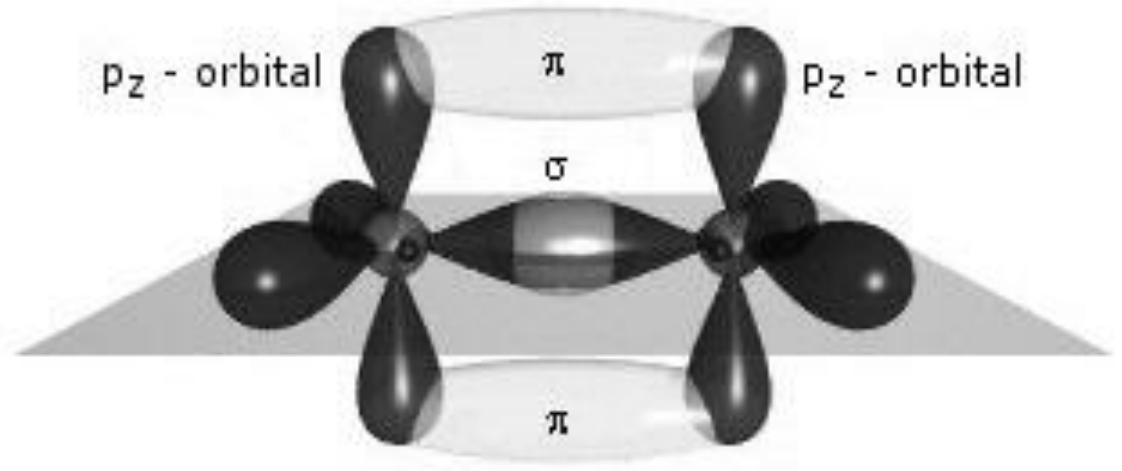

Figura 1 - Representação dos orbitais moleculares $\pi$ e $\sigma$ formados entre dois átomos de carbono $\mathrm{sp}^{2}$.

Os elétrons dos orbitais $\sigma$ são responsáveis pelo rigidez das ligações covalentes e são localizados entre os dois núcleos adjacentes. Os elétrons $\pi$ também envolvidos na ligação tendem a formar ligações fracas e não localizadas (31).

Em contraste com as substâncias químicas comuns, os polímeros não são produtos homogêneos; contém mistura de moléculas, de variados pesos moleculares, apresentando o que se chama de polimolecularidade. Devido à sua grande massa, não ocorrem, em geral, modificações fundamentais pela entrada ou retirada de alguns átomos ou grupos de átomos, ao contrario do que se observa nos compostos químicos usuais. O conceito de polímero puro é bem diferente do que se aplica a química, em geral, já que não se obtém, nem se interessa obter, frações com absoluta uniformidade molecular, para qualquer finalidade de aplicação na indústria.

Isolantes, por muito tempo, tais moléculas eram vistas apenas como péssimas condutoras de eletricidade, aliás, esse era sua principal aplicação por volta dos anos 70, quando através da dopagem do poliacetileno tornou-se evidente que não havia nenhuma razão para que um polímero orgânico não pudesse ser um bom condutor de eletricidade (31). Atualmente muito se foi feito a respeito da condução e da luminescência dos polímeros, estes conduzem e luminescem a níveis que tornam quase que ilimitadas as suas aplicações. Tais fenômenos serão descritos nas próximas seções, sendo mais detalhado o processo de luminescência. 


\subsubsection{Estrutura eletrônica}

As propriedades luminescentes em polímeros podem ser explicadas através da estrutura eletrônica dessas moléculas, ou seja, a forma com a qual ocorrem interações moleculares que definem sua constituição final.

Em sólidos orgânicos, as interações intramoleculares são principalmente covalentes, mas as interações intermoleculares são devido a forças de van der Waals e de London, que são muito mais fracas. Como resultado, as principais bandas de valência e de condução são muito mais estreitas que nos sólidos inorgânicos. A superposição dos orbitais $\mathrm{p}_{z}$ é a característica eletrônica determinante em compostos $\pi$-conjugados. Devido a esta superposição orbital, os elétrons $\pi$ são delocalizados dentro da unidade molecular e a lacuna de energia entre o orbital molecular ocupado de mais alta energia (HOMO) e o não ocupado de mais baixa energia (LUMO) é relativamente pequena (poucos elétronvolts), ou seja, com energias dentro do espectro visível.

Os elétrons envolvidos nessas ligações são os que pertencem às camadas mais externas dos átomos. Com isso, surgem orbitais moleculares $\sigma$ e $\pi$, os elétrons dos orbitais $\sigma$ são responsáveis pela rigidez das ligações covalentes e os elétrons $\pi$ também envolvidos na ligação tendem a formar ligações fracas e não localizadas (32). Os elétrons pertencentes aos orbitais $\sigma$ moleculares efetuam ligações $\sigma$ eletrônicas onde o mesmo ocorre para os elétrons dos orbitais $\pi$. A alternância das ligações $\sigma$ (simples e longas) e $\pi$ (duplas e curtas) ao longo de toda a cadeia polimérica é denominada de conjugação ou dimerização. Elas surgem da configuração eletrônica adquirida pelo polímero quando da sua polimerização ou após alguma dopagem posteriormente realizada $(32,33)$.

De acordo com a teoria de bandas (34), as condições básicas para uma boa condução eletrônica nos materiais são: (A) um sistema contínuo com um grande número de orbitais atômicos fortemente interagentes que permite a formação de uma banda de estados eletrônicos e; (B) a presença de um número insuficiente de elétrons para preencher esta banda. No caso de condutores tradicionais como os semicondutores e os metais, os orbitais atômicos de cada átomo se sobrepõem entre si de maneira a criar um número contínuo de bandas de energia (Figura 2). 

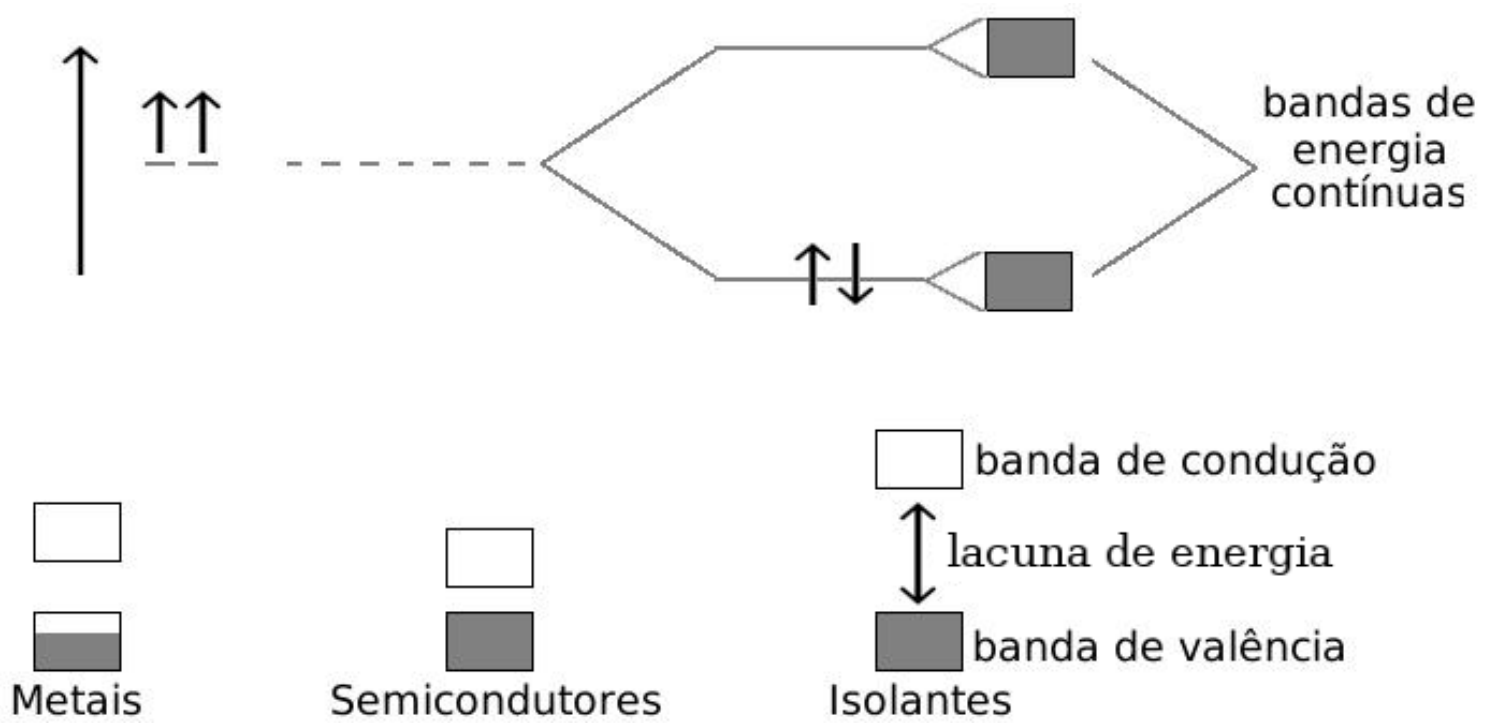

Figura 2 - A parte superior da figura mostra um esquema da formação da banda quando os níveis de energia estão muito próximos. A parte inferior da figura mostra as bandas de valência e de condução dos três tipos de materiais classificados de acordo com a teoria de bandas.

Cada uma dessas bandas de energia é separada por uma região de energias proibidas denominado de "lacuna de energia". A banda ocupada de mais alta energia é denominada banda de valência e a banda desocupada de menor energia é denominada banda de condução. Quando a banda de valência é parcialmente preenchida, os elétrons presentes nesta banda estão livres para se moverem quando aplicado um campo elétrico, resultando numa condução denominada metálica. Quando a banda de valência é completamente preenchida, a condução somente ocorre quando os elétrons são promovidos para a banda de condução, criando vacâncias ou "buracos" na banda de valência. O grau de interação entre os orbitais que se sobrepõem é o que determina a extensão da deslocalização dos estados de fronteira (HOMO e LUMO) e também a largura da banda.

A respeito de bandas de energia em polímeros, pode se falar inicialmente que o comprimento de conjugação de uma molécula tem significativa influência no estudo de suas propriedades elétricas e ópticas. Em sistemas poliméricos o tamanho da conjugação é um valor médio da distribuição aleatória de segmentos conjugados ${ }^{\S}$ com diferentes comprimentos de conjugação, sendo na maioria das vezes determinada por defeitos químicos na cadeia principal, tais como: impurezas, inclusão de segmentos saturados ou não conjugados, torções conformacionais da molécula conjugada (35).

A superposição desses orbitais $p z$ em um plano perpendicular ao plano da cadeia faz com que existam bandas permitidas semi-preenchidas, caracterizando um material metálico,

\footnotetext{
${ }^{\S}$ Extensão máxima em que ocorrem ligações simples e duplas alternadas consecutivas.
} 
ou então, completamente preenchidas caracterizando material semicondutor, para isto, ainda deve ser levado em consideração o valor da banda proibida (lacuna de energia) que é a diferença entre os valores do topo da banda de valência e o fundo da banda de condução. A maior parte dos polímeros conjugados possui essa diferença de energia entre $1,5 \mathrm{eV}$ e 3,5 eV, e são freqüentemente chamados semicondutores orgânicos (36). Na Tabela 1 são apresentados alguns valores de "lacuna de energia" e seus respectivos monômeros.

As ligações $\pi$ que ocorrem nestes sistemas em que o orbital $p z$ é deslocalizado, também chamados de sistemas- $\pi$ conjugados, tem seus elétrons- $\pi$ fracamente ligados e podem se mover ao longo do segmento conjugado da molécula ao invés de serem localizados numa região particular da molécula, como acontece com os elétrons da ligação $\sigma$. Sendo assim, esta ligação $\pi$ tem caráter probabilístico $(37,38)$ ao longo do plano dos átomos de carbono, esse mesmo caráter impede que a mesma possa ser identificada como parte de uma ligação particular entre um par de átomos (39).

Tabela 1 - Exemplo de monômeros de algumas moléculas de polímeros conjugados com suas respectivas energias de lacuna de energia.

\begin{tabular}{|c|c|c|}
\hline Nome & Fórmula estrutural & $\mathbf{E}_{\text {lacuna }}(\mathbf{e V})$ \\
\hline $\begin{array}{c}\text { Poliacetileno } \\
(\mathrm{CH})_{\mathrm{x}}\end{array}$ & 1,5 \\
\hline $\begin{array}{c}\text { Polipirrol } \\
\text { (PPy) }\end{array}$ & 3,10 \\
\hline $\begin{array}{c}\text { Poli(p-fenileno } \\
\text { vinileno) } \\
\text { MEH-PPV }\end{array}$ & \\
\hline $\begin{array}{c}\text { Polietileno } \\
\text { dioxitiofeno } \\
\text { (PEDOT) }\end{array}$ & \\
\hline $\begin{array}{c}\text { Polianilina } \\
\text { (PANI) }\end{array}$
\end{tabular}


Os estados eletrônicos em sistemas poliméricos diferem substancialmente daqueles observados em sistemas atômicos isolados. Isto se deve às imperfeições (desordem) da cadeia polimérica. Desta forma, a análise da forma de linha nesses materiais fornece relevantes informações sobre os estados energéticos e as possíveis perturbações dos mesmos. Estas perturbações são impostas pelas características estruturais e morfológicas em que estes materiais são preparados. Assim, um modelo físico molecular para um polímero é baseado na presença destes estados eletrônicos não localizados, distribuídos, em unidades repetitivas aleatórias, descritas por meio de uma distribuição de tamanhos de segmentos conjugados presentes na matriz sólida polimérica (40).

Um modelo mais realista (41-43), que descreve os polímeros conjugados emissores de luz, considera a desordem conformacional de modo que a cadeia é composta por estruturas ou segmentos conjugados menores (modelo molecular) de diferentes tamanhos distribuídos estatisticamente ao longo da cadeia. Vários modelos têm sido propostos para descrever a conformação em polímeros conjugados. A maioria deles cai dentro de duas categorias: aqueles em que a cadeia apresenta predominantemente torções (modelo "wormlike") (44-46) e outros contendo quebras de conjugação ou cadeia segmentada.

No modelo 'wormlike' a estrutura polimérica possui pequenas rotações de cada unidade repetitiva, o que produz uma conformação curvilínea contínua (do tipo helicoidal). Neste modelo, as quebras de conjugação são menos óbvias, ou seja, há uma pequena quebra de conjugação ao longo da cadeia.

No modelo molecular, defeitos estruturais (defeitos químicos, por exemplo), juntamente com os defeitos conformacionais (formados pela mudança da estrutura espacial do polímero, tais como dobras da cadeia), reduzem a superposição dos estados $\pi$, agindo como centros localizados que interrompem a conjugação ao longo da cadeia polimérica. Conseqüentemente, esta aproximação leva em conta quebras de conjugação produzidas por defeitos conformacionais variados que determinam a modificação do tamanho de conjugação. Ou seja, um polímero, quando forma um sólido desordenado, pode ser considerado em primeira aproximação como um conjunto de unidades de segmentos de cadeia distribuídos aleatoriamente em tamanho (energia), em orientação e em posição. 


\subsection{Processos Óticos em Polímeros Conjugados}

A desordem em tamanho produz a formação de uma densidade de estados larga. A excitação é associada com uma forte correlação do par elétron-buraco (éxcitons) que é delocalizada sobre uma determinada unidade de segmento conjugado. Deste modo, a excitação é extremamente localizada em relação ao comprimento total da cadeia principal e é ainda capaz de migrar ao longo da arquitetura segmental da cadeia. Assim, fenômenos de formação de éxcitons e sua relaxação energética são possíveis nessa aproximação(47, 48). Os processos óticos do estado excitado serão determinados pela estrutura eletrônica alargada de um polímero conjugado (sistema não-homogêneo) que está intimamente ligada com a desordem estrutural de sua cadeia.

Esta seção pretende descrever de forma sucinta os processos óticos fundamentais que ocorrem desde a geração do estado molecular excitado (aqui definido como excitação) através da absorção de um fóton até à sua desativação por meio de um processo radiativo, envolvendo a emissão de um fóton ou de um processo não-radiativo associado a estados de um centro supressor da excitação. No curto intervalo temporal entre a geração do estado excitado inicial e a desativação radiativa final deste estado podem ocorrer processos rápidos que são responsáveis pela relaxação energética e a migração da excitação através de estados intermediários presentes no sistema.

\subsubsection{Processos Intermoleculares}

No caso de polímeros conjugados luminescentes, a unidade molecular está associada a segmentos conjugados dispostos ao longo da cadeia, que devido à desordem imposta pela conformação molecular, podem ser considerados distintos e de tamanho de conjugação dado por uma distribuição de tamanho destes segmentos. Neste sistema molecular, a energia da excitação pode relaxaratravés de vários caminhos ou processos óticos que estão ilustrados esquematicamente na Figura 3. 


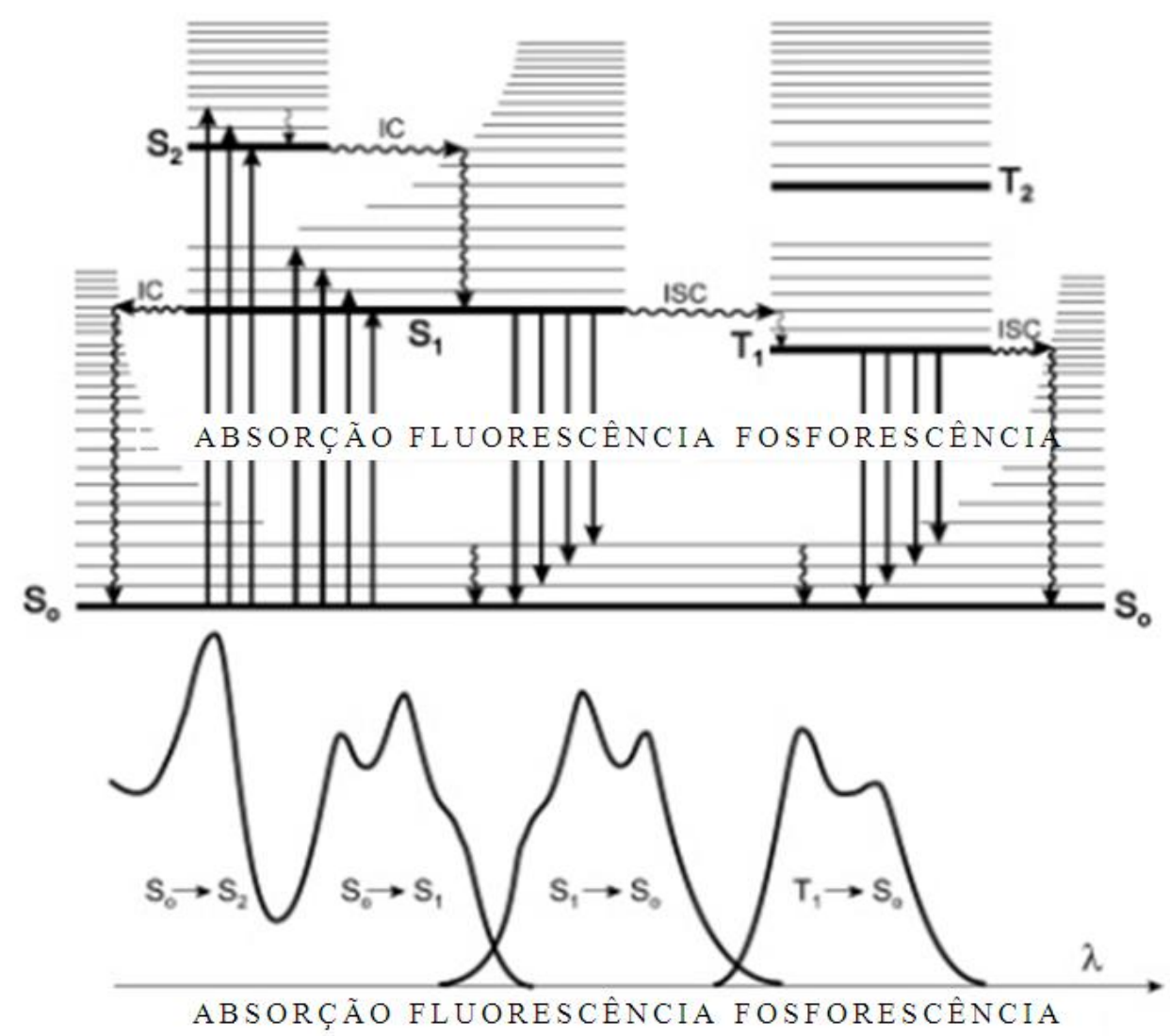

Figura 3 - Diagrama e ilustração dos processos óticos em polímeros conjugados e das posições relativas para os espectros de absorção, fluorescência e fosforescência.

Quando ocorre a absorção de luz por uma molécula em seu estado fundamental (fotoexcitação), um elétron de menor energia pertencente a orbitais moleculares ocupados da (banda de valência) é excitado, produzindo um novo estado energético (banda de condução) com uma nova estrutura configuracional, chamado de estado excitado. A excitação de um segmento conjugado (chamado aqui de doador $D$, ou estado $S_{0}$ na Figura 3) se faz pela absorção de um fóton com energia $h v$ em um intervalo da ordem de $10^{-15} \mathrm{~s}$. Este pode ser representado da seguinte forma

$$
D+h v \rightarrow D^{*} \quad \text { absorção }
$$

Inúmeros processos podem atuar para desativar o estado excitado $D^{*}$ (ou estado excitado $S_{1}$ ) após a fotogeração. Experimentos demonstram que um dos canais mais eficientes é a relaxação energética mediados por estados vibracionais dentro de uma banda, ou relaxação interna através de processos multifônons (esquematizados por setas onduladas na Figura 3). Este processo se passa em uma escala de tempo ultra rápida $(<300 \mathrm{fs})(49,50)$. O estado final 
alcançado pela excitação poderá ser um estado emissivo $\left(S_{1}\right)$ ou não-emissivo $\left(S_{0}\right)$ via processos multifônons a partir do estado singleto $S_{1}$ ou tripleto $T_{1}$.

Após o processo de relaxação energética a excitação pode decair radiativamente em uma escala de nanosegundos, o que é denominado de fluorescência:

$$
D^{*} \rightarrow D+h v \quad \text { fluorescência }
$$

Assim como as propriedades elétricas, as características ópticas também surgem da natureza conjugada destas macromoléculas $(32,51)$. À exceção do fenômeno de incandescência (emissão de luz por um corpo aquecido), todas as outras formas de emissão são chamadas de luminescência. Este tipo de emissão existe de diversas maneiras na natureza. Onde a diferenciação é feita, na maioria das vezes, através da determinação da fonte de excitação dos elétrons. Desta forma: quimiluminescência é a forma de emissão proveniente de reações químicas; bioluminescência das reações químicas em organismos vivos; radioluminescência por um sistema radioativo; eletroluminescência quando a emissão é gerada por uma corrente elétrica através do material. Para a fotoluminescência, que é fator primordial neste trabalho, a emissão ocorre proveniente da energia fornecida por meio de absorção de luz visível, ultravioleta ou infravermelho (52).

Com relação ao momento angular atribuído a um elétron, este é representado por seu número quântico "s" (spin). Existem apenas dois valores possíveis para o "s", um que indica orientação para cima $(s=1 / 2)$ e outro que indica orientação para baixo $(s=-1 / 2)$. Grande parte dos elementos em sua forma natural apresenta-se em seu estado fundamental. Estes possuem elétrons que ocupam o mesmo orbital e que possuem spins opostos, comumente representados por $\mathrm{S}_{0}(53)$. Todavia, quando por algum motivo um elétron é promovido para um estado de mais alta energia, seu momento angular pode assumir tanto a orientação anterior, como pode sofre uma reorganização em seu novo estado e ter seu "spin" invertido com relação à orientação original.

Referente à mudança do "spin" eletrônico, existem os estados denominados singleto, aquele em que o elétron mantém sua orientação inicial, e o estado conhecido como tripleto, correspondente ao elétron que sofre inversão do seu momento angular. Para polímeros conjugados, o elétron pode ser promovido através da absorção de luz, passando de um orbital $\pi$ de mais baixa energia para um orbital $\pi^{*}$ de mais alta energia, os valores dessas energias já 
foram apresentados na Tabela 1. Neste tipo de processo, não ocorre mudança no estado de "spin", fazendo com que o estado excitado seja do tipo singleto.

A luminescência pode ocorrer tanto através do estado singleto como do tripleto, o processo radiativo denominado fluorescência ocorre a partir do estado singleto e é denominado fosforescência quando é proveniente do estado tripleto. Porém, a fluorescência é um tipo de emissão menos provável de acontecer, pois, embora a maior parte dos elétrons excitados esteja no estado singleto, existe um processo chamando de Cruzamento Intersistema (54), onde cerca de $75 \%$ dos elétrons excitados singletos migram para o estado tripleto (mediante inversão do spin), que é mais estável por possuir menor energia. Além disto, ainda existem outros meios para dissipação de energia em moléculas excitadas, tais como conversão intersistema, conversão interna e relaxação vibracional, que são exemplos de processos intramoleculares.

Existem outros caminhos com os quais uma molécula possa vir a alcançar um estado excitado. Alguns destes são conhecidos como processos de transferência de energia não radiativos (a seguir).

\subsubsection{Processos Intramoleculares}

Dentre os muitos caminhos a serem tomados pela excitação $\left(D^{*}\right)$, dois deles estão associados aos processos entre outra molécula aceitadora $(A)$ que pode ser de mesma natureza (homotransferência) ou de natureza distinta (heterotransferência) equacionados por:

$$
\begin{aligned}
& D^{*}+D \rightarrow D+D^{*} \quad \text { homotransferência } \\
& D^{*}+A \rightarrow A+D^{*} \quad \text { heterotransferência }
\end{aligned}
$$

Em um sistema polimérico a excitação é transferida entre segmentos conjugados como descrito acima. Porém, tanto condições envolvendo a posição e orientação relativa entre os dipolos moleculares como fatores de ressonância entre estados energéticos devem ser satisfeitos. A Figura 4 representa este processo para duas moléculas para as quais os estados vibracionais e eletrônicos emissivos do doador estão sobrepostos aos estados absorcivos do aceitador. 


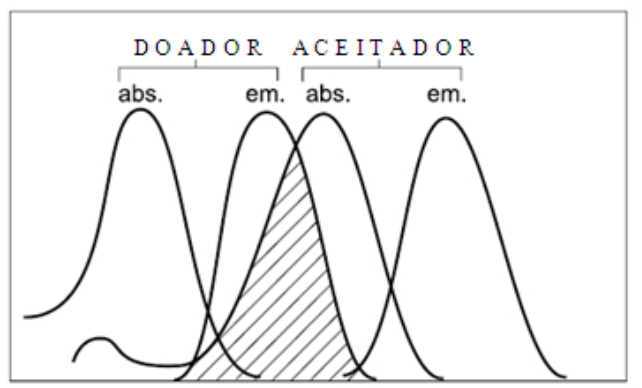

Comprimento de onda

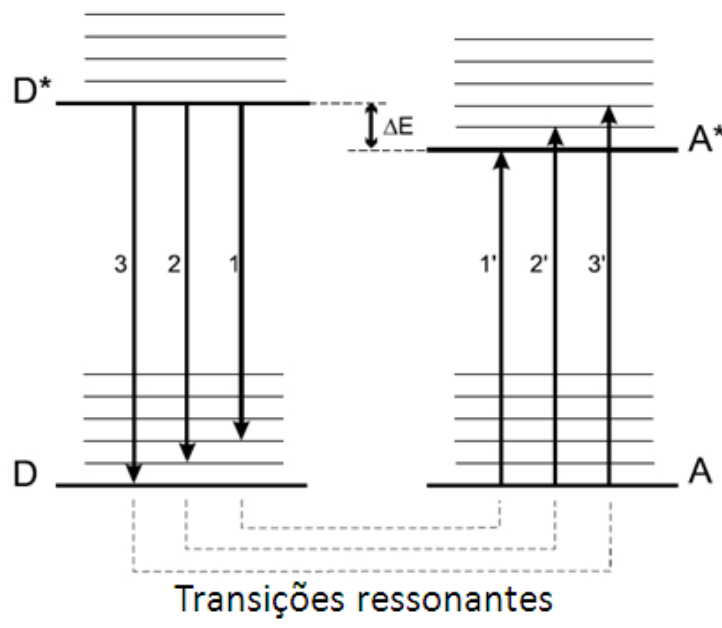

Figura 4 - Sobreposição do espectro de absorção de uma molécula aceptora pelo espectro de emissão de uma molécula doadora.

Dois processos equivalentes são responsáveis pela transferência do estado excitado entre moléculas: os processos de reabsorção, relaxação interna e re-emissão e os processos de transferência de energia do tipo Förster. Eles são equivalentes porque, quando não existe competição com outros processos intermediários (não-radiativos, por exemplo), os resultados iniciais (excitação pela absorção de um fóton) e finais (emissão de um fóton ou fluorescência) são os mesmos. Porém os processos intermediários que ocorrem em cada um deles se diferem pelas distâncias típicas envolvidas nesses fenômenos.

Os processos envolvendo reabsorção/relaxação/re-emissão ocorrem para separações moleculares características da ordem do livre caminho do fóton $\ell$ re-emitido, que é igual ao produto $\Delta N$, seção de choque $\Delta$ e a densidade $N$ de centros absorvedores. Experimentalmente, o livre caminho do fóton é dado pela relação: $\ell=L / A$, onde $L$ é o caminho ótico total do material ou amostra e $A$ é a sua absorbância (Figura 5). Após a excitação molecular em alta energia, inúmeros processos de reabsorção/relaxação/re-emissão podem acorrer ao longo do caminho ótico quando $L>>\ell$ antes da emissão molecular final em baixa energia. Para uma amostra de espessuras típicas $L=1 \mu \mathrm{m}$ e absorbância $A=1$, o livre caminho típico 
do é $\ell=1 \mu m$. Já uma amostra de mesmo caminho ótico, porém de espessura $L=100 \mathrm{~nm}$, deverá ter uma concentração de centros absorvedores dez vezes menor.

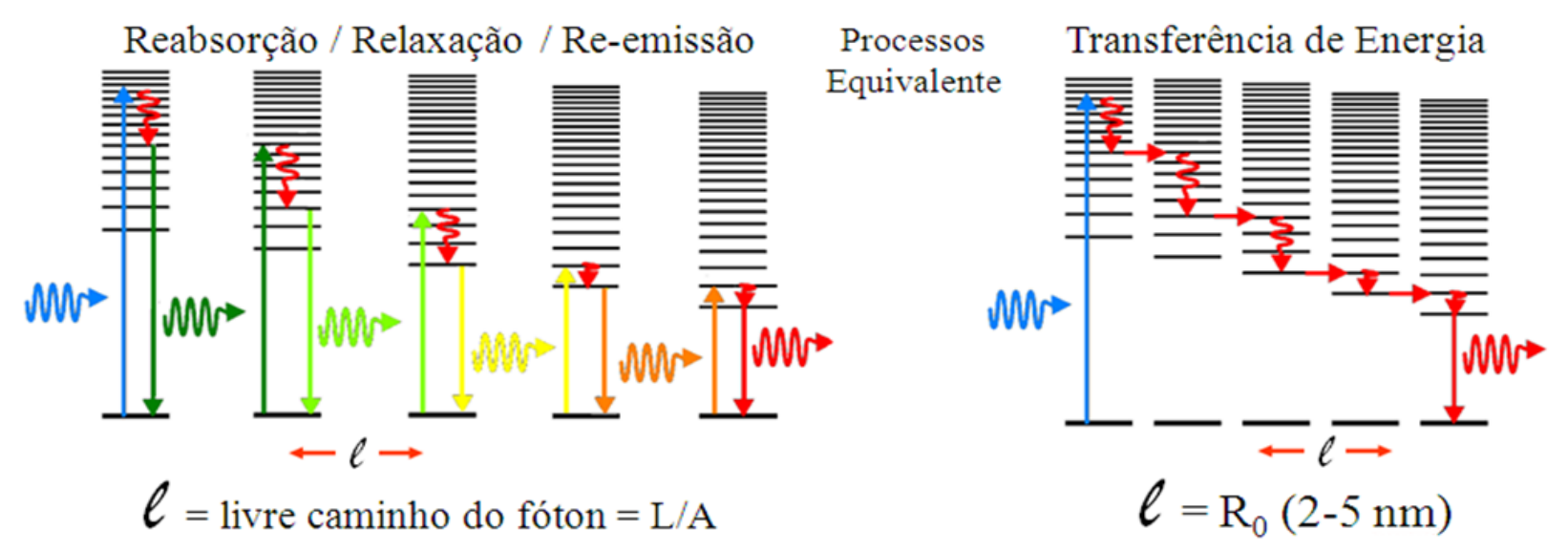

Figura 5 - Processos responsáveis pela transferência do estado excitado entre moléculas: os processos de reabsorção, relaxação interna e re-emissão e os processos de transferência de energia do tipo Förster.

Os processos de reabsorção/relaxação/re-emissão correspondem a uma transferência de energia radiativa. Esta transferência não requer nenhuma interação entre os pares, mas depende de uma sobreposição espectral e da concentração dos mesmos $(52,55)$. Podendo ser representada da seguinte maneira

$$
D^{*} \rightarrow D+h v
$$

Já os processos de transferência de energia do tipo Förster (Figura 5, à direita) envolvem a interação Coulombiana (termo dipolar) entre a molécula excitada e aquela para qual o estado excitado é transferido. Este processo é não-radiativo e ocorre em uma região chamada zona de campo próximo (56), em que a superposição das funções de onda dos estados inicial e final é alta, ou seja, as distâncias intermoleculares sejam pequenas quando comparadas ao comprimento de onda típico da mluz de emissão no material (56). Isto faz com que esse processo ocorra na região de alguns nanômetros, que é exatamente a escala de distâncias típicas entre estados localizados (segmentos conjugados) nos polímeros estudados. Os processos de transferência de energia tipo Förster ocorrem para distâncias moleculares $R$ dentro de um raio de interação típico $R_{o}$ (raio de Förster) da ordem de alguns nanômetros. Para a região onde $R / R_{0} \sim 0.3$ a taxa de transferência de energia é da mesma ordem que a taxa de relaxamento vibracional, isto significa que esses processos competem eficientemente 
um com o outro (Figura 5), sendo responsáveis pelo relaxamento vibracional dentro da banda. Para a região onde $R / R_{0} \sim 0.1$, o processo de transferência não-radiativo compete com o processo de emissão radiativa final. Para as moléculas com distâncias muito maiores que $R_{0}$ a probabilidade de transferência é muito pequena, pois a taxa cai com a sexta potência da distância.

A transferência de energia ocorre entre um estado excitado doador $D^{*}$ e um estado aceitador $A$ no estado fundamental. $O$ estado final é um estado doador $D$ no estado fundamental e o aceitador no estado excitado $A^{*}$ como ilustra a Figura 6 para estados vibracionais.

Se, por outro lado, cromóforos aceitadores (por exemplo, centros supressores ou armadilhas) estão presentes (defeitos) ou são introduzidos na matriz polimérica, a excitação pode migrar entre segmentos conjugados e finalmente alcançar esta molécula aceitadora e ser suprimida por este centro. Se esse evento não ocorrer, o estado excitado poderá decair radiativamente após sofrer múltiplas transferências e relaxações internas. A supressão do estado excitado por centros não radiativos é responsável pelo decréscimo da eficiência de emissão em sistemas moleculares. O caso limite ocorre quando a concentração de doadores é pequena tal que a transferência de energia se faz diretamente do segmento conjugado doador para o centro supressor e corresponde ao caso de supressão direta da excitação. Particularmente para polímeros conjugados, os processos transferência são extremamente rápidos e podem ser observados nos espectros de luminescência resolvidos no tempo na escala de picosegundos.

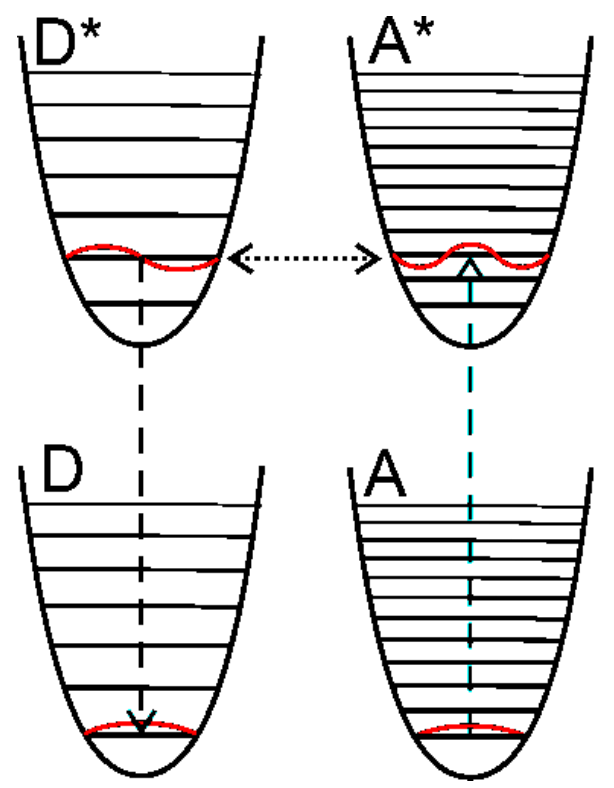

Figura 6 - Mecanismo Förster de transferência de energia. Um estado inicial $D^{*}$ transfere energia de forma não radiativa para um estado $A^{*}$ e então retorna para o estado fundamental $D$. 


\subsection{Guias de onda}

Já no século XX, o termo guia de onda já era conhecido, pesquisas realizadas por Hondros e Debye foram pioneiras neste novo dispositivo mostrando a existência de propagação de modos no guia no seu trabalho "Elektromagnetische Wellen an Dielektrischen Drähten" (Ondas Eletromagnéticas em fios dielétricos) de 1910. Nos anos de 1916 e 1920, Zahn e Schriever respectivamente, estudaram alguns modos de propagação nessas estruturas. Após alguns anos de desenvolvimento, guias de onda planares começaram a ser fabricados de forma sistemática em 1966 (18). Nos anos seguintes o desenvolvimento continuou de forma acelerada e novas técnicas de preparação de guias eram apresentadas constantemente, tais como: Implantação de prótons e íons (57, 58), deposição a partir de soluções $(59,60)$, “sputtering" (61), evaporação (62), crescimento epitaxial (63), troca de íons (64), difusão (65), técnicas de Langmuir-Blodgett (66), e deposição química em fase vapor (67).

Atualmente, os guias de onda fazem parte do nosso dia-a-dia. A existência de linhas de transmissão de microondas** ${ }^{*}$ com destaque à transmissão e processamento de ondas eletromagnéticas de freqüência e/ou potência muito (elevada e as fibras óticas responsáveis pela transmissão de radiação de comprimentos de onda principalmente no visível e infravermelho próximo. Quando o tema guia de onda é apresentado nos cursos de graduação e pós-graduação, em geral, estes têm a forma de cilindros metálicos ocos com seção transversal geralmente constante (guia uniforme) ou aqueles que contêm um dielétrico interno homogêneo (ar ou um gás inerte) (68). Sendo que os guias uniformes podem ser classificas como: guias de seção retangular, cilíndrica, elíptica e de forma menos comum os guias com ressalto/ saliência ("ridged"). Os mais comuns certamente são os retangulares e circulares (fibras óticas). Como mencionado anteriormente, os guias de onda podem ser usados em microondas para transmissão de energia, porém, existem outras inúmeras aplicações como acopladores, defasadores, atenuadores, isoladores, circuladores, filtros, chaves, que baseados no funcionamento dos guias, apresentam ganhos de qualidade (18). Atualmente, guias de onda óticos vem ganhando destaque nas pesquisas visando aplicação sensores $(12,15)$.

\footnotetext{
**O tamanho físico do guia de ondas fica muito grande quando freqüências abaixo de $1000 \mathrm{MHz}$ são utilizadas, tornando inviável a utilização do mesmo.
} 


\subsubsection{Propagação nos guias de onda}

A existência de propagação das ondas eletromagnéticas dentro de um guia é atribuída a múltiplas reflexões nas paredes metálicas ou nas superfícies de separação entre diferentes meios dielétricos. A teoria de Maxwell é o que descreve detalhadamente todo o comportamento de ondas eletromagnéticas dentro destes guias. As equações de Maxwell são escritas de acordo com o sistema de coordenadas mais adequado, baseado na forma geométrica da seção transversal do guia de onda, e ao mesmo tempo aplicando as condições de contorno referentes às paredes do guia. Em um caso ideal, em que as paredes se comportam como condutores perfeitos, a componente tangencial do vetor campo elétrico é nula nas superfícies, fazendo com que não exista nenhuma perda de energia da onda.

Como descrito anteriormente, as condições de contorno dos guias determinam as configurações espaciais dos campos que podem existir nestas estruturas. Sendo assim, as configurações espaciais dos campos eletromagnéticos que satisfazem as condições de contorno determinam os possíveis modos de propagação no guia considerado. Estes modos são distinguidos pela forma de interação dos Campos Elétricos (E) e Magnéticos (M) com as paredes ou interfaces do guia. Assim, existem duas condições para essas interações: (i) o campo elétrico variável é perpendicular à superfície de um condutor e (ii) o campo magnético variável com linhas de campo fechadas e perpendiculares ao campo elétrico, porém paralelas ao condutor. Portanto, os modos em um guia de onda podem ser classificados como Transversal Elétrico (TE) e Transversal Magnético (TM) conforme é esquematizado na Figura 7 para o guia retangular. Assim por exemplo, o modo TE é caracterizado por um campo magnético longitudinal, estando todo o campo elétrico no plano transversal à propagação (69).O contrário se aplica ao modo TM.

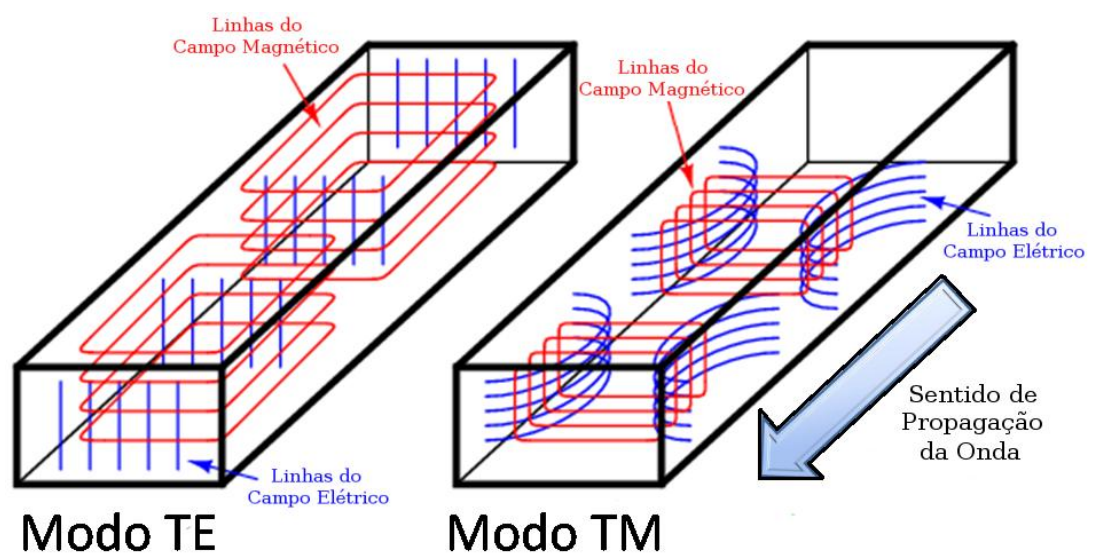

Figura 7 - Destaque para os modos TE e TM na propagação de uma onda eletromagnética no interior de um guia. 


\subsubsection{Guias de onda planares multipoliméricos}

Neste trabalho, sugerimos o estudo de guias de onda planares à base de polímeros emissores de luz. Estudos preliminares realizados em nossos laboratórios mostram que é possível preparar com sucesso guias de onda luminescentes planares à base de materiais mesoporosos à base de alumina porosa luminescente (20). A emissão destes guias é fortemente dependente de sua geometria e do índice de refração efetivo. Nesta configuração de emissão lateral, a luz emitida adquire características interessantes do ponto de vista de aplicação tecnológica (2, 14, 70-72). É possível observar o efeito de filtro espacial da emissão da alumina porosa através do forte estreitamento da linha de emissão para os dois modos do guia de onda (TE e TM). A ocorrência de interferência construtiva e destrutiva (cavidade Fabry-Perot) para a luz propagando entre as interfaces metálica e de ar no filme poroso de alumina gera esses dois modos de propagação paralelo (TE) e perpendicular (TM) de altíssima polarização.

O conceito de um guia de onda planar luminescente polimérico que estamos introduzindo é ilustrado na Figura 8. A radiação de excitação incide sobre a matriz transparente de índice de refração $n$ espessura $L$ (Figura 8b). Este material de espessura $L$ é envolto por meios ou camadas de índices de refração $n_{1}$ e $n_{2}$, sendo que um destes pode ser um metal refletor como mostra a Figura 8b. Cromóforos ou polímeros luminescentes estão dispersos na camada da matriz ativa e são excitados por uma luz com comprimento de onda em uma ampla faixa de absorção dos mesmos. Com a re-emissão dos cromóforos asseguramos que a luz absorvida seja acoplada ao guia. A luz emitida pelos cromóforos pode ser reabsorvida, re-emitida e parcialmente guiada $\left(\mathrm{n}_{1}, \mathrm{n}_{2}<\mathrm{n}\right)$, ou escapar para as camadas adjacentes.

Devido às múltiplas reflexões nas interfaces do guia (Figura 8c), a luz escapada (leaky-mode) sofre interferência (72). A condição de maior interferência construtiva e destrutiva encontra-se para ângulos de escape próximos da condição de reflexão total (ver Figura 8c). A luz que escapa nessas condições possui estruturas espectrais extremamente estreitas e intensas, que correspondem às mesmas franjas de interferência em cavidade do tipo Fabri-Perot de espessura do filme $L(15,73)$. Estas franjas de interferência são mais evidentes se um dos meios ( $\mathrm{n}_{2}$, por exemplo) for um metal. Para a luz propagando entre as interfaces 
com o metal e com o ar, por exemplo, dois modos distintos de propagação com campo elétrico TE e TM são observados.

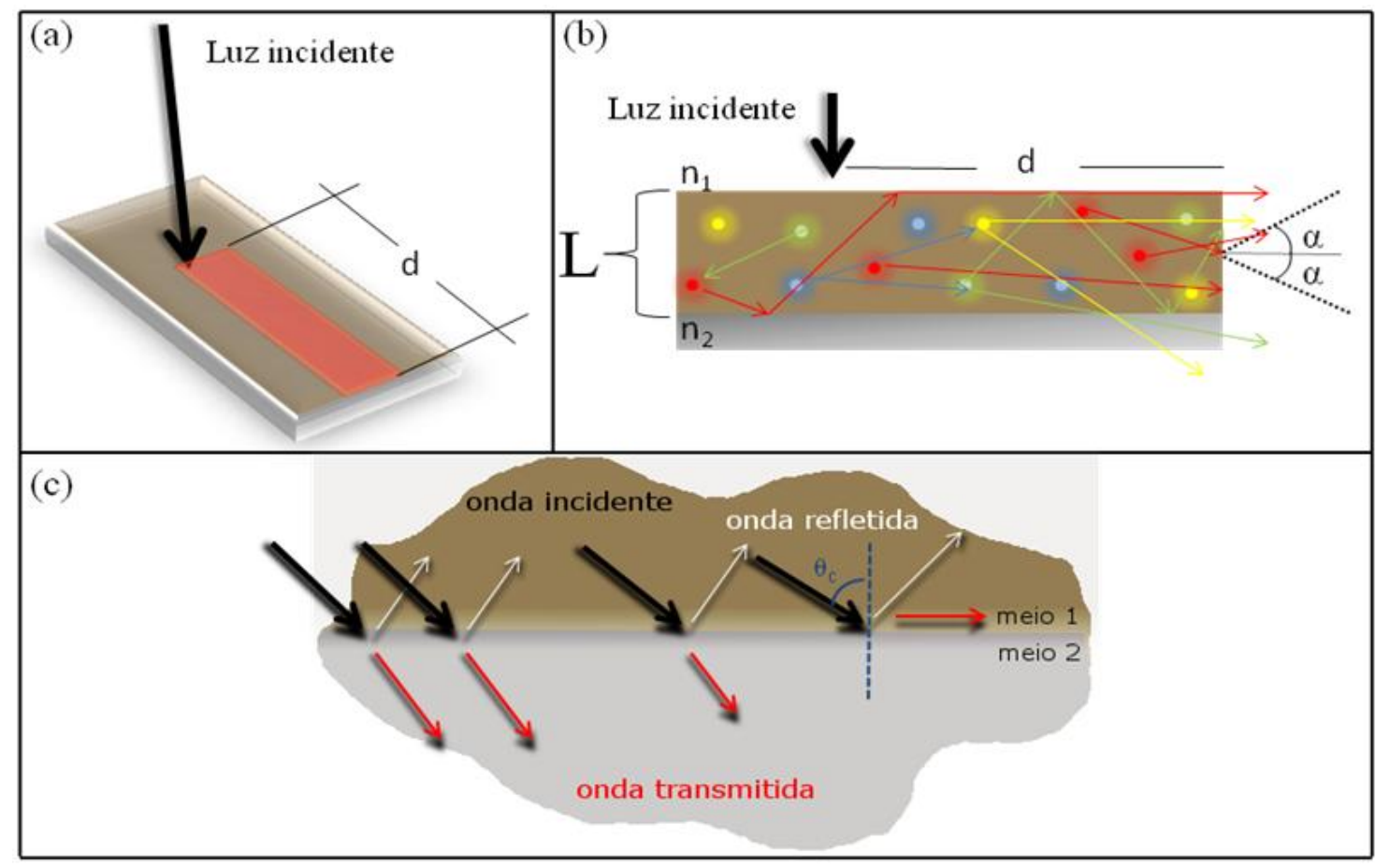

Figura 8 - (a) Representação do guia de onda obtido para os estudos de emissão lateral neste trabalho. (b) Visão lateral do guia constituído por três meios distintos: ar, meio 1 e meio 2 com seus respectivos índices de refração $n_{a r}, n_{1}$ e $n_{2}$. (c) Esboço de como ocorrem reflexões e transmissões em interfaces com diferentes índices de refração.

Quando o raio luminoso atinge a interface meio 1/meio 2 parte da energia luminosa é refletida e parte penetra no segundo meio. Essa refração caracteriza um ângulo que é feito entre a normal e o raio incidente, chamado de ângulo crítico $\left(\theta_{\mathrm{c}}\right)$ como pode ser visto na

Figura 8c. Este ângulo descreve um caso específico em que nenhuma luminosidade passa do meio 1 para o meio 2, tal que: $n_{2}>n_{1}>n_{a r}$. A determinação deste ângulo depende do ângulo de incidência e da relação entre as velocidades da onda nos meios em questão, tais fatores são levados em conta na Lei de Snell que permite escrever a expressão para $\theta_{c}$ como segue

$$
\operatorname{sen} \theta_{c}=n_{2} / n_{1}
$$

onde $n_{l}$ e $n_{2}$ representam os índices de refração dos meios envolvidos.

No limite de $\theta_{c}$ ainda existe o que se chama de modo rasante, onde a luminosidade percorre o limite entre os dois meios (Figura 8c). Para ângulos de incidência maiores que $\theta_{c}$, não existe raio refratado; toda energia é refletida. Este fenômeno é denominado reflexão 
interna total e ocorre somente quando a luz se encontra inicialmente no meio que possui o maior índice de refração.

Estes modos razantes que escapam do guia (leaky modes) fazem parte de sistemas onde o guia de onda é constituído por ao menos uma interface transparente. Estes podem ser tratados como um caso mais geral de interferência múltipla de vários feixes que permeiam o interior do guia. O meio mais comum para a produção de grande número de feixes com coerência múltipla é através da divisão pela amplitude da onda. Esta divisão ocorre quando acontecem múltiplas reflexões entre duas paredes paralelas parcialmente refletoras. Um dispositivo ótico capaz de reproduzir um sistema como este é conhecido como interferômetro de Fabry-Perot, conforme ilustrado na Figura 9.

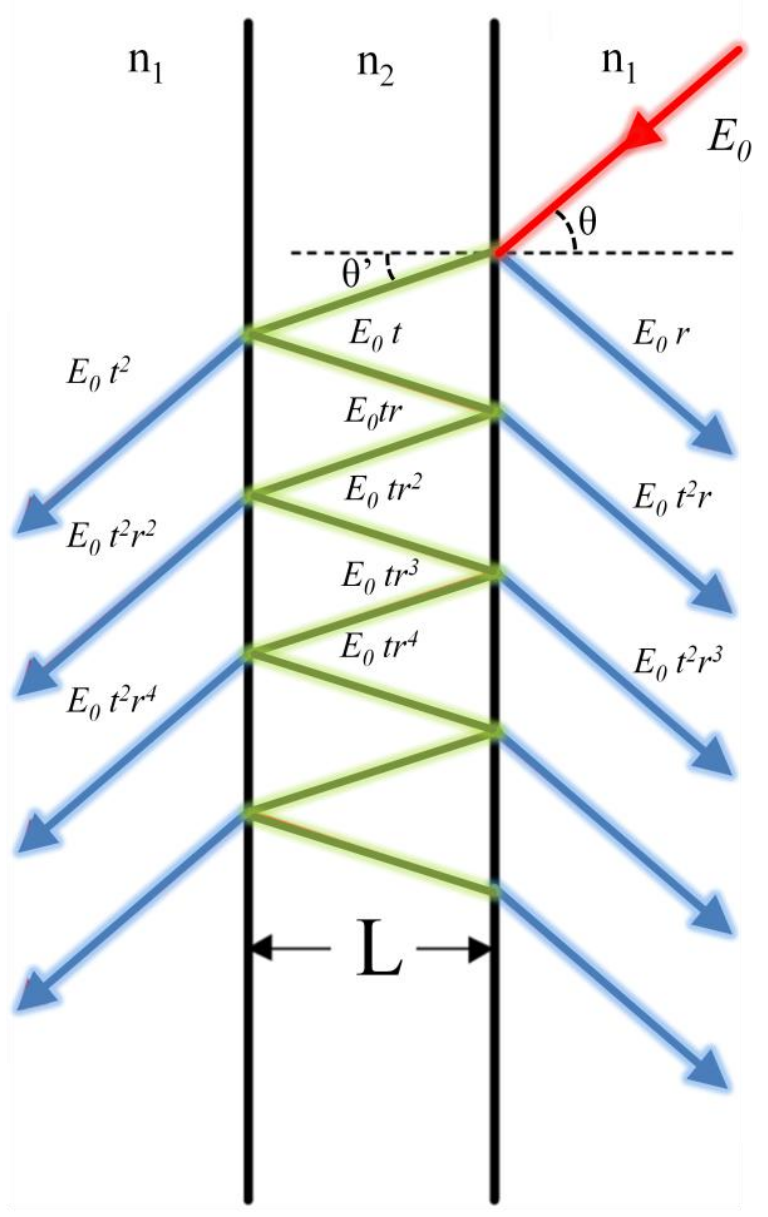

Figura 9 - Trajetórias de múltiplos raios de luz entre duas superfícies semitransparentes. Cálculos que levam em conta a diferença entre dois sucessivos raios podem ser usados para encontra a intensidade da luz transmitida $(\mathrm{T})$ e da luz refletida $(\mathrm{R})$. Esta função mostra o comportamento espacial das franjas de interferência em um experimento de múltiplos feixes como o interferômetro de Fabry-Perot. 
Entre feixes transmitidos (refratados) consecutivos como os representados na Figura 9 pelas amplitudes dos campos elétricos $E_{0} t^{2}, E_{0} t^{2} r^{2}, E_{0} t^{2} r^{4}$ ocorre o fenômeno de interferência devido à diferença de fase entre estes feixes.

Esta diferença de fase $\delta=2 \pi \Delta \mathrm{x} / \lambda$ pode ser obtida a partir dos parâmetros ilustrados na Figura 10a para um caso simplificado onde $\theta^{\prime} \sim \theta$ (74). Os feixes $A^{\prime}$ e $B^{\prime}$ de comprimento de onda $\lambda$ possuem diferença de caminho $\Delta x$ (Figura 10b) devido a reflexão no interior do material de índice de refração $n$.

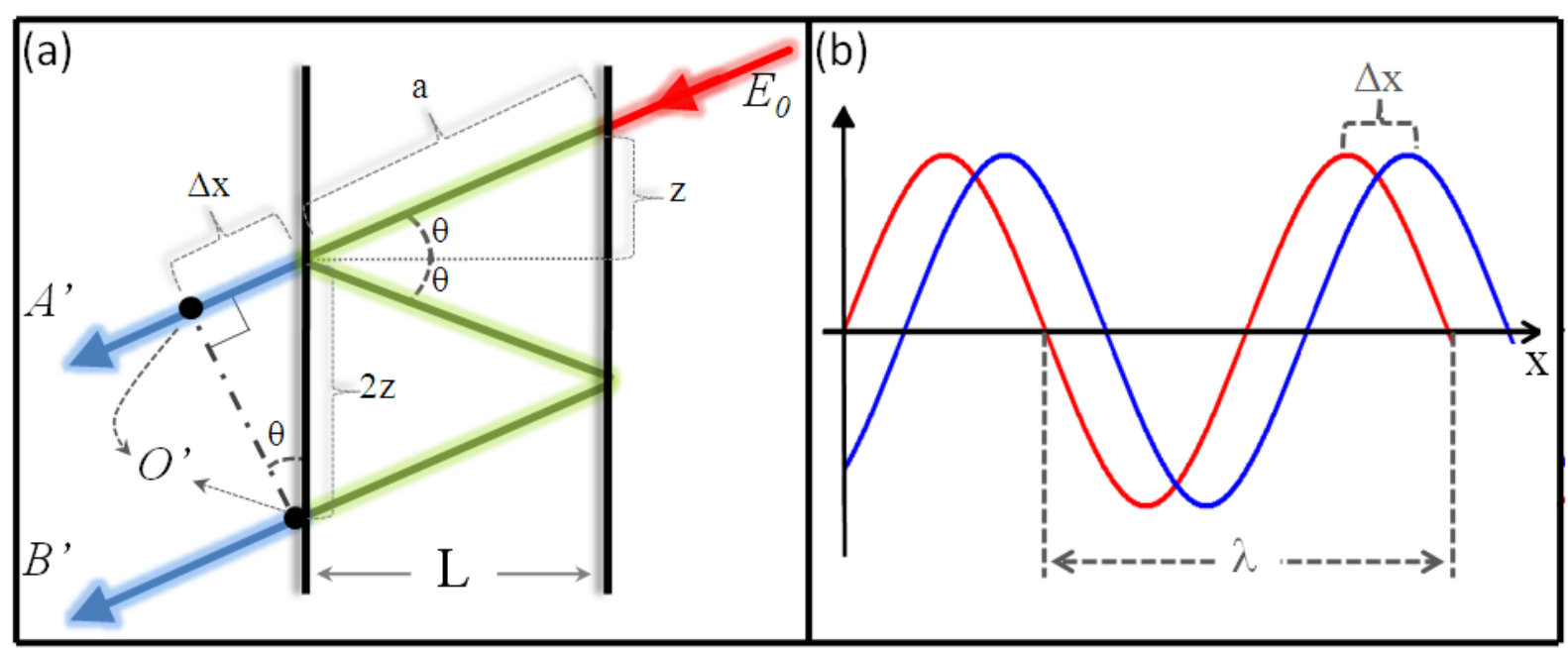

Figura 10 - (a) Esquematização do processo de interferência entre dois feixes consecutivos no limite $\theta^{\prime} \sim \theta$. Os cálculos necessários para se obter a diferença de fase existente em tal sistema podem ser realizados através das informações geométricas apresentadas nesta figura. (b) Diferença de fase gerada por uma diferença de caminho.

No interior do material o comprimento de onda $\lambda^{\prime}$ pode ser escrito em função do comprimento de onda no vácuo $\lambda$ da seguinte maneira: $\lambda^{\prime}=\lambda / n$. A expressão final para $\delta$ é escrita como

$$
\delta=4 \pi\left(\frac{n \mathrm{~L}}{\lambda}\right) \cos \theta
$$

Levando em conta esta diferença de fase, pode ser escrito uma soma em cima de todas as ondas transmitidas em uma das faces

$$
E_{T}=E_{0} t^{2}+E_{0} t^{2} r^{2} e^{i \delta}+E_{0} t^{4} r^{4} e^{2 i \delta}+\cdots
$$


que se trata de uma série geométrica infinita de razão $r^{2} e^{i \delta}$. Dividindo ambos os lados por esta razão e resolvendo para $E_{T} a$ intensidade da onda transmitida pode ser escrita como

$$
I_{T}=I_{0} \frac{|t|^{4}}{\mid 1-r^{2} e^{\left.i \delta\right|^{2}}}
$$

Os fatores $t$ e $r$ representam inicialmente a transmitância e a refletância, porém, quando ondas eletromagnéticas atravessam regiões com diferentes índices de refração ocorrem mudanças de fase. Além disso $r$ e $t$ são apresentados na forma complexa, fato que deve ser levado em conta, pois uma grandeza complexa não pode ser medida por qualquer instrumento físico real. Por este motivo tanto $r$ como $t$ devem ser escritos em função de variáveis macroscópicas, substituídos por $T$ e $R$ que representam a transmissão e reflexão reais respectivamente.

$$
\begin{aligned}
& R=|r|^{2}=r r^{*} \\
& T=|t|^{2}=t t^{*}
\end{aligned}
$$

Assim, a intensidade transmitida pode ser escrita da forma

$$
I_{T}=I_{0} \frac{T^{2}}{\left|1-R e^{i\left(\delta_{r}+\delta\right)}\right|^{2}}
$$

onde $\delta_{r}+\delta$ representa a diferença de fase entre dois feixes sucessivos.

Desenvolvendo o denominador da equação 4 e substituindo $\delta_{r}+\delta$ por $\Delta$ podemos obter a intensidade de outra forma (74)

$$
I_{T}=I_{0} \frac{T^{2}}{(1-R)^{2}}\left\{\frac{1}{1+\left[\frac{4 R}{(1-R)^{2}}\right] \operatorname{sen}^{2}\left(\frac{\Delta}{2}\right)}\right\}
$$

o termo entre chaves da equação 5 como Airy function. O termo entre colchetes recebe o nome de coeficiente de "finesse" ou fator de qualidade. Diretamente ligado aos espectros de interferência, o fator de qualidade está associado com a largura das fanjas de interferências mostradas na Figura 11. O máximo de qualquer valor obtido através do coeficiente de fineza é obtido quando o $\Delta / 2$ é um múltiplo inteiro de $\pi$. Este coeficiente é pequeno quando $R$ é pequeno e tem um valor alto quando $R \sim 1$, o que torna as franjas bem estreitas. 


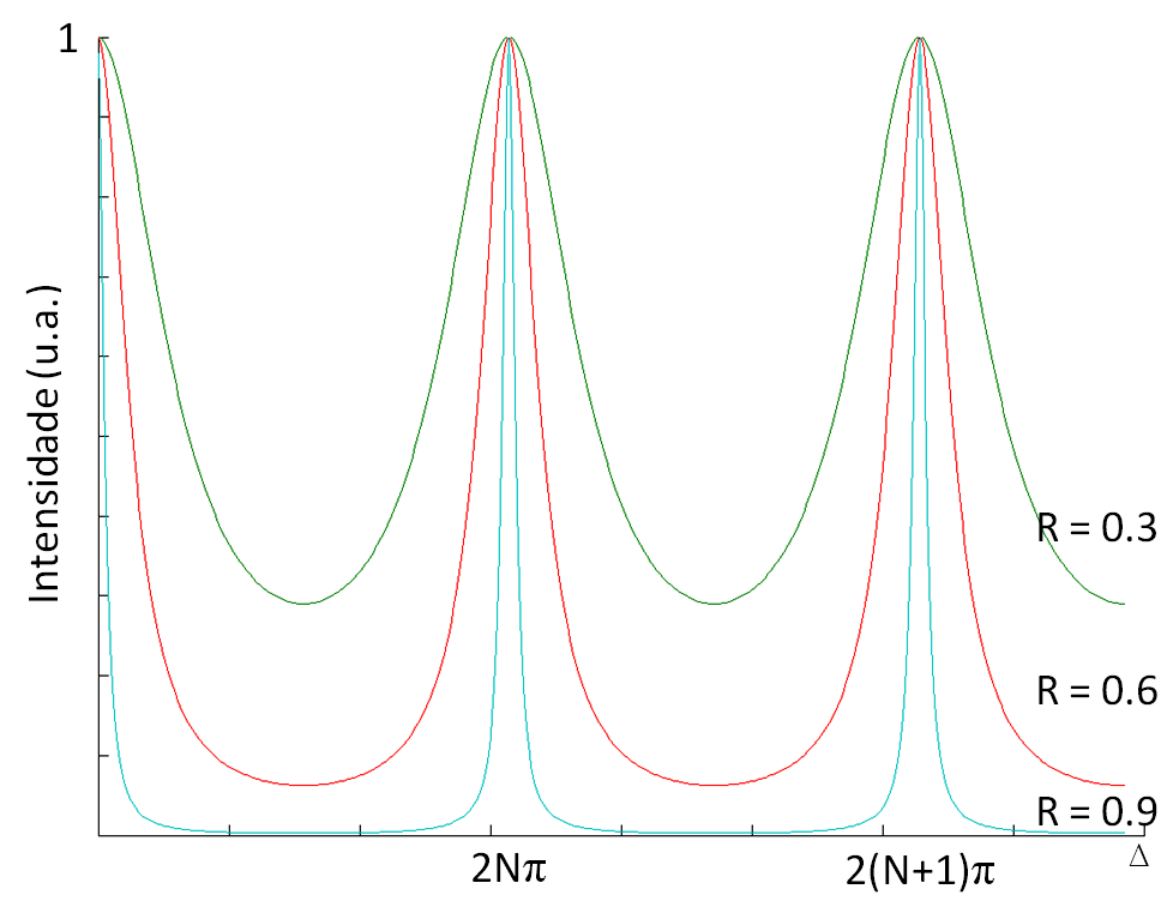

Figura 11 - Representação da Airy function para a distribuição de intensidades para diferentes valores da refletância $R$.

Para tanto, múltiplos inteiros de $\pi$ podem ser escritos como condição de interferência construtiva máxima em que $\Delta / 2=m \pi$, onde $m$ é um inteiro igual a $0, \pm 1, \pm 2$, etc. Anteriormente foi definido que $\Delta=\delta+\delta_{r}$, de modo que a equação 2 pode ser expressa em função do comprimento de onda como

$$
2 m \pi=4 \pi\left(\frac{n L}{\lambda}\right) \cos \theta+\delta_{r}
$$

Para o caso específico do modo rasante ou de escape, $\theta \sim \pi / 2$ e para uma interface tal que $n_{1}=n_{2}<n, \delta_{r}=0$. Assim a condição de interferência construtiva máxima é dada pela relação

$$
m \lambda=2 n L
$$

Escrita para um índice de refração efetivo $n=n_{e f}$, substituído na equação 6 no caso do guia de onda estar embebido em meios com diferentes índices de refração $(2,15,73)$.

Neste trabalho, os guias de onda polímeros são compostos por vários polímeros luminescentes embebidos em uma matriz transparente planar de polimetacrilato. Estes polímeros absorvem e emitem em uma larga faixa espectral. Assim a emissão lateral que escapa do guia (leaky-mode) é composta por aqueles comprimentos de onda resultantes da 
condição de interferência construtiva, ou seja, a emissão larga produzida pelos polimeros dá origem à emissão lateral composta de franjas estreitas nos comprimentos de onda estabelecidos pela equação 7 .

\subsection{Sensores a base de Guias de onda Poliméricos}

Dispositivos ópticos são essenciais para a realização da comunicação entre sistemas que utilizam a luz como meio de transmissão de dados. A característica básica que todos estes dispositivos mantém um com relação ao outro é o fato de ocorrer a propagação de uma onda óptica ao longo de um guia de onda. De acordo com a teoria de propagação da luz, guias de onda dependem da diferença do índice de refração entre a região do guia de onda e o meio que o rodeia. Diferentes técnicas podem ser utilizadas para obter uma mudança de índice de refração desejada. Cada método tem sua vantagem e desvantagem, tanto que não pode ser afirmado que um é melhor do que o outro (75).

Atualmente existem inúmeras pesquisas que buscam aproveitar a boa sensibilidade de dispositivos ópticos como guias de onda $(2,72,76)$ para diversos fins. A utilização de polímeros luminescentes na fabricação de guias de onda é um ramo promissor na área de biosensores, uma vez que tais moléculas apresentam uma alta eficiência quântica. Este fato permite a fabricação de dispositivos mais baratos, com uma engenharia mais simples e uma maior diversidade de constituintes que podem sem aplicados devido ao grande número de polímeros conhecidos. Esta mesma diversidade de polímeros faz com que uma maior gama de comprimentos de onda esteja a disposição para serem aplicados como partículas luminescentes nos guias de onda, fazendo com que uma maior região do espectro eletromagnético esteja acessível.

Na configuração de guia de onda planar com emissão lateral, a luz emitida adquire características interessantes de interferência, apresentando-se como um espectro com bandas estreitas que dependem da geometria e do índice de refração efetivo do guia. Esta propriedade pode ser empregada em sensores ópticos, pois a emissão lateral pode sofrer deslocamentos na posição de seus picos ou alterar as suas intensidades pela presença de moléculas que entram em contato com a superfície do guia (variação de $n_{e f}$ ou da espessura $L$ ). A detecção poderá 
ser feita por meio do deslocamento espectral $(\Delta \lambda)$ das franjas de interferência ou da alteração da intensidade da emissão $(\Delta \mathrm{I})$, conforme ilustra a Figura 12.

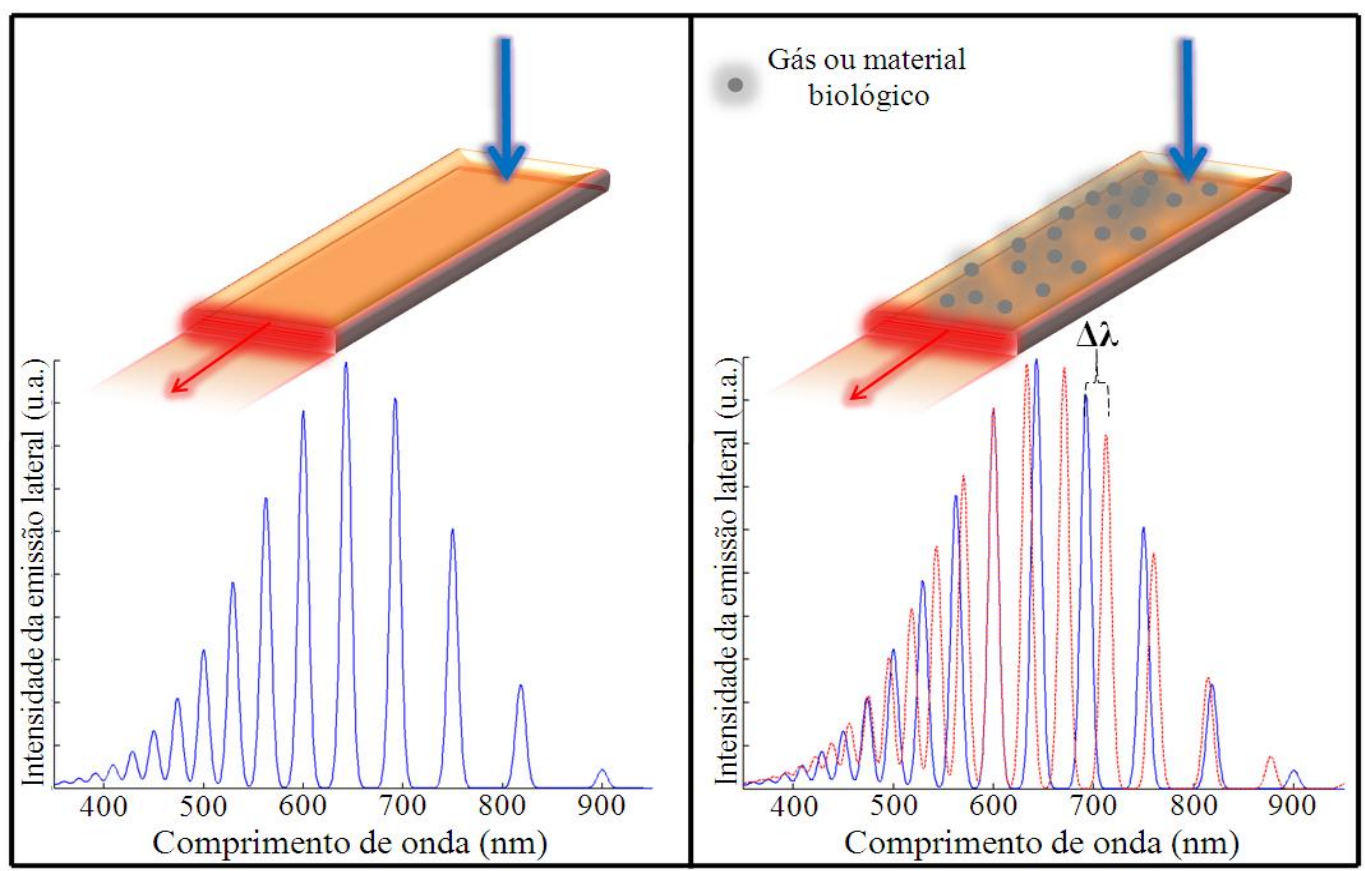

Figura 12 - Ilustração do princípio de funcionamento dos sensores ópticos a partir de guias de onda luminescentes.

\subsection{Conversores de comprimento de onda}

De maneira geral, um conversor de comprimento de onda (LSC) é um dispositivo que absorve luz ${ }^{*}$ em uma ampla faixa espectral e a redireciona ao longo de um guia composto de material transparente contendo cromóforos que, através de processos de reabsorção/relaxação/re-emissão converte a radiação absorvida em radiação de menor comprimento de onda. O conceito de conversores de comprimento de onda é ilustrado na Figura 13.

O princípio de funcionamento se baseia na propagação da luz em um meio desordenado contendo cromóforos ou moléculas emissores de luz extremamente diluídas que possuem uma distribuição energética larga na região espectral de interesse (Figura 13a). A luz absorvida e re-emitida ao longo do guia ótico se desacopla do meio quando não há mais

* O termo "luz" quando usado aqui não está associado a apenas os espectro visível, mas sim a todo o espectro eletromagnético da fonte em questão. 
moléculas de menor energia que absorva essa radiação, o que caracterizada por uma emissão deslocada para o vermelho (Figura 13b). Ao sair lateralmente do guia de onda, a luz contém um único comprimento de onda. É interessante notar que qualquer alteração dos processos óticos desse conversor de comprimento de onda altera o estado final emissivo. $\mathrm{O}$ fato da luz se propagar ao longo de grandes distâncias faz com que este dispositivo seja sensível a estas alterações e, conseqüentemente, seja utilizado também como sensor.

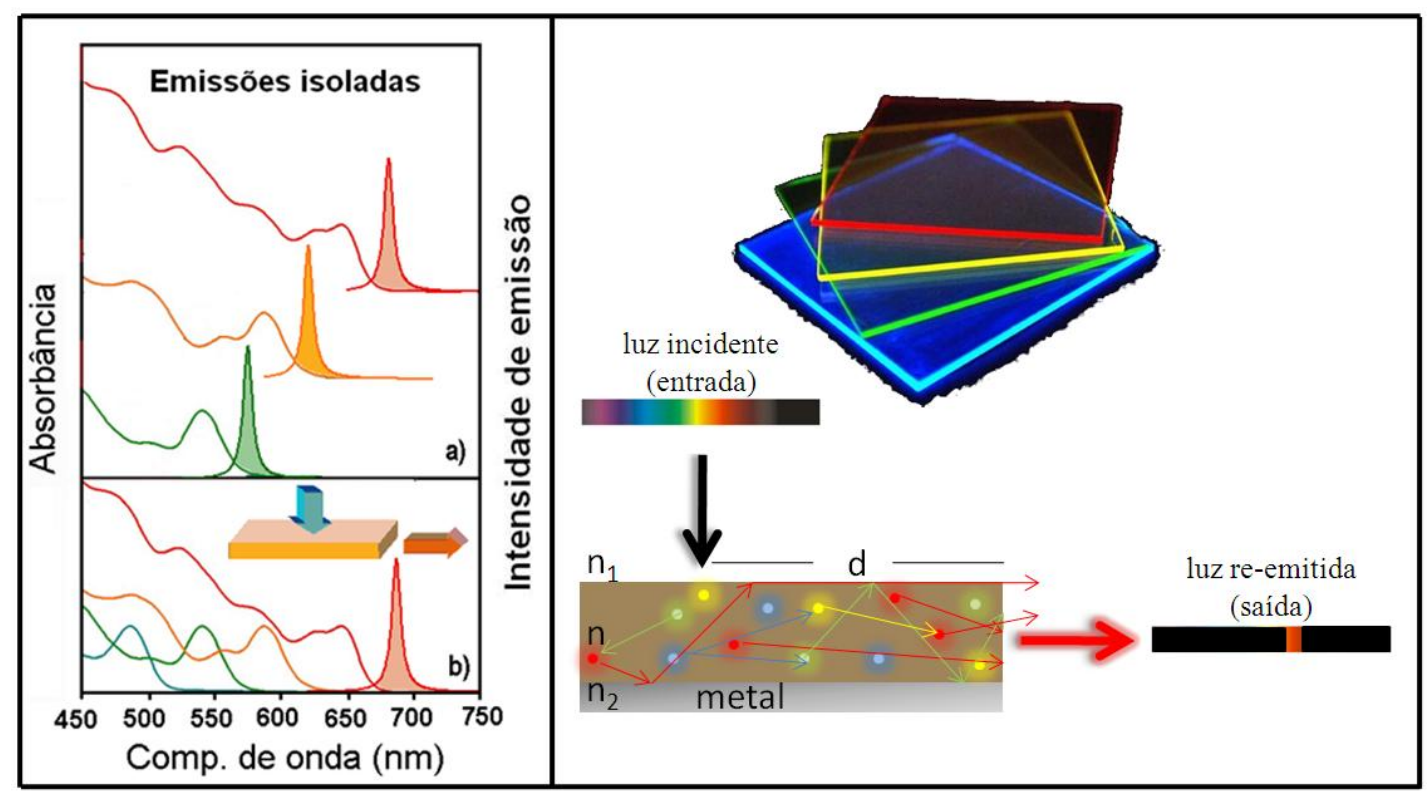

Figura 13 - O conceito de conversores de comprimento de onda.

Existem dois componentes com funcionalidades específicas em um conversor a base de espécies luminescentes. O primeiro é a possibilidade de redirecionar parte da luz incidente ao longo do conversor através do primeiro processo de absorção/emissão. O segundo é que pode se acoplar uma célula solar com absorção sintonizada no comprimento de onda de interesse ou qualquer outro elemento que retire proveito da emissão lateral proveniente do coletor (face lateral). Assim, um dos principais desafios é aperfeiçoar esse sistema, visando aplicações específicas $(4,8,77,78)$.

No ano de 1976, os pesquisadores W. H. Weber e John Lambe (5), em seu artigo denominado "Luminescent greenhouse collector for solar radiation", propuseram a utilização de um "luminescent solar collector" acoplado a uma célula solar para melhorar o seu desempenho. Tal dispositivo concentrava a radiação solar que incidia normalmente no seu plano e a guiava até uma de suas laterais, como pode ser visto na Figura 14. 


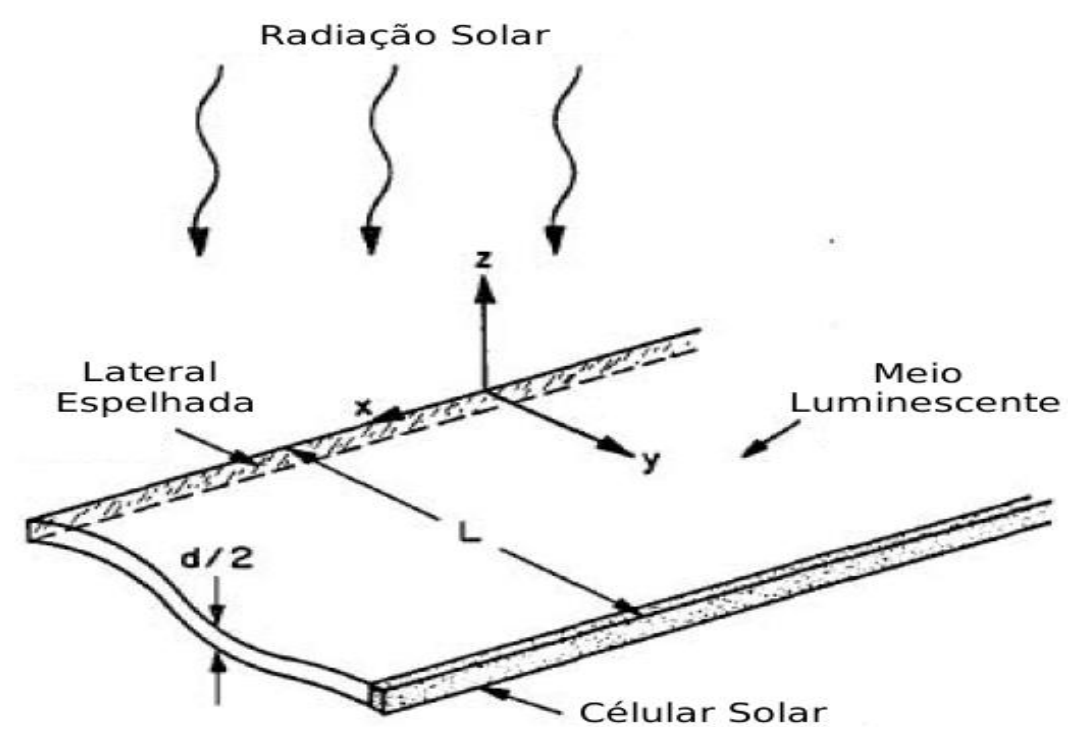

Figura 14 - Esquema original proposto em 1976 por W. H. Weber e John Lambe para um "Luminescent Solar Collector" ou LSC.

Logo após este anúncio, o questionamento inicial a respeito da longevidade (durabilidade) de um LSC tornou-se fato importante, uma vez que o mesmo estaria exposto a diversos eventos climatológicos. Levando isso em conta, os polímeros acrílicos foram uma boa alternativa, uma vez que resistem as variações do clima e ao mesmo tempo não interferem de maneira direta no quesito de absorção e emissão da luz. Outro aspecto da pesquisa foi a determinação das propriedades de absorção e emissão da matriz e dos crómorfos incorporados nesse meio. Outra frente buscava a determinação da eficiência dos LSCs que, como comentado anteriormente, suas perdas estão relacionadas com o índice de refração e a degradação dos componentes poliméricos da matriz.

O meio luminescente é responsável pela absorção da luz incidente. Sendo assim, responsável por grandes problemas relacionados à eficiência dos LSCs. A estabilidade ao longo do tempo depende fortemente da resistência dos cromóforos à fotodegradação, que por sua vez depende do isolamento em relação ao meio ambiente (79). Tipicamente os cromóforos possuem uma alta eficiência quântica e são frequentemente escolhidos por apresentarem picos de absorção desde o ultra-violeta ao infravermelho próximo. Devem ser solúveis ao mesmo solvente e possuírem boa dissolução em matrizes sólidas.

Diversas pesquisas e desenvolvimentos foram feitos ao longo de várias décadas e diferentes rotas foram traçadas, sempre em busca de uma maior eficiência, todas direcionadas a uma melhor utilização do espectro solar. Isto está sendo chamado Célula Solar de Terceira Geração (80). Como exemplo células com uma "lacuna de energia" intermediária (81), e 
concentradores com nanopartículas quânticas (82). Com o passar dos anos, várias alternativas surgiram, dando origem a uma vasta gama de materiais que poderiam substituir as moléculas orgânicas. Outra alternativa foi o uso de "Quantum Dots", introduzidos dentro das matrizes dos conversores como elementos absorvedores/luminescentes na tentativa de melhorar de forma significativa as emissões resultantes. Desde então o desempenho tanto dos QDs como das moléculas orgânicas foram aprimorados como espécies luminescentes em LSCs (83). Isso fez com que pesquisas em diferentes frentes fossem realizadas, expondo fatores positivos e negativos a respeito do uso de moléculas orgânicas e QDs (84).

$\mathrm{Na}$ Figura 15 pode ser visto o funcionamento de um LSC por um diagrama de um "Planar Solar Concentrador" (PSC), construído de um material transparente onde moléculas emissoras com banda de absorção tanto no visível como ultravioleta são diluídas. Os fótons provenientes da fonte de luz são absorvidos pela face superior e emitidos pela lateral. A lei de Snell diz que uma grande fração desses fótons é aprisionada por reflexões internas; próximo de 74\% para uma emissão isotrópica em uma matriz de PMMA com índice de refração de 1,49. Essa luminescência é transportada para as laterais por sucessivas reflexões.

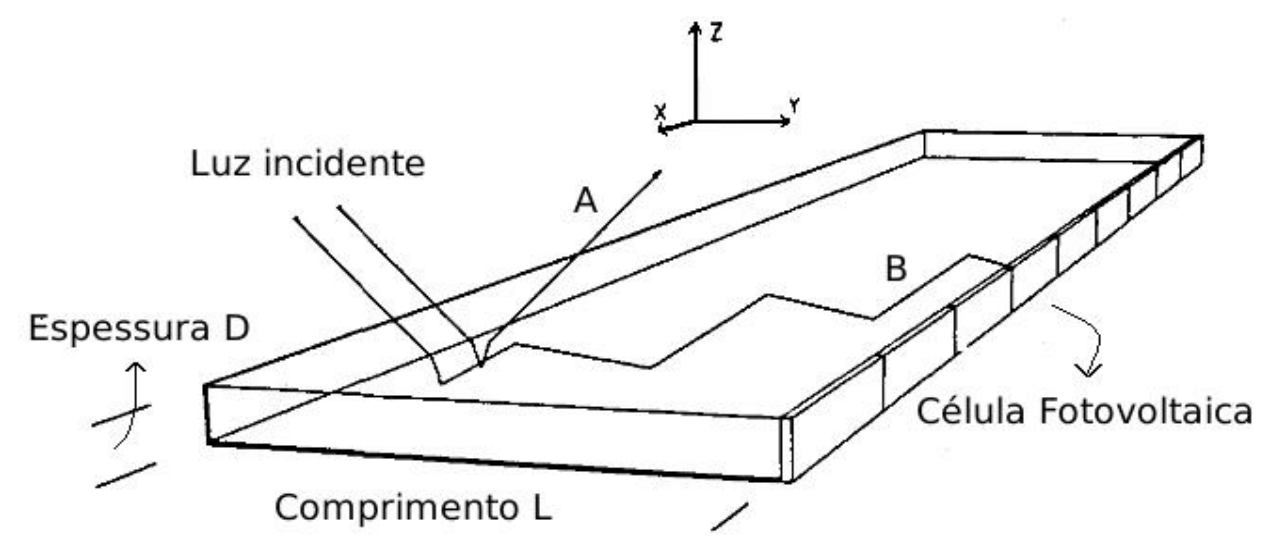

Figura 15 - "Planar Solar Concentrator" ou PSC. A luz solar incide sobre a face superior e uma fração é aprisionada dentro da espessura "D". Está fração pode tanto escapar (A) como pode ser guiada por reflexões (B). 


\section{Materiais e Métodos}

Nessa seção, ênfase será dada à descrição dos materiais e da metodologia utilizadas nesse trabalho. A maioria dos materiais empregados nos guias de onda e LSCs foram obtidos através da cooperação com o Grupo de Polímeros Bernhard Gross (GPBG) do IFSC, que cedeu seus laboratórios para a preparação e a realização de parte da caracterização óptica desses materiais e dispositivos.

\subsection{Materiais}

A fabricação de guias de onda e LSCs planares requer um número bem reduzido de materiais. Caso estes dispositivos forem constituídos apenas de um tipo de material luminescente, uma matriz (acrílica) e seus respectivos solventes, fica apenas a critério o uso de um substrato ou um molde onde essa solução possa ser aplicada. No entanto, os dispositivos propostos no presente trabalho são baseados, além da matriz acrílica transparente e do substrato, na utilização de um sistema multipolimérico luminescente. Ao todo foram utilizados cinco polímeros com bandas de absorção/emissão distintas que cobrem parte do ultravioleta próximo até o vermelho (de $350 \mathrm{~nm}$ a $650 \mathrm{~nm}$ ). O objetivo aqui é cobrir uma faixa espectral larga de absorção e emissão de modo a demonstrar melhor a funcionalidade e aplicabilidade destes dispositivos puramente óticos.

De forma abreviada, os materiais utilizados neste trabalho foram: o solvente Tolueno (C6H5CH3, da QUEMIS); poli (metil metacrilato) (PMMA) (ISI, PM: $70.000 \mathrm{~g} / \mathrm{mol}$ ) em grãos; os polímeros luminescentes ADS-329BE, ADS-108GEda American Dye Source, Inc.; o Super Yellow da Covion Organic Semicondutors agora Merck; o MEH-PPV da Sigma Aldrich e o LAPS-16sintetizados pela Prof. Dr. Leni Akcelrud no Laboratório de Polímeros Paulo Scarpa (LaPPS) UFPR.

O substrato escolhido para a aplicação da solução polimérica foi o vidro BK7, com índice de refração $\mathrm{n}=1,38$ (em $588 \mathrm{~nm}$ ). Conhecido como BK7, é uma placa com $36 \mathrm{~mm}$ de comprimento com $12 \mathrm{~mm}$ de altura e $1 \mathrm{~mm}$ de espessura, é um vidro com maior qualidade 
superficial que o vidro comum. Geralmente esta lâmina é aplicada em diversos estudos como substrato para deposição de filmes finos, LBL, "spin coating" entre outros.

Importante frisar que os guias de onda estudados aqui não são unidimensionais propriamente ditos, diferentemente do que é feito em outros estudos $(1,7,18,19)$, pois aqui propomos estruturas planares, porém com propriedades de guia de onda no plano luminescente, sendo este utilizado para o confinamento da radiação. A escolha foi baseada apenas por ter uma geometria adequada para captar radiação em uma área maior e pelas diferentes possibilidades de aplicações. Essa geometria possibilita a realização de metalização com um maior grau de qualidade.

\subsubsection{Poli (Metil Metacrilato) (PMMA)}

Existem inúmeros matérias que fazem parte da classe dos acrílicos termoplásticos (85). Porém, os que despertam um maior interesse comercial é o poli (metil metacrilato) (PMMA) para plásticos e tintas e as fibras de poli (acrilo nitrila) para uso têxtil. O PMMA é obtido em pó, grânulos ou em placas o qual é moldado pelas técnicas convencionais de transformação dos termoplásticos. Tem como unidade básica o metacrilato de metila que é comumente chamado de acrílico, faz parte dos termoplásticos devido à maleabilidade adquirida quando dissolvido ou aquecido. $\mathrm{O}$ metacrilato de metila pode ser polimerizado por diversas técnicas de polimerização (emulsão, massa, suspensão e solução). A polimerização em massa possibilita a obtenção direta do produto desejado, sendo assim a técnica 'cast' a mais utilizada para fabricação das chapas. Assim se obtém chapas com alta transparência, grande resistência mecânica, mínimas tensões térmicas e distorções ópticas(85).

O acrílico utilizado neste trabalho se encontrava na forma de grãos, deste modo, todo o processo descrito acima já havia sido realizado. O PMMA como matriz polimérica, oferece boas vantagens para a confecção de guias de onda planares, como a alta solubilidade em solventes orgânicos, o alto índice de refração $(n=1,49)$, a alta transparência devido à facilidade na formação de um filmes devido ao bom ordenamento molécular (86). Além disso, os polímeros conjugados emissores de luz utilizados formam mistura homogênea em solução de PMMA em alta concentração (200 g/l). Entretanto, existem alguns inconvenientes, como por exemplo, o fato do acrílico não ter uma boa aderência ao vidro, e de ser também sensível às taxas de evaporação do solvente na fabricação de filmes "cast". 


\subsection{Processamento das amostras}

\subsubsection{Preparação e metalização do substrato}

Quanto à limpeza do substrato, essa na maioria das vezes, amplia as possibilidades de obtermos um filme com boa qualidade, ainda mais no caso de dispositivos que serão metalizadas. Portanto, uma boa limpeza é fator determinante para obtenção de bons resultados. A limpeza foi feita mediante a imersão das lâminas de BK7 em uma solução de 1:4 de permanganato de potássio $\left(\mathrm{KMnO}_{4}\right)$ e água Milli-Q, respectivamente, por 24 horas. Como consequiência da imersão em $\mathrm{KMnO} 4$, as superfícies ficam cobertas por um óxido, resultante da limpeza feita por oxidação nas superfícies das mesmas. Este é eliminado com uma nova imersão em uma solução de 1:20 de peróxido de hidrogênio $\mathrm{H}_{2} \mathrm{O}_{2}$ e água respectivamente, por 30 minutos. Após esse tempo os substratos foram lavados em água Milli-Q e posteriormente secos em fluxo de $\mathrm{N}_{2}$ ultralimpo. As lâminas de BK7 foram armezenadas em placas de Petri para posterior metalização ou deposição da solução polimérica.

Os padrões produzidos através das metalizações nas lâminas de vidro para a fabricação dos guias de onda seguem o esquema da Figura 16. Faixas metálicas de alumínio de $200 \mathrm{~nm}$ de espessura e $3 \mathrm{~mm}$ de largura foram metalizadas. Para a fabricação dos LSCs, a metalização de alumínio foi aplicada em toda a área da lâmina de vidro.

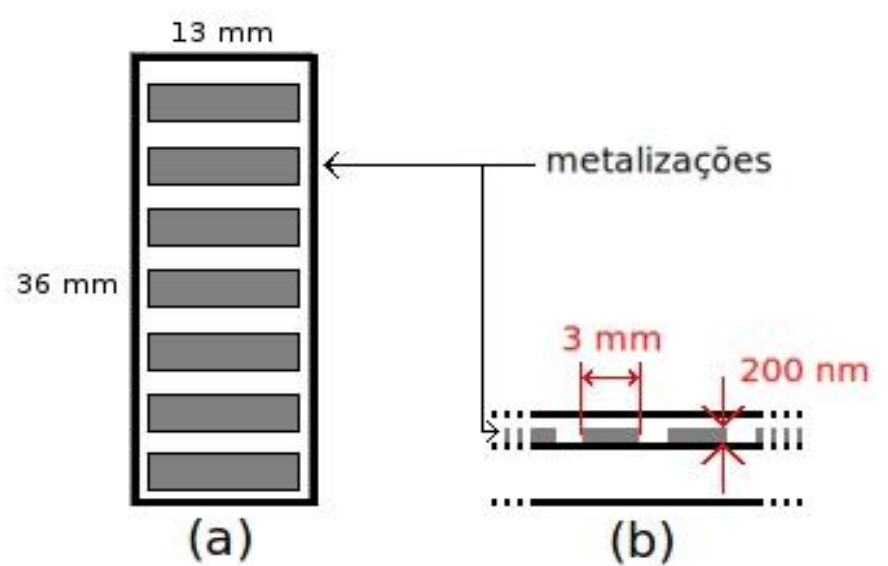

Figura 16 - Substrato de vidro contendo superfícies refletoras de alumínio. (a) padrão visto por cima indicando largura e comprimento. (b) vista lateral indicando a espessura de $200 \mathrm{~nm}$ e largura da metalização de $3 \mathrm{~mm}$. 


\subsubsection{Soluções poliméricas}

As soluções de poli (metil metacrilato) (PMMA) em tolueno com concentração de 40g/l para os guias de onda e 200g/l para os LSCs foram preparadas com o auxílio de uma balança de precisão, uma placa aquecedora / agitadora (hot plate, respectivamente a $60{ }^{\circ} \mathrm{C} \mathrm{e}$ $80{ }^{\circ} \mathrm{C}$ ). Foram preparados $60 \mathrm{ml}$ dessa solução, tendo em vista que ela é o componente mais utilizado no processo de fabricação dos dispositivos, uma vez que os polímeros luminescentes foram utilizados em concentrações muito menores.

Tabela 2 - Fórmula química e comprimento de onda de emissão dos polímeros conjugados utilizados.

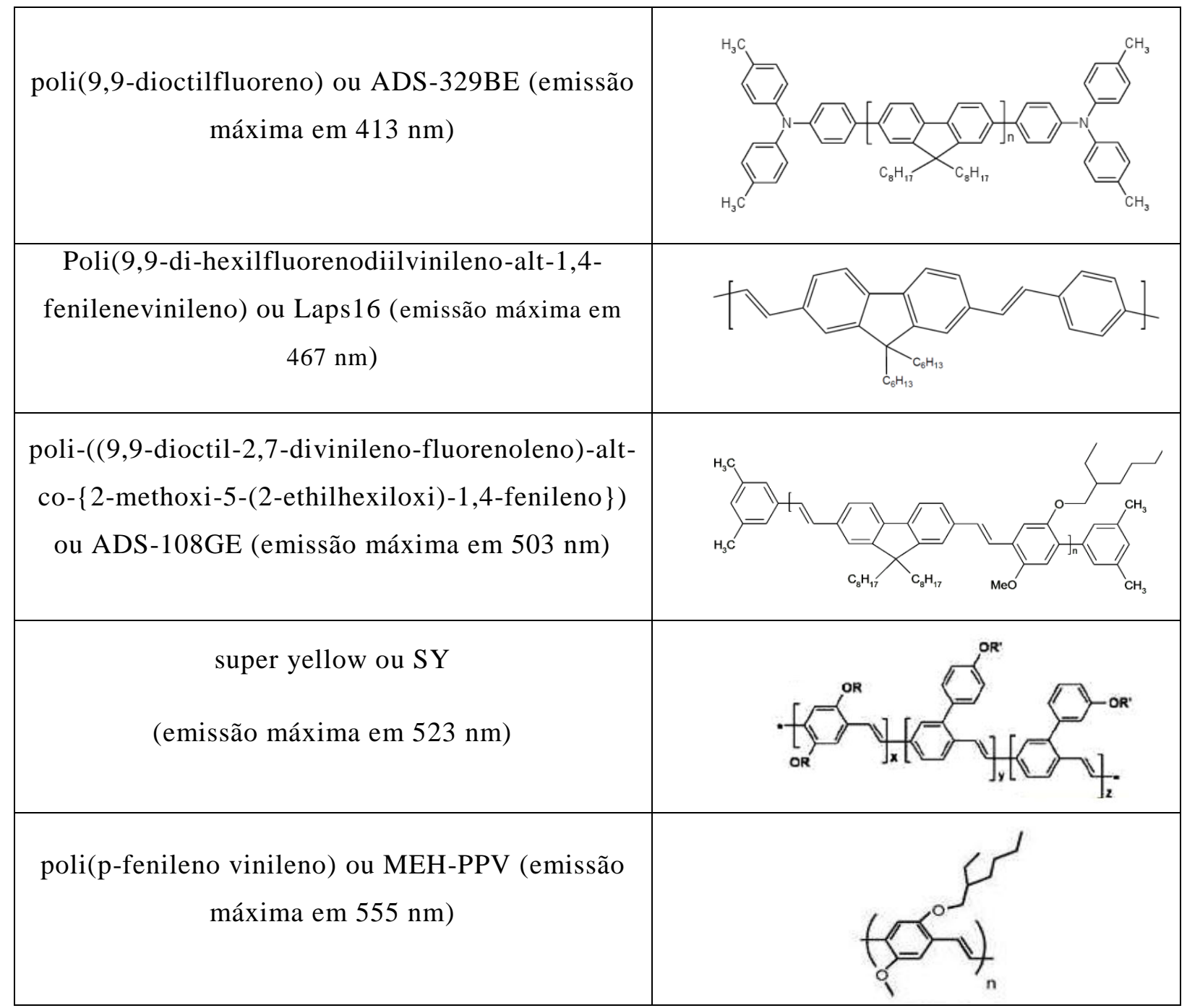

Os polímeros utilizados neste trabalho são (Tabela 2): o poli (9,9-dioctilfluoreno) ou (ADS-329BE) PFO (emissão máxima em 413 nm), o poli-(9,9'-n-dihexil-2,7fluorenodilvinilene-alt-1,4-fenilenovinileno) ou Laps16 (emissão máxima em 467 nm), o poli- 
((9,9-dioctil-2,7-divinilenofluorenoleno)-alt-co-\{2-methoxi-5-(2-ethilhexiloxi)-1,4-fenileno\}) ou ADS-108GE (emissão máxima em 503 nm), o super yellow ou SY (emissão máxima em $523 \mathrm{~nm}$ ) e o poli-(2-methoxi-5-(2'-etilhexiloxi)-p-fenileno vinileno) ou MEH-PPV, emissão em $555 \mathrm{~nm}$ ) em solução de tolueno. Destas soluções primárias de polímeros conjugados, filmes com diversas concentrações foram obtidos.

Os polímeros ADS-329BE, LAPS-16, ADS-108GE, Super Yellow (SY) e MEH-PPV foram separadamente diluídos em tolueno, compondo um conjunto de soluções primárias. Para cada uma destas, uma quantidade de $10 \mathrm{ml} \mathrm{a} 0,5 \mathrm{~g} / \mathrm{l}$ em tolueno foi preparada para ser misturada em quantidades reduzidas na solução de acrílico. A quantidade de cada solução primária incorporada à solução de PMMA foi diferente para os guias de onda e os conversores, pois foram preparadas diferentes concentrações da solução de PMMA. Filmes "cast" de guia de onda foram depositados com espessura variando de 0,6 a $3000 \mathrm{~nm}$ e, por isso, foram feitos com solução de PMMA em tolueno a $40 \mathrm{~g} / \mathrm{l}$. Já os filmes dos LSCs foram preparados com espessura em torno de $30 \mu \mathrm{m}$ através de solução de PMMA a $200 \mathrm{~g} / \mathrm{l}$. A metodologia para se determinar os valores adequedos de cada polímero nas duas soluções acima é descrita abaixo.

Basicamente, a concentração de cada polímero na solução de PMMA foi estipulada por medidas de absorbância. Alíquotas de $30 \mu 1$ da solução primária de cada polímero foram acrescentadas separadamente à solução de PMMA de forma a se obter aproximadamente 0,6 unidades de absorbância no máximo da banda conjugada, como pode ser visto na Figura 17. Com esse procedimento, um valor de absorbância em torno de 1 seria obtido na faixa espectral de trabalho (entre 350 e $600 \mathrm{~nm}$ ) através da superposição das bandas conjugadas em filmes contendo todos os polímeros. A razão disso é que, a absorbância em torno de 1 daria um livre caminho médio de $1 \mu \mathrm{m}$ em um filme de mesma espessura, por exemplo. Cada polímero utilizado tem características de absorção específicas. Deste modo a quantidade acrescentada não obedeceu a uma constante para cada um. Assim, uma alíquota de $30 \mu \mathrm{l}$ de qualquer solução primária a $0,5 \mathrm{~g} / 1 \mathrm{em} 10 \mathrm{ml}$ de PMMA corresponde a uma concentração $\mathrm{C}_{0}=0,0015 \mathrm{~g} / \mathrm{l}$. Nessa concentração, os espectros da Figura 17 foram obtidos adicionando-se

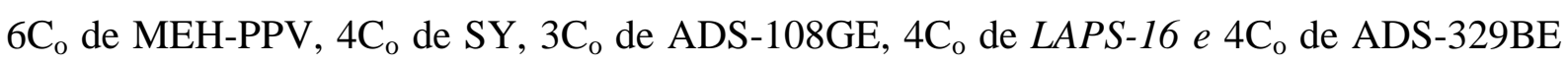
em $10 \mathrm{ml}$ de PMMA. 


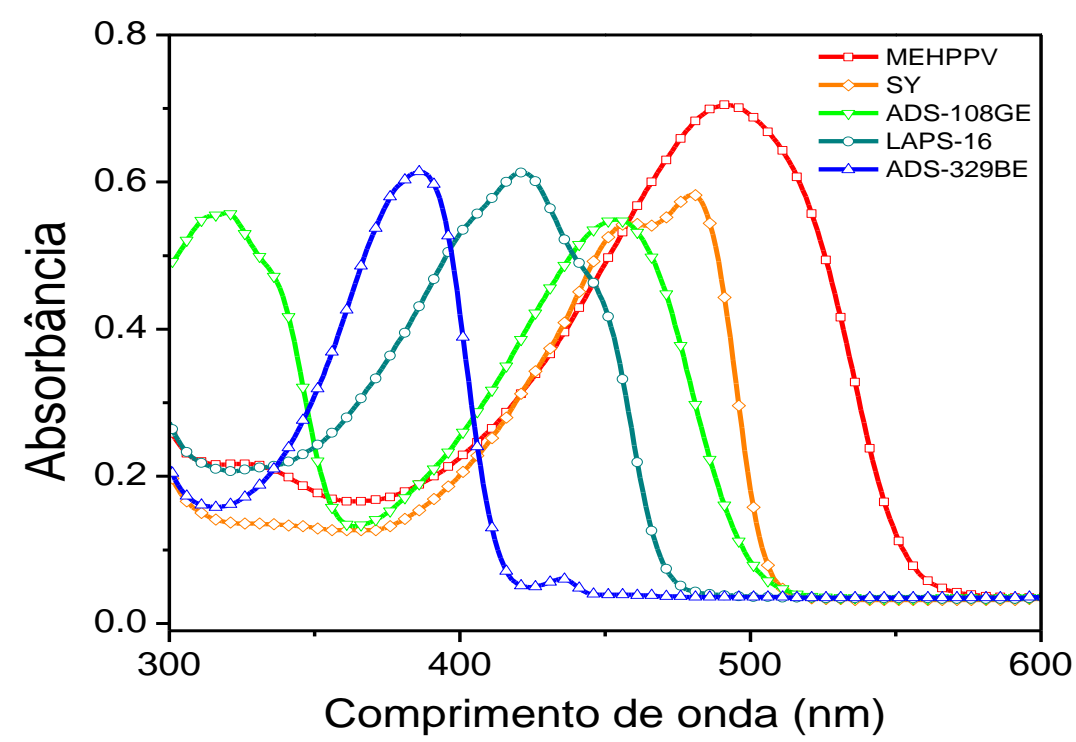

Figura 17 - Espectros de absorbância de cada polímero utilizado, todos em solução de PMMA em tolueno a 40 $\mathrm{g} / \mathrm{l}$.

A solução final, que a partir deste instante passa a ser denominada de solução polimérica (SP), resulta da adição de todas estas alíquotas em um único volume de solução de PMMA, que é específico para a aplicação em guias de onda e LSCs (veja adiante). Uma representação esquemática para a obtenção da solução final pode ser vista na Figura 18.

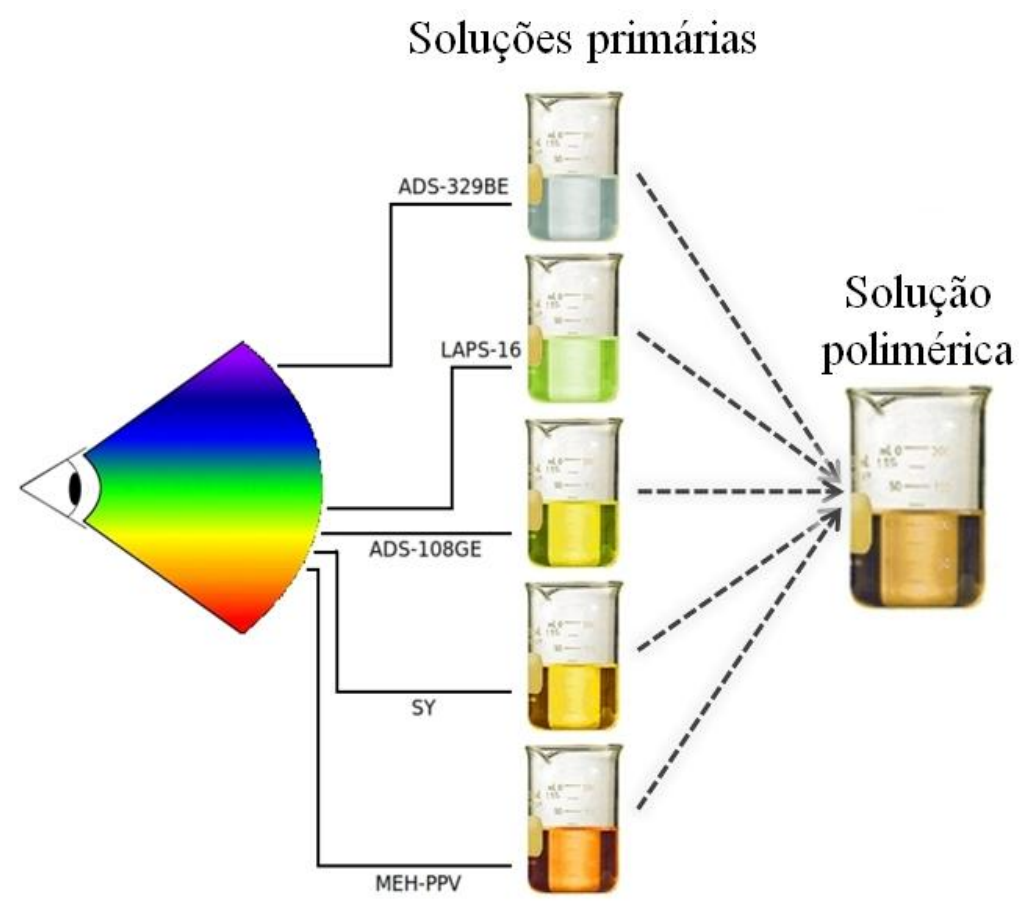

Figura 18 - Polímeros conjugados diluídos a 0,5 g/l em tolueno foram utilizados em apenas alguns microlitros (aproximadamente 30 microlitros na solução precursora de PMMA) resultando em uma nova solução, chamada de solução polimérica. 
As caracterizações das soluções foram feitas através de medidas de absorbância realizadas em um espectrômetro UV-Vis (U-2900, Hitachi) utilizando uma cubeta de quartzo (10 mm), já as medidas de emissão e de excitação da luminescência foram realizadas em um Fluorímetro (Shimadzu RF-5301 PC) entre 350 nm e $750 \mathrm{~nm}$.

\subsubsection{Preparação do(s) guia(s) de onda}

Tendo em mão todas as soluções de cada polímero em PMMA, adicionamos volumes iguais de cada um em um Becker de vidro até termos a amostra final em quantidade suficiente para realizarmos as mediadas de absorbância, emissão, excitação e confeccionarmos filmes da mesma sobre substratos de vidro contendo superfícies refletoras metalizadas e/ou somente sobre o vidro. A aplicação sobre as diferentes superfícies (vidro e/ou vidro metalizado) é determinada através do tipo de estudo que se deseja realizar ou do tipo de dispositivo que se deseja obter. A solução foi espalhada sobre os substratos através da técnica "casting" em duas diferentes configurações que podem ser vistas na Figura 19a.

A solução precursora de PMMA utilizada teve uma concentração de $40 \mathrm{~g} / \mathrm{l} \mathrm{em}$ tolueno. Volumes iniciais $\mathrm{V}_{0}$ de aproximadamente $30 \mu \mathrm{l}$ de cada polímero a $0,5 \mathrm{~g} / 1 \mathrm{em}$ tolueno foram acrescentados em $10 \mathrm{ml}$ da solução acrílica com o auxílio de uma micro-pipeta. Assim, a concentração de polímeros luminescentes de PMMA para cada acréscimo de uma alíquota $\mathrm{V}_{0}$ foi de $\mathrm{C}_{0}=0,0015 \mathrm{~g} / \mathrm{l}$.

Deste modo, a composição final da solução polimérica em PMMA foi de: $4 \mathrm{C}_{0}$ (ADS-

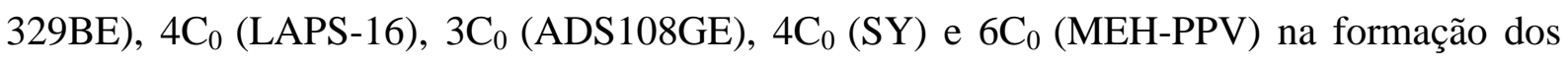
guias de onda. Volumes múltiplos de $200 \mu 1$ dessa solução foram utilizados para preparar os guias de onda com diferentes espessuras por deposição "cast" no substrato previamente metalizado (Figura 19a). A secagem lenta ocorreu dentro de uma placa de Petri por um período de três a quatro horas. Após o término da evaporação do solvente as amostras eram levadas até o Laboratório de Luminescência onde medidas de emissão lateral foram realizadas com o auxílio de um laser de He-Cd (KIMMON) com excitação em $325 \mathrm{~nm}$. A montagem do experimento é mostrada na seção 3.3 . 


\subsubsection{Preparação dos LSCs}

Alíquotas (volumes $\mathrm{V}_{0}$ de aproximadamente $30 \mu \mathrm{l}$ ) foram acrescentadas a $1,5 \mathrm{ml} \mathrm{da}$ solução precursora de PMMA em tolueno a $200 \mathrm{~g} / \mathrm{l}$ com o auxílio de uma micro-pipeta. O volume da solução polimérica de $1,5 \mathrm{ml}$ em tolueno foi suficiente para depositar filmes "cast" de espessura em torno de $30 \mu \mathrm{m}$. Deste modo, a concentração de cada polímero na solução de PMMA foi um múltiplo de $\mathrm{C}_{0}=0,01 \mathrm{~g} / \mathrm{l}$. Como padrão nesse trabalho, quando fizermos referência a alguma concentração, utilizaremos múltiplos de $\mathrm{C}_{0}$. Portanto, deste ponto em diante as amostras serão nomeadas como segue: Amostra $(4,4,2)$, quando constituída por três polímeros genéricos. Isto significa que a composição geral é de $\left(4 \mathrm{C}_{0}\right.$ (Polímero $\left.\mathrm{X}\right), 4$ $\mathrm{C}_{0}$ (Polímero Y), $2 \mathrm{C}_{0}($ Polímero Z)).

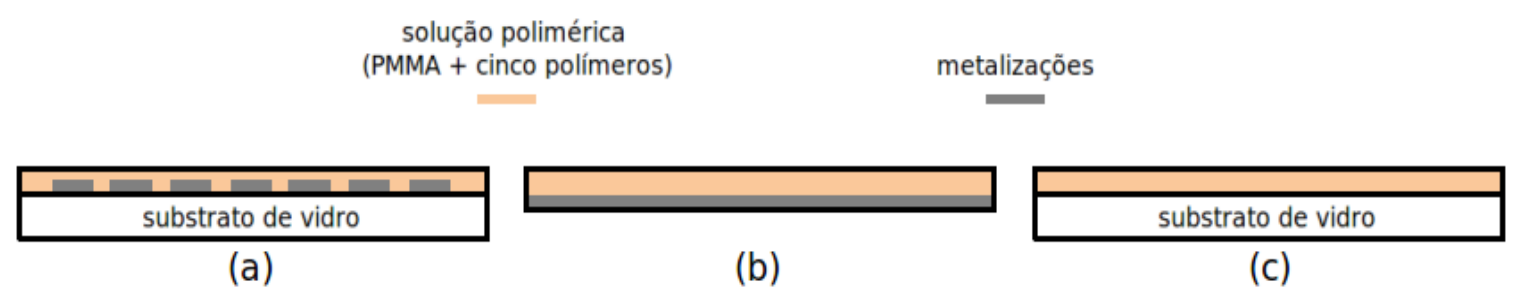

Figura 19 - Representação das amostras com e sem metalizações obtidas por "casting" da solução polimérica em substratos de vidro com e sem metalização. (a) para guia de ondas, (b) e (c) para LSCs.

Foram confeccionados dois tipos de conversores de comprimento de onda (Figura 19b e Figura 19c). Os dispositivos diferem somente por uma camada metalizada presente em um

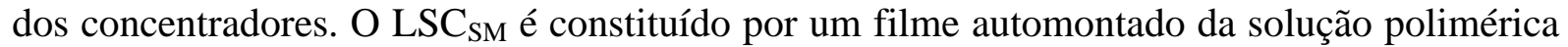
obtido através da técnica "casting” sobre substrato de vidro. Já o LSC $_{\mathrm{CM}}$ possui uma interface metalizada de $200 \mathrm{~nm}$ de Al aplicada sobre vidro. Além disso foram preparadas três LSC $_{\mathrm{SM}}$ com diferentes concentrações de espécies luminescentes. A solução polimérica, como descrita anteriormente, foi preparada com os seguintes cromóforos: ADS-329BE, LAPS-16, ADS108GE, SY e MEH-PPV. Utilizando o padrão de nomenclatura adotado neste trabalho as três amostras foram rotuladas como: $\operatorname{LSC}_{\mathrm{SM}}(4,4,4,3,5), \operatorname{LSC}_{\mathrm{SM}}(6,6,6,5,7)$ e $\mathrm{LSC}_{\mathrm{SM}}$ $(8,8,8,6,10)$.

O mesmo procedimento foi realizado para a deposição dos conversores com superfície metálica (Figura 19b). Foram preparadas três amostras com diferentes concentrações de 
espécies luminescentes rotuladas como: $\operatorname{LSC}_{\mathrm{CM}}(4,4,4,3,5), \operatorname{LSC}_{\mathrm{CM}}(6,6,6,5,7)$ e $\operatorname{LSC}_{\mathrm{CM}}$ $(8,8,8,6,10)$.

Com a superfície do substrato limpa, a solução polimérica foi uniformemente distribuída em toda a superfície do vidro com o auxílio de uma micro pipeta (Figura 19c). Uma placa de Petri foi utilizada como apoio para a face inferior do substrato, na tentativa de obter um filme plano em toda sua extensão, proporcionando à superfície a qualidade desejada para a realização dos experimentos. Outra placa de Petri, com diâmetro maior que a primeira, foi utilizada para cobrir a placa contendo a amostra de modo que a evaporação total do solvente (tolueno) ocorra após $12 \mathrm{~h}$. A partir deste ponto os dispositivos já estavam prontos para a realização dos ensaios experimentais.

\subsection{Detecção da emissão lateral}

Para as análises dos guias, o feixe sintonizado na linha de $325 \mathrm{~nm}$ de um laser de HeCd (KIMMON) foi alinhado de modo a incidir perpendicularmente à amostra. A luz guiada era coletada por uma fibra óptica de diâmetro de $200 \mu \mathrm{m}$ acoplada a um monocromador (Ocean Optics HR-4000). Um computador conectado ao monocromador fez a aquisição dos espectros através do software Ocean Optics. Em cada amostra com o padrão da Figura 19a, o feixe do laser incidia sobre uma área metalizada específica. Os processos descritos acima podem ser vistos na figura Figura 20. Um polarizador foi inserido entre a saída do guia e a fibra ótica de modo a separar os modos TE e TM e permitir a obtenção de um espectro de emissão lateral com picos estreitos e definidos.

As medidas dos conversores de comprimentos de onda foram realizadas através de uma adaptação feita em um espectrofotômetro (fluorímetro) Shimadzu RF-5301 PC com auxílio de uma fibra ótica fixada a um suporte com variação micrométrica. Um aparato foi desenvolvido para que a amostra pudesse se movimentar em relação ao feixe de luz, embora o contrário também possa ser aplicado (ver imagens no capítulo de resultados). Deste fluorímetro apenas a luz de excitação foi utilizada, uma vez que um monocromador HR-4000 da "occean optics" acoplado a fibra ótica estava conectado a um computador encarregado de expor as formas de emissão de cada amostra. 


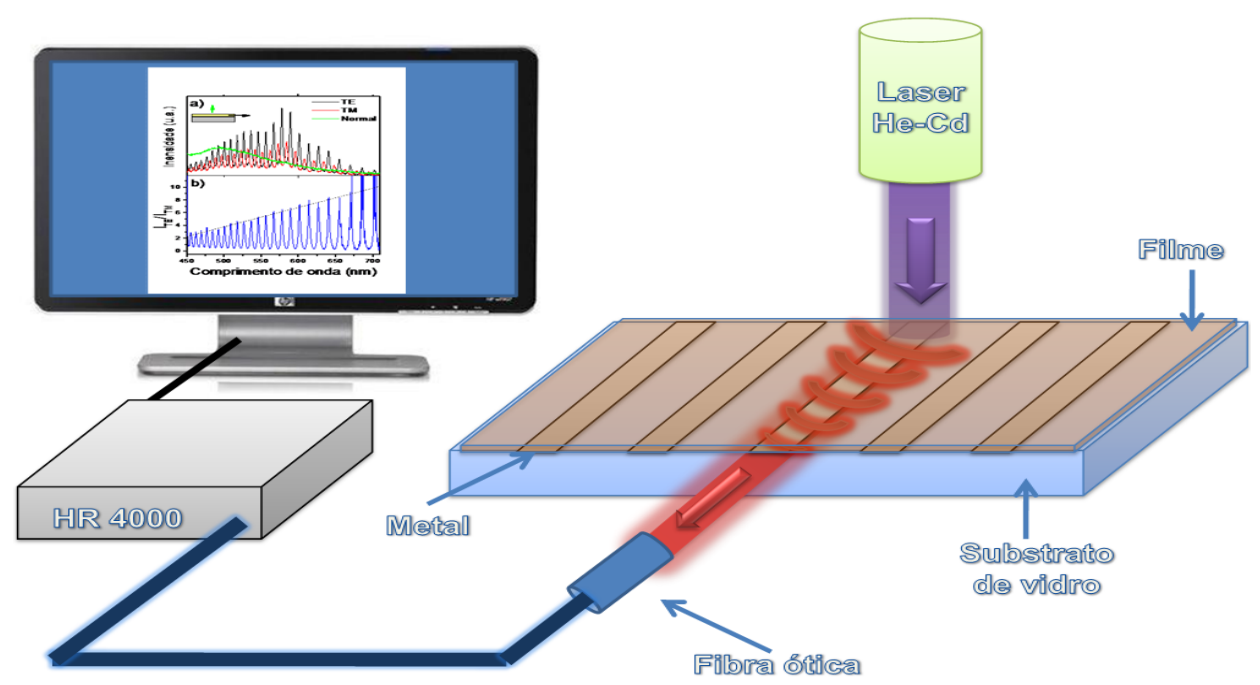

Figura 20 - Configuração do sistema para medidas laterais dos guias de onda.

A Figura 21 esquematiza o movimento das amostras em milímetros. O ajuste para essa variação foi feito através de um posicionador milimétrico. A fibra ótica matinha a mesma distância entre a face dos filmes em todas as medidas realizadas, para isto se movimentava juntamente com a amostra. A variação na posição da luz de excitação sobre o filme foi feita em relação à saída do guia de onda nas proximidades da fibra ótica (Figura 21). Estes procedimentos garantem uma melhor observação no andamento do experimento, tanto em relação ao comportamento de conversor de comprimentos de onda como a eficiência dessa conversão para diferentes concentrações de cromóforos em solução de PMMA.

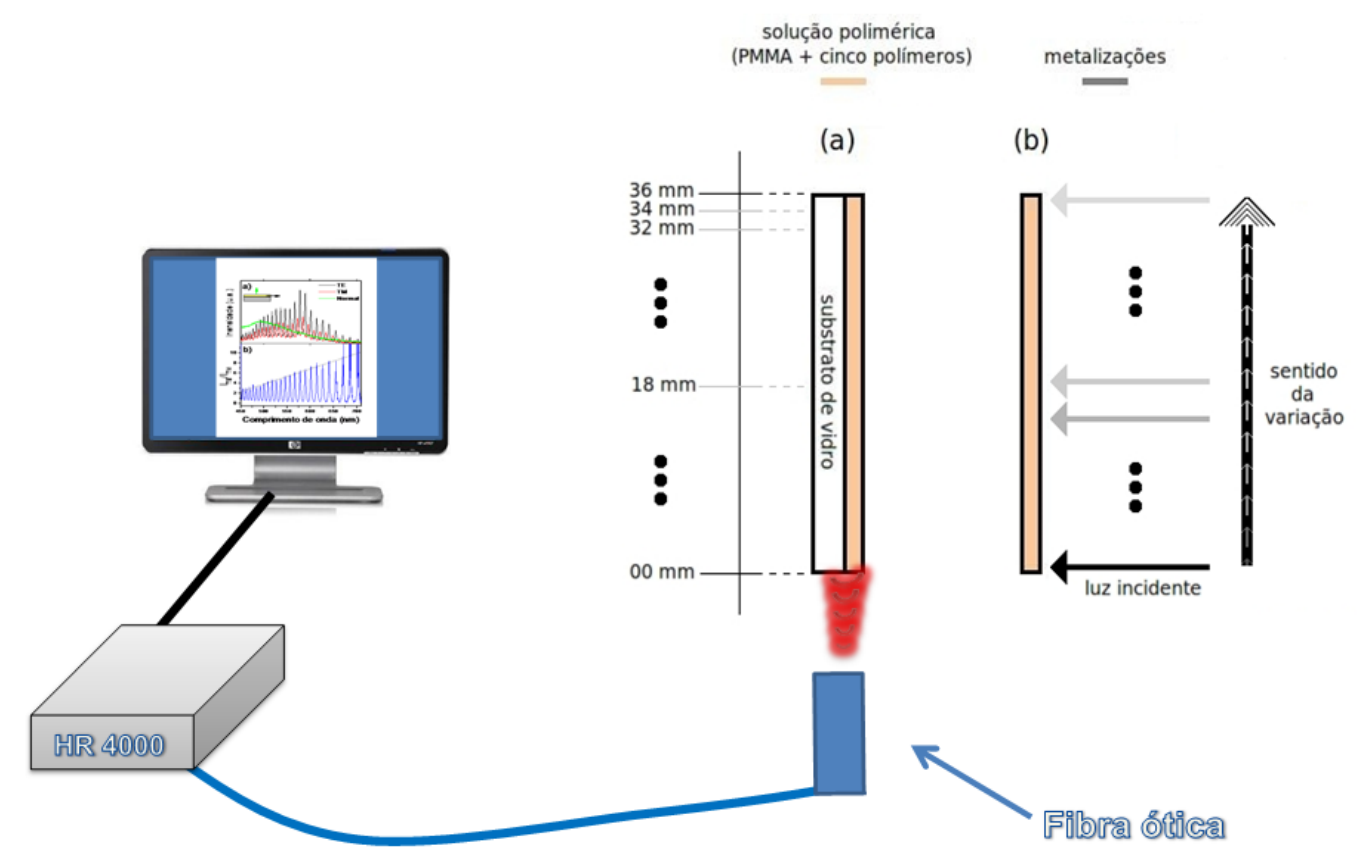

Figura 21 - Esquema do aparato experimental para medida da emissão lateral nos LSCs. A posição de incidência da luz sobre os LSCs foi variada por meio do aparato esquematizado acima através de passos micrométricos. 


\subsection{Metodologia na deposição da solução polimérica}

Queremos destacar a etapa de deposição da solução nos substratos, esta é importante devido a alta concentração da solução de PMMA e a necessidade de se obter filmes espessos (da ordem de 30 micrômetros) e uniformes. Vários ensaios foram realizados até a obtenção de um filme com certa qualidade morfológica. As observações a respeito das diversas tentativas podem ser resumidas em: (i) a evaporação é determinante na qualidade final da amostra, esta deve acontecer de forma lenta; (ii) a temperatura se torna crítica quando se deseja obter filmes menos espessos (menores que $1000 \mathrm{~nm}$, ou seja, menores que da ordem do micro); (iii) o fluxo de ar durante a secagem do filme deve ser mínimo ou simplesmente inexistente; (iv) devido a alta concentração da solução da matriz (PMMA), a deposição deve acontecer da forma mais rápida possível, em uma tentativa de minimizar o acúmulo de ar dentro da amostra.

Sendo assim, fatores como temperatura, concentração, secagem e o modo de deposição são críticos na obtenção de LSCs. Uma das maneiras que obtivemos dispositivos com uma boa qualidade foi fazer a evaporação do solvente em uma atmosfera enriquecida com o próprio solvente, tolueno. Para isto utilizamos placas de Petri, fazendo com que o ambiente permanecesse fechado, evitando com isso o fluxo de ar no mesmo. A espessura das amostras, da ordem de $30 \mu \mathrm{m}$, dispensou um controle maior da temperatura. Embora todas as amostrar neste trabalho tenham sido obtidas em torno de 25 (mais ou menos 2) ${ }^{\circ} \mathrm{C}$ (ambiente), já em dias que as temperaturas alcançavam 17 (mais ou menos 2 ) ${ }^{\circ} \mathrm{C}$ geralmente não eram obtidos bons resultados ${ }^{\dagger \dagger}$. Após a secagem total, os filmes foram caracterizados por medidas de absorbância e luminescência.

\footnotetext{
${ }^{+\dagger}$ Não foram realizados estudos a respeito da influência da temperatura, apenas observações da temperatura no instante em que as amostras eram preparadas.
} 


\section{Resultados e Discussão}

Neste capítulo apresentaremos os resultados obtidos através de caracterizações ópticas tanto das soluções poliméricas precursoras dos filmes como dos guias de onda e concentradores de comprimento de onda. As técnicas utilizadas nestas caracterizações foram a Espectroscopia de Absorbância, Fotoluminescência (PL) e Excitação. Além dos resultados, uma discussão a respeito dos processos fotofísicos que predominantemente coordenam as possíveis transições energéticas nesses sistemas será apresentada. Processos de reabsorção da emissão e interferência óptica ao longo dos filmes são fundamentalmente os fenômenos básicos que regem o comportamento da emissão lateral observada nos guias de onda e LSCs.

\subsection{Caracterizações ópticas das soluções}

De acordo com a metodologia aplicada neste trabalho, descrita no Capítulo 4, as soluções precursoras de polimetacrilato em tolueno foram preparadas com diferentes polímeros luminescentes. Alíquotas de soluções dos polímeros ADS-329BE, LAPS-16, ADS108GE, SY e MEH-PPV deram origem à solução polimérica (SP), meio luminescente utilizado para a fabricação dos filmes que formam os guias de onda e LSCs.

A quantidade de polímero nestas soluções de PMMA em tolueno foi ajustada a partir de alíquotas (30 microlitros) de soluções a $0.5 \mathrm{~g} / 1$ de cada polímero emissor de luz em tolueno de modo a se obter absorbância de 0,6 no máximo da banda conjugada. Com esse valor esperamos obter um livre caminho médio da ordem da espessura típica de para um fóton com comprimento de onda de $500 \mathrm{~nm}$ para os guias de onda utilizados neste trabalho. A comparação entre os espectros de absorbância das soluções contendo cada polímero com aquela que contêm todos os polímeros pode ser observada na Figura 22. Pode-se ver que a condição de valor máximo de absorbância em torno de 0,6 foi estabelecida. 


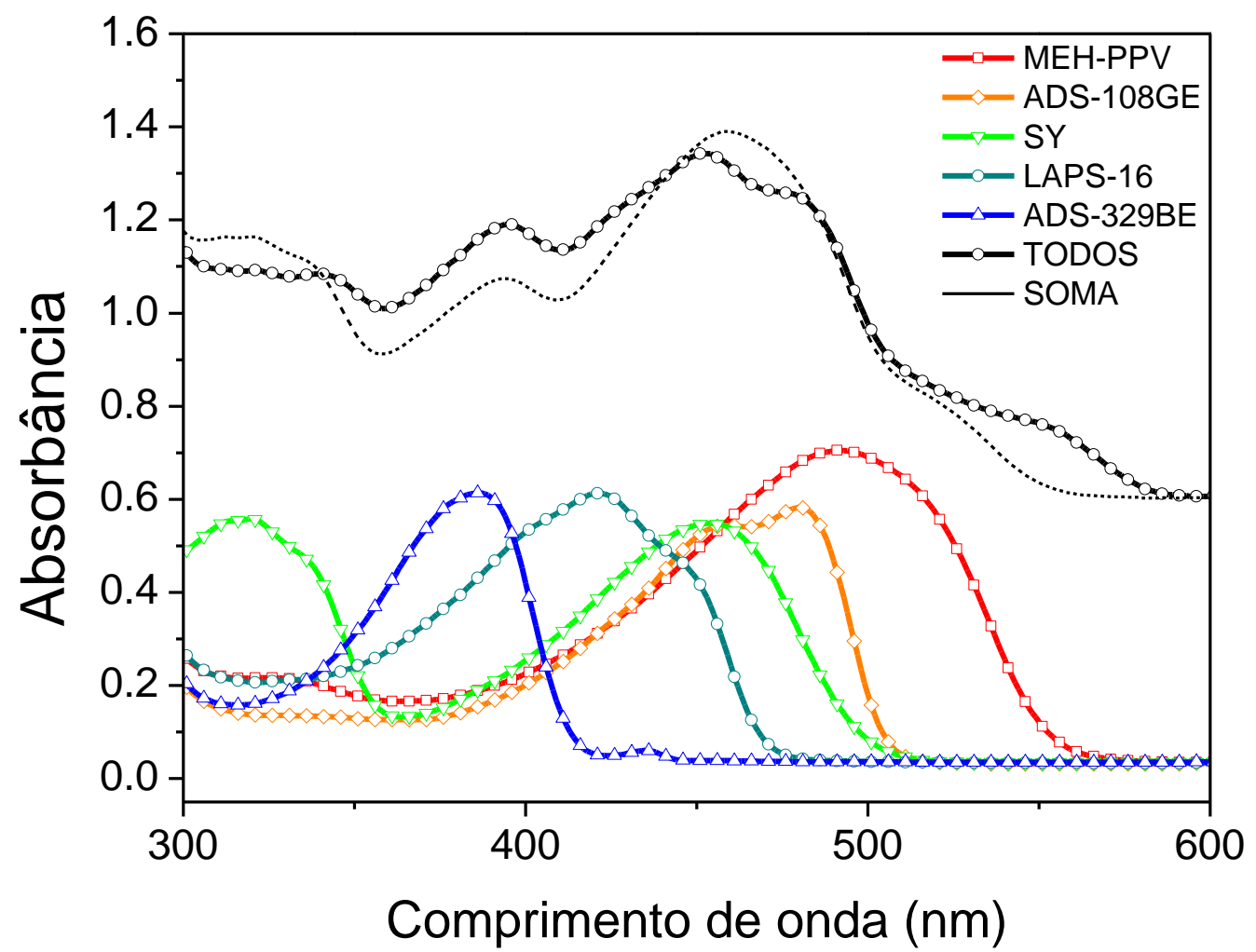

Figura 22 - Na parte inferior podem ser vistas as curvas de absorbância de cada polímero utilizado, todos em solução de PMMA em tolueno. Deslocados, na parte superior, são mostrados para comparação os espectros da solução de PMMA contendo todos os polímeros (círculos pretos) e da soma de cada espectro em separado da parte inferior (tracejado).

Conforme mostra a Figura 22 cada polímero possui banda distinta de absorção associada a transições ópticas entre estados conjugados $\pi$ e $\pi^{*}$ que estão localizadas em uma ampla faixa de absorção entre 300 e $550 \mathrm{~nm}$. É interessante notar que as mesmas características espectrais de absorção são obtidas tanto para a solução contendo todos os polímeros (espectro com linha preta) como para a soma dos espectros individuais (linha pontilhada). No entanto, uma nova banda de absorção aparece entre 550 e $600 \mathrm{~nm}$ que não está presente no espectro obtido pela soma de cada espectro individual. Isto pode significar que a adição dos polímeros em solução concentrada de PMMA pode produzir modificações na estrutura molecular ou favorecer a formação de aglomerados entre cromóforos (separação de fase) ou entre cromóforo e PMMA. Estas hipóteses serão verificadas abaixo. Espera-se que em baixas concentrações moleculares $\left(C_{0}\right.$ da ordem de $0,006 \mathrm{~g} / 1$ em solução de tolueno) não são suficientes para gerar agregados da mesma espécie para os polímeros utilizados nesse trabalho.

Para a obtenção dos espectros de emissão, cada solução foi excitada nos respectivos máximos de absorção. Os resultados podem ser vistos na Figura 23. 


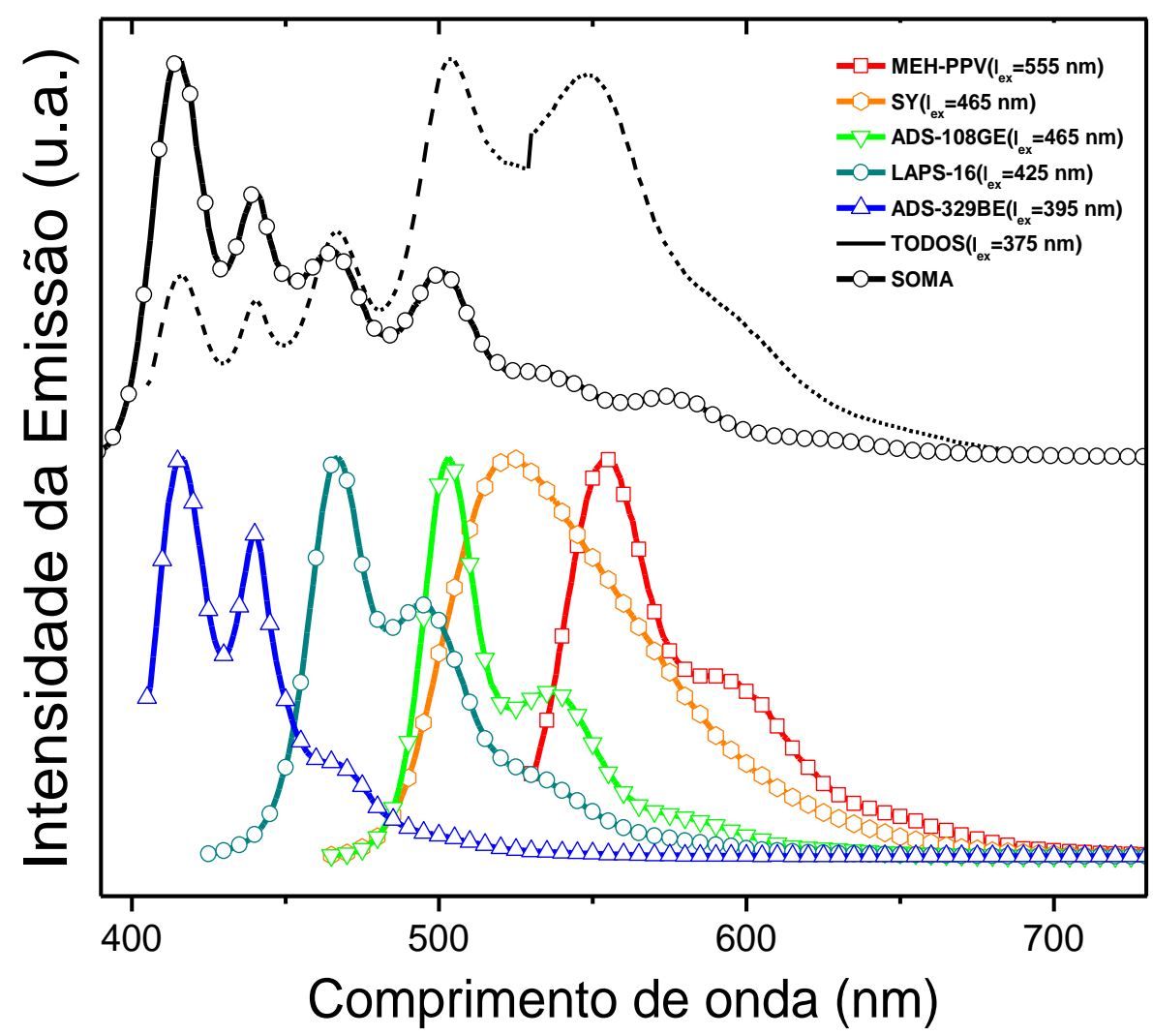

Figura 23 - Na parte inferior podem ser vistas as curvas de emissão de cada polímero utilizado, todos em solução PMMA. Na parte superior pode ser visto o espectro de todos os polímeros em uma mesma solução de PMMA.

Os espectros destas emissões referentes aos polímeros luminescentes apresentadas na Figura 22 podem ser vistos na Figura 23 (parte inferior). Essa figura também mostra os espectros correspondentes à solução que contêm todos os polímeros, mas que preserva a concentração em separado dos mesmos (linha preta). A soma da contribuição de cada polímero é apresentada para comparação (linha pontilhada).

Pode-se observar que os espectros de emissão apresentam deslocamentos espectrais semelhantes aos da absorção na Figura 22. Porém, a forma de linha espectral do espectro correspondente à solução que contêm todos os polímeros difere substancialmente daquele que é resultado da simples soma de cada espectro em separado. Isto se deve ao fato de que a intensidade da emissão de cada polímero (espécie componente) depende do comprimento de onda de excitação. No caso da solução contendo todos os polímeros, as macromoléculas ADS-329BE e LAPS16 possuem maior absorção no comprimento de onda de excitação $\left(\lambda_{\mathrm{ex}}=375 \mathrm{~nm}\right)$ e, por isso, apresentam maior intensidade da luminescência na região espectral de emissão entre 400 e $500 \mathrm{~nm}$. 
Os espectros de excitação da luminescência de cada solução de PMMA em tolueno contendo os polímeros luminescentes apresentadas nas Figura 22 e Figura 23 podem ser vistos na Figura 24 (parte inferior).

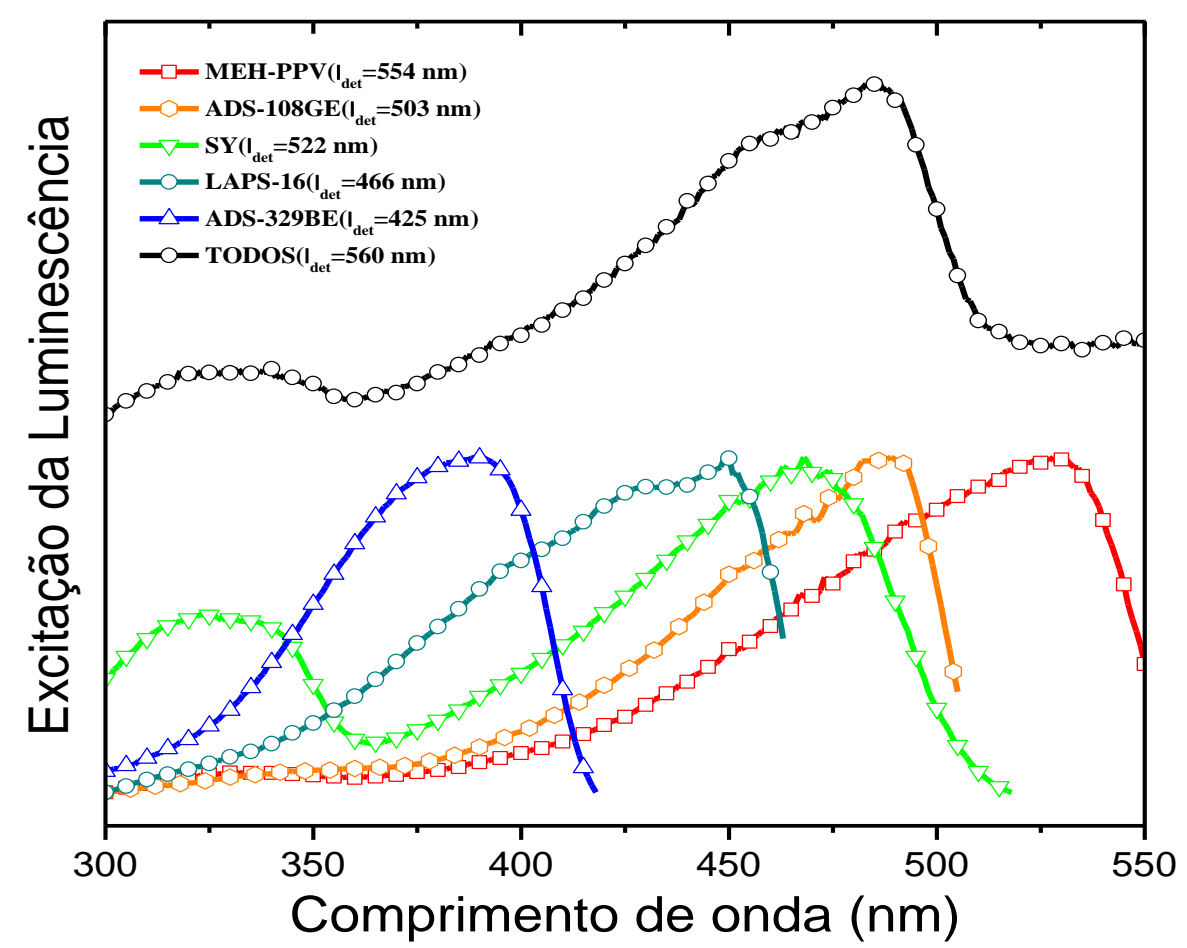

Figura 24 - Na parte inferior podem ser vistas as curvas de Excitação de cada polímero utilizado, todos em solução PMMA. Na parte superior pode ser visto o espectro de todos os polímeros em uma mesma solução de PMMA.

Os comprimentos de onda de detecção $\left(\lambda_{\text {det }}\right)$ na excitação da luminescência para cada solução correspondem ao máximo de cada espectro de emissão. A Figura 24 mostra para efeito de comparação o espectro de excitação correspondente à solução que contêm todos os polímeros, mas que preserva a concentração em separado dos mesmos. Nesse caso o comprimento de onda de detecção foi tomado em $560 \mathrm{~nm}$, que corresponde ao máximo de emissão do MEH-PPV.

Por se tratar de quantidades muito pequenas de polímeros luminescentes em solução de PMMA em tolueno, as medidas de excitação de cada espécie devem apresentar deslocamentos e formas espectrais semelhantes aos das absorções apresentadas na Figura 22 (parte inferior). $\mathrm{O}$ mesmo ocorre com a forma de linha do espectro de excitação $\left(\lambda_{\text {det }}=560 \mathrm{~nm}\right)$ da solução contendo todos os polímeros, a qual possui grande semelhança com a medida de absorção correspondente (Figura 22 superior). Isto significa que os cromóforos são igualmente excitados e que processos de migração energética estão ausentes devido à alta diluição das moléculasem solução de 
PMMA. É importante salientar que a banda de absorção adicional, inicialmente não esperada, medida entre 550 e $600 \mathrm{~nm}$ (associada a agregados) é emissiva, ou seja, ela está presente também nos espectros de excitação.

\subsection{Guias de onda poliméricos}

Seguindo esta linha de materiais que possuem suas propriedades ópticas modificadas quando em sistemas de geometria restrita, verificamos recentemente que eles apresentam propriedades interessantes quando a emissão é observada lateralmente, ou seja, quando observamos efeito de guia de onda.

Guias de onda de polimetacrilato (PMMA) foram preparados sobre substrato de vidro contendo trilhas de alumínio com espessura de $200 \mathrm{~nm}$. Ao PMMA foram adicionados quantidades dos polímeros ADS-329BE (emissão máxima em 413 nm), LAPS-16 (emissão máxima em 467 nm), ADS-108GE (emissão máxima em 503 nm), SY (emissão máxima em $523 \mathrm{~nm}$ ) e MEH-PPV (emissão em $555 \mathrm{~nm}$ ); todos diluídos em tolueno. Esta solução foi espalhada sobre substrato através da técnica "casting".

Emissões dos guias de onda são detectadas lateralmente, ou seja, na direção paralela ao plano do filme. No entanto, espectros das emissões perpendiculares (normal ao guia) foram obtidos para efeito de comparação. A Figura 25a compara o espectro típico de emissão lateral e normal excitados com laser He-Cd em $441 \mathrm{~nm}$. Pode-se ver que a emissão normal (sem efeito de guia de onda) é larga e contem as componentes de todos os polímeros excitados com a linha $441 \mathrm{~nm}$. Já a emissão lateral é composta por modos TE (linha preta) e TM (linha vermelha) de guia de onda. Estes modos possuem direção de campo elétrico perpendicular e paralelo ao plano do guia de onda que foram separados por meio de um polarizador. A luminescência lateral foi medida sobre a superfície contendo alumínio. Pode-se observar que os dois modos possuem picos de emissão extremamente estreitos (largura de $3 \mathrm{~nm}$ ) e intensos ao longo de toda a faixa espectral dos polímeros que compõem o guia. Esses modos correspondem aos únicos comprimentos de onda resultantes da emissão de todos os polímeros dispersos no filme de PMMA que se acoplam com o guia de onda. Eles são o resultado da interferência construtiva da emissão refletida/transmitida na interface polímero(n 1.6) / $\operatorname{ar(n~1)~e~na~interface~polímero/metal.~Além~disso,~os~máximos~da~emissão~normal~e~lateral~}$ 
estão deslocados. Isso significa que à medida que a luz propaga no guia óptico ela é reabsorvida e re-emitida e, com isso, sofre relaxação energética cada vez que é absorvida por um cromóforo específico. Com isso, a luz se desacopla das moléculas de maior energia à medida que se propaga ao longo do guia, sofrendo um número maior de reflexões nas interfaces e se polarizando com maior eficiência. Este é o primeiro passo para se obter conversores de comprimento de onda.

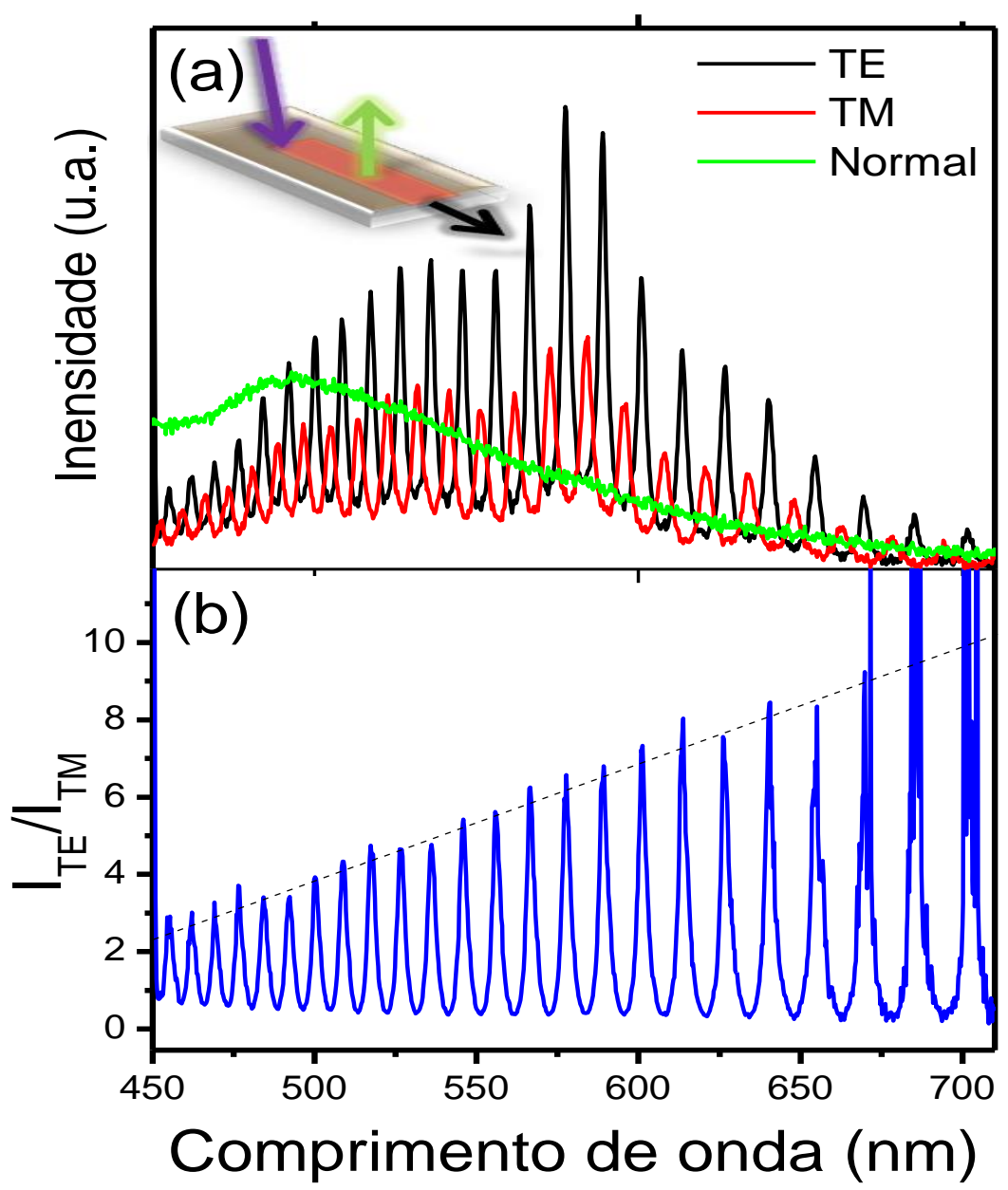

Figura 25 - (a) Modo TE e TM de guia de onda contendo material polimérico emissor de luz. O espectro da emissão normal (sem efeito de guia de onda) é mostrado para comparação. (b) Razão das intensidades do modo TE e do modo TM.

$\mathrm{Na}$ Figura 25b pode ser observada a razão das intensidades do modo TE e do modo TM. Essa razão dá a polarização da emissão lateral. Pode-se ver que os modos são extremamente polarizados e que a polarização cresce com o aumento do comprimento de onda. Isto significa que a superposição de cada modo é menor para comprimentos de onda maior. 
A Figura 26 mostra a dependência da emissão lateral do modo TE com a espessura da camada polimérica que constitui o guia de onda. Pode-se ver que o número de modos propagantes no guia de onda decresce com o decréscimo da espessura do guia. As características espectrais do guia de onda são análogas às franjas de interferência de FabryPérot (15). As múltiplas reflexões nas interfaces do guia permitem que ocorram tanto interferências construtivasquanto destrutivas da luz. Na ocorrência de interferência construtiva, a posição do máximo de cada pico segue a mesma relação representada pela expressão $m \lambda=2 n \ell$, onde " $m$ " é um número inteiro que representa a ordem espectral do modo, “ $\lambda$ ” é o comprimento de onda do pico no filme de índice de refração $n$ e " $n \ell$ " é a espessura óptica efetiva do guia.

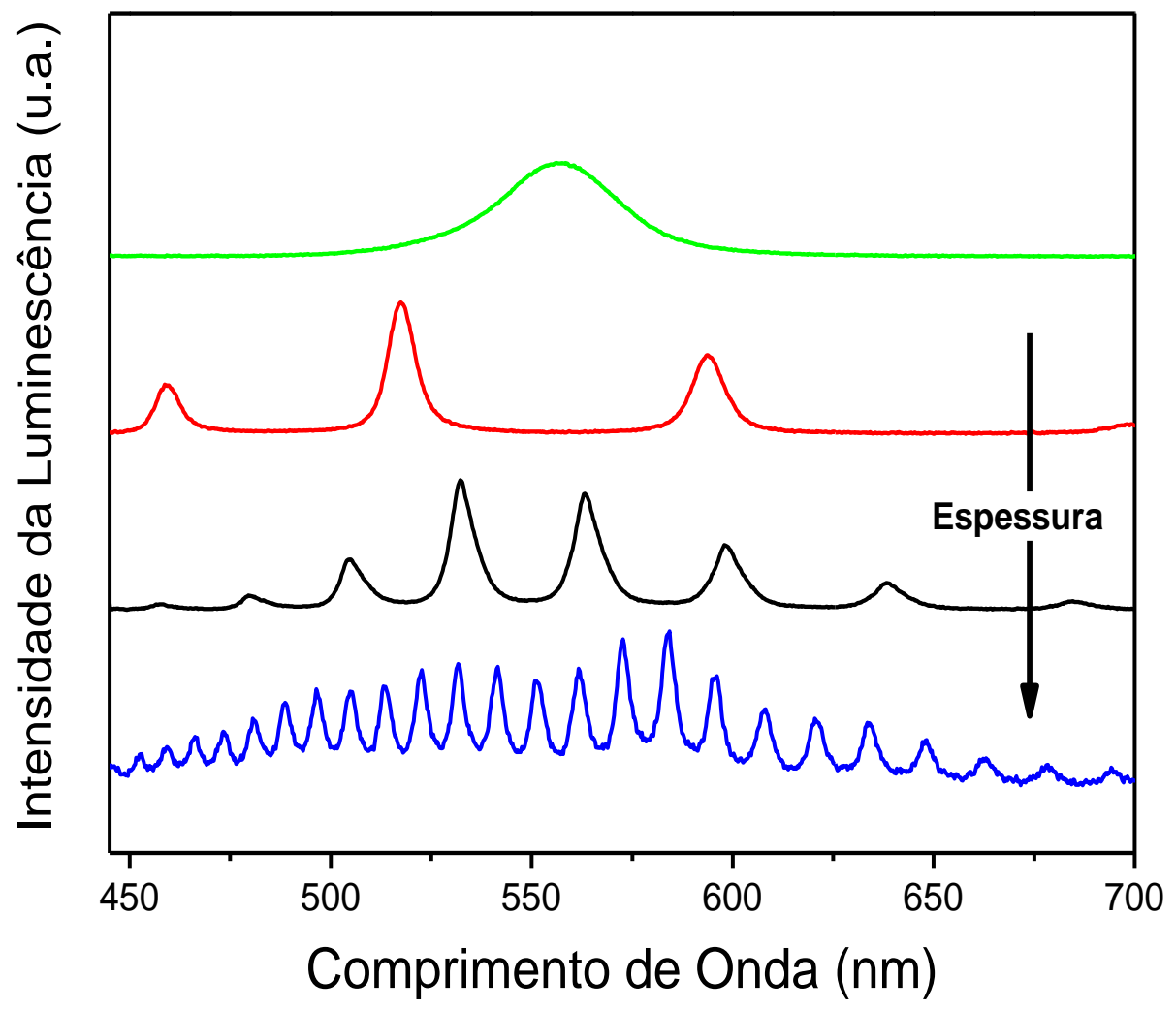

Figura 26 - Dependência da emissão lateral com a espessura do filme polimérico do guia de onda.

Pode-se observar que a largura do pico de emissão de cada modo aumenta com a diminuição da espessura do guia, indicando que as imperfeições do guia (rugosidade nas interfaces, por exemplo) afetam a emissão lateral quão mais estreitos forem os guias. É interessante frisar que a posição de cada modo não depende do comprimento de onda de excitação. Este segundo efeito será usado para se obter conversores de comprimento de onda. 
O resultado da emissão lateral para várias espessuras do guia de onda apresentado na Figura 26 foi simulado conforme mostram as Figura 27a e Figura 27b. Nessa simulação foi feita a superposição de gaussianas (modos) com amplitudes moduladas por uma gaussiana envelope (curva pontilhada), que corresponde à emissão larga de todos os polímeros presentes no filme de um guia de índice de refração próximo ao PMMA $(n=1,5)$

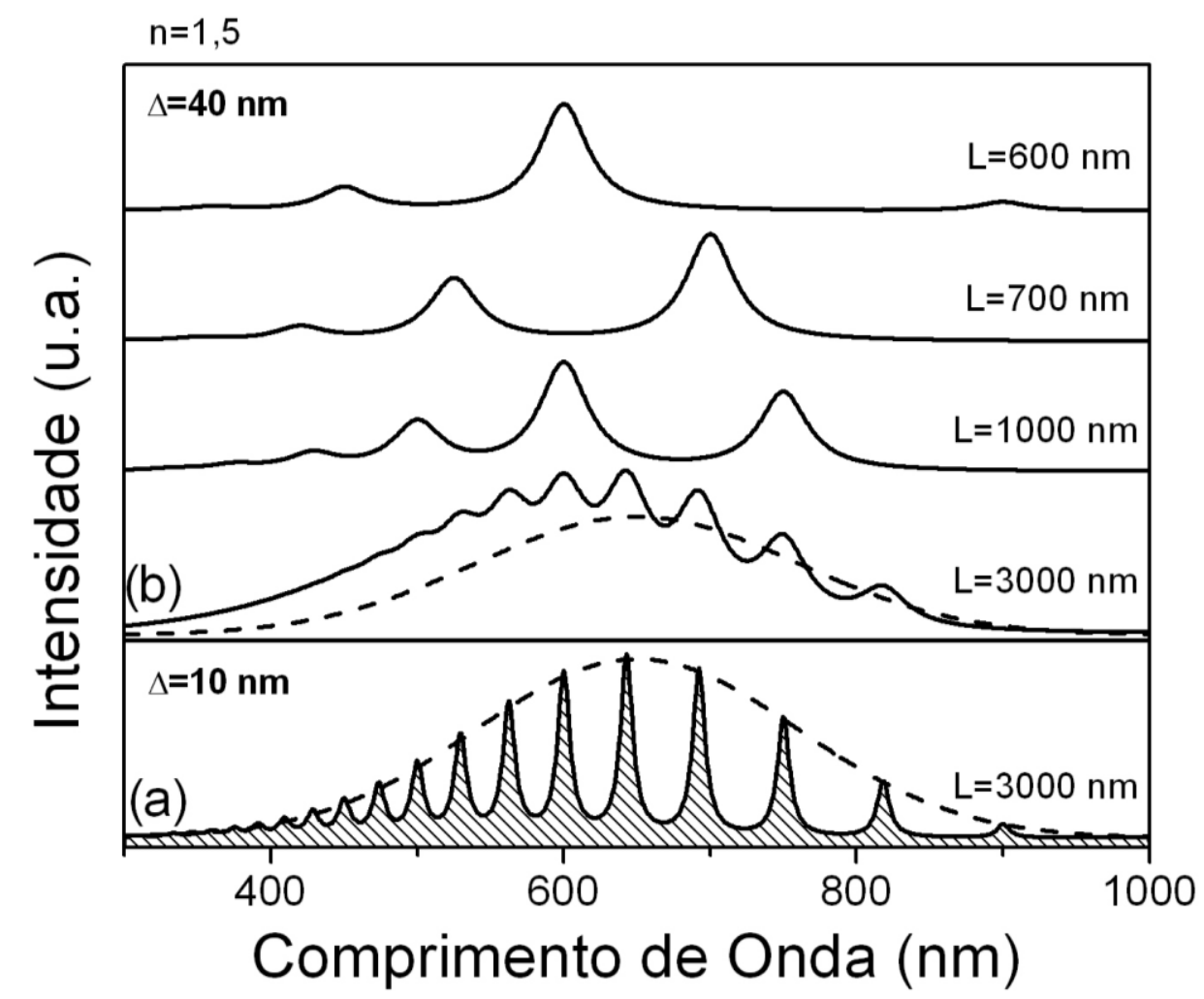

Figura 27 - Simulação da emissão lateral para diferentes espessuras e fator de qualidade (a) $\Delta=10 \mathrm{~nm}$ e (b) $\Delta=40 \mathrm{~nm}$ de um guia de onda.

A posição de cada modo é dada por $\lambda_{m}=(2 n l) / m$. Duas larguras diferentes $(\Delta=10 \mathrm{~nm}$ na Figura 27a e $\Delta=40 \mathrm{~nm}$ na Figura 27b) para os modos foram utilizadas de modo a simular o efeito da variação do fator de qualidade na emissão lateral. A diminuição do fator de qualidade promove a perda da resolução espectral pela superposição dos modos (Figura 27b, $\mathrm{L}=3000 \mathrm{~nm}$ ) e ao aumento do peso espectral para a região de baixos comprimentos de onda. Dessa simulação pode-se ver que os guias de onda medidos e apresentados na Figura 26 possuem espessuras no intervalo de 0.6 a $3 \mu \mathrm{m}$. Para guias mais espessos e cavidades com fator de qualidade menor, as formas espectrais para emissões laterais e normais medidos (Figura 26) são semelhantes às simuladas na Figura 27b. 


\subsection{Concentradores de comprimento de onda}

Os concentradores de comprimento de onda ou LSCs (Luminescent Solar Concentrators) são constituídos de uma matriz acrílica oticamente inerte na qual espécies luminescentes foram dispersas em diferentes concentrações. A característica principal é a absorção de radiação em uma larga faixa espectral (luz solar, por exemplo) ao longo de toda a superfície coletora, com posterior conversão desta luz incidente em uma radiação contendo uma faixa estreita de comprimentos de onda. Esta conversão é obtida através de sucessivos processos de re-absorção e re-emissões ao longo do guia de onda, levando-se em conta a relaxação interna nos segmentos conjugados. Por fim, a luz convertida é direcionada para uma das faces laterais do guia. A luz é guiada através de reflexões internas entre as interfaces que compõe o sistema. Neste trabalho foram obtidos dois concentradores, um com interface vidro/PMMA/ar e outro com metal/PMMA/ar. Propriedades como a eficiência na absorção da luz incidente e comportamento de filtro de luz (87) foram observados através dos resultados apresentados nas seções subseqüentes.

\subsubsection{LSCs sem interface metálica}

Como descrito na seção 3.2.4, LSCs foram preparados a partir da deposição de soluções de PMMA em tolueno contendo diferentes concentrações de polímeros luminescentes por casting diretamente sobre substrato de vidro (BK7, n=1,523 em $590 \mathrm{~nm})$. A emissão lateral proveniente dos LSCs sem metal pode ser observada através de medidas de luminescência para uma montagem específica em um fluorímetro. Na Figura 28a pode ser visto um esquema dos dispositivos fabricados e da montagem utilizada. A amostra foi fixada em um posicionador micrométrico. Para a excitação foi utilizada luz colimada (área de $\sim 1 \mathrm{~mm}$ X 5mm) perpendicular ao plano do LSC com comprimento de onda de $350 \mathrm{~nm}$. A emissão foi coletada junto à saída lateral do LSC por uma fibra ótica de abertura de $200 \mathrm{~nm}$ que também foi fixada sobre o posicionador. Nessa configuração, a posição da luz de excitação foi variada sobre o LSC sem alterar o caminho ótico do sistema. O modo como os concentradores foram 
fixados para a realização das análises é apresentado na Figura 28 b tão como o posicionamento da fibra óptica em relação ao filme.

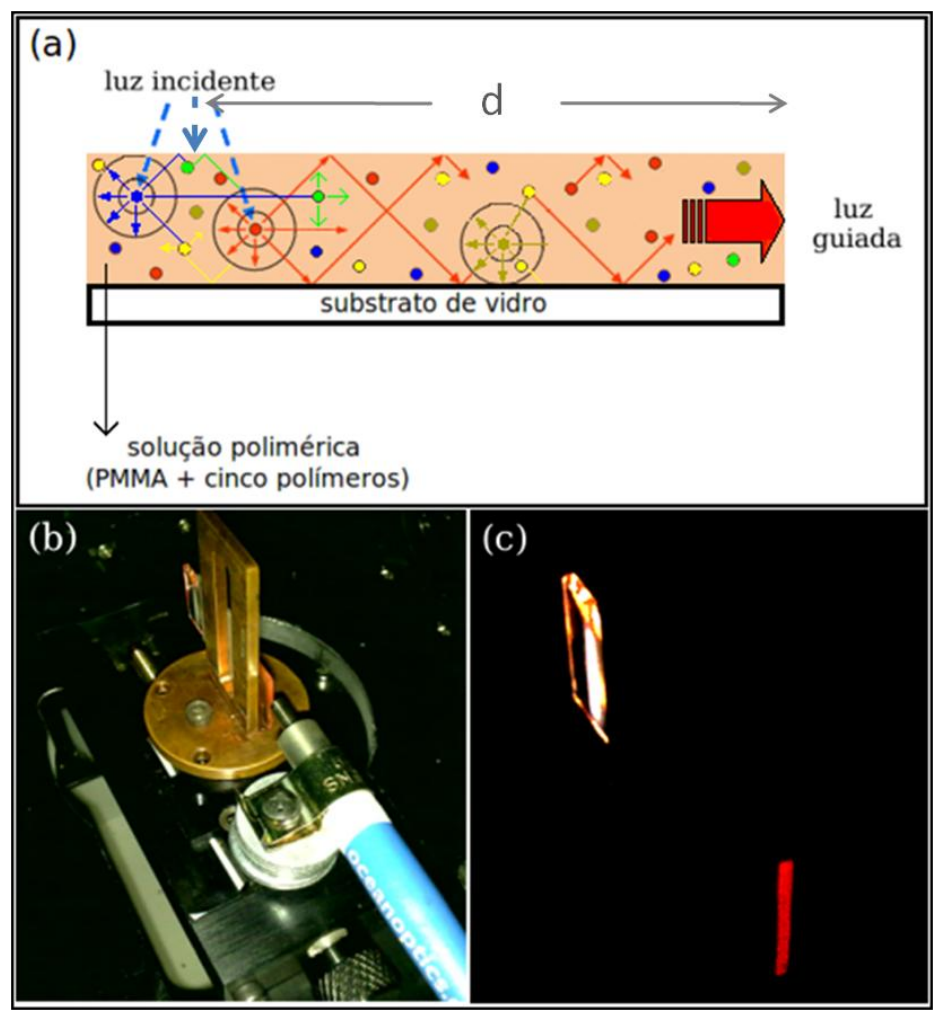

Figura 28 - (a) representação esquemática do LSC sem interface metálica, (b) posicionamento da fibra óptica em relação ao concentrador, (c) destacando-sr a emissão lateral característica da SP utilizada.

Três conversores em matriz de PMMA com diferentes concentrações dos cinco polímeros utilizados neste trabalho foram obtidos: $\operatorname{LSC}_{\mathrm{SM}}(4,4,4,3,5), \operatorname{LSC}_{\mathrm{SM}}(6,6,6,5,7)$ e $\operatorname{LSC}_{\mathrm{SM}}(8,8,8,6,10)$ com espessuras de aproximadamente $30 \mu \mathrm{m}$. Os conversores sem interface metálica não possuem nenhum tipo de artifício que ajude ou melhore sua eficiência em guiar a luz para uma de suas faces laterais. Os índices de refração do substrato de vidro $(n=1,52)$ e do PMMA (n=1.49) são muito próximos, o que favorece o escape da luz guiada no filme para o substrato. Sendo assim, possíveis mudanças na eficiência, para melhor ou pior, podem apenas ser atribuídas às mudanças de concentrações entre os três dispositivos caracterizados. A Figura $28 \mathrm{c}$ dá uma mostra da luminescência na posição da luz de excitação e na saída do $\operatorname{LSC}_{S M}(6,6,6,5,7)$. A luminescência provinda da posição da luz de excitação é praticamente branca. Porém, a emissão lateral é praticamente vermelha. Nesse experimento, a fibra ótica foi posicionada diretamente sobre a lateral do filme de PMMA, de modo que a luz coletada provinha em grande parte desse filme. Isto demonstra o efeito da conversão de comprimentos de onda. 
Este efeito de conversão de comprimento de onda pode ser melhor observado na Figura 29. Nesse experimento, espectros da emissão lateral foram obtidos para diferentes posições médias $d$ em milímetros entre a luz de excitação $(350 \mathrm{~nm})$ e à saída lateral dos LSCs contendo diferentes concentrações de polímeros luminescentes. Pode-se observar que a emissão praticamente branca na saída do LSC se transforma em vermelha (600 nm), isto ocorre logo nos primeiros milímetros, quando a posição da área da luz de excitação em relação à saída do conversor é alterada. Pode-se notar que a intensidade da luz de emissão cai com o aumento de $d$, o que pode estar associado em parte às perdas para o vidro e para o ambiente. A emissão correspondente a posição $d=12 \mathrm{~mm}$ depende da concentração e ocorre na região de menor absorção do filme do LSC, ou seja, no canto de decaimento da absorção para o $\operatorname{LSC}_{S M}(6,6,6,5,7)$ (espectro pontilhado na Figura 29a) para altos comprimentos de onda. Esta faixa espectral corresponde às emissões relacionadas às transições ópticas associadas à estrutura energética vibracional do MEH-PPV (veja espectro tracejado no maio da Figura 29a). Isto significa que parte da emissão de alta energia (linhas de zero-fônon e a sua primeira réplica entre 550 e 600 nm na Figura 29a) do MEH-PPV está sendo convertida. Como a região espectral associada à estrutura vibracional possui menor intensidade, a queda na intensidade das emissões observada acima pode estar associada em parte a esse efeito.

Os espectros de emissão para diferentes posicionamentos $d$ foram transformados em coordenadas CIE (Commission internationale de l'éclairage) e podem ser observados no diagrama cromático da Figura 29b. Este digrama representa as cores de acordo com a sua cromaticidade (eixos x e y) e a sua luminância (eixo z). O diagrama de cromaticidade (ou diagrama cromático) representa na sua periferia as cores puras, ou seja, as radiações monocromáticas que correspondem às cores do espectro (cores do arco-íris) em comprimento de onda. Pode-se observar que o ponto $(\mathrm{x}, \mathrm{y})$ das coordenadas CIE se desloca da posição central do diagrama (verde-amarelado, $\mathrm{x}=0,43 ; \mathrm{y}=0,32$ ) para a posição da luz de excitação em $d=0 \mathrm{~mm}$ até o laranja-avermelhado $(\mathrm{x}=0,59 ; \mathrm{y}=0,39)$ em torno de $590 \mathrm{~nm}$ para a posição $d=12 \mathrm{~mm}$ do $\operatorname{LSC}_{\mathrm{SM}}(8,8,8,6,10)$. Este comprimento de onda final se desloca para o laranja para menores concentrações de polímeros no LSC. O efeito da mudança de concentração somente produz alteração na eficiência de conversão com a distância $d$. Deste modo, tanto o $\operatorname{LSC}_{S M}(4,4,4,3,5)$ como o $\operatorname{LSC}_{S M}(6,6,6,5,7)$ possuem menor eficiência para a conversão de comprimentos de onda, fato relacionado à quantidade reduzida de moléculas diluídas que poderiam absorver e re-emitir a luz de menor energia para a saída do guia. 

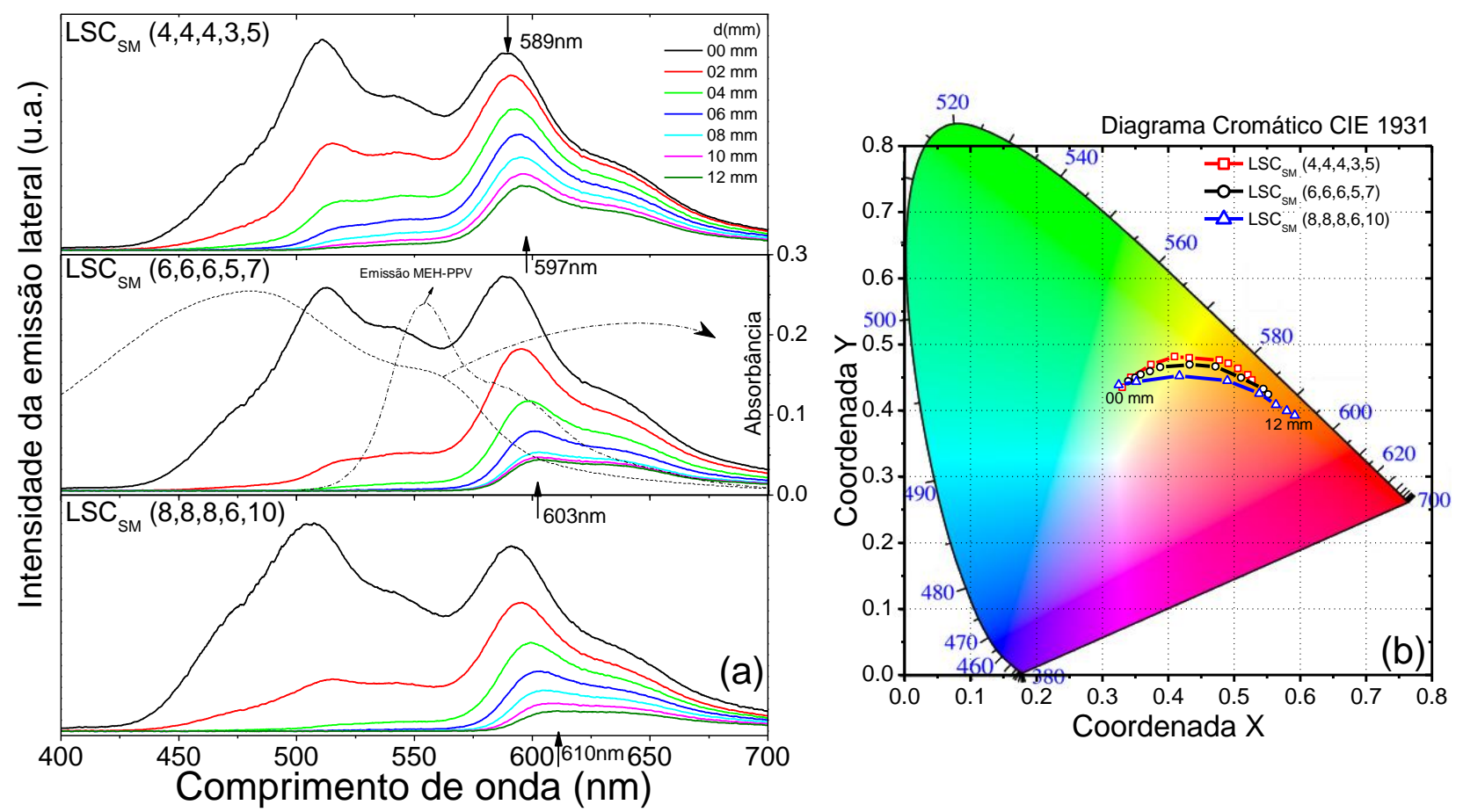

Figura 29 - (a) Emissão lateral em função da distância $d$ para os concentradores: $\operatorname{LSC}_{\mathrm{SM}}(4,4,4,3,5)$, LSC $_{\mathrm{SM}}$ $(6,6,6,5,7)$ e $\operatorname{LSC}_{\mathrm{SM}}(8,8,8,6,10)$, juntamente com a absorção do $\operatorname{LSC}_{\mathrm{SM}}(6,6,6,5,7)$ e absorção do MEH-PPV em filme. (b) Coordenadas CEI em um diagrama cromático 1931 respectivamente em vermelho (quadrado), preto (círculo) e azul (triângulo). A distância da luz incidente aumenta com relação ao maior caminho ótico da esquerda para a direita.

Um fato interessante pode ser observado nos espectros de emissão lateral dos LSCs estudados acima. Estes conversores possuem polímeros luminescentes que absorvem no ultravioleta entre 300-400 nm (ver Figura 22) e possui um polímero (o ADS-329BE) que emite na região espectral entre 400-450 nm. Porém, as emissões deste polímero não são observadas nos espectros dos LSCs, apesar de serem excitados pela luz de excitação em 350 $\mathrm{nm}$.

Veremos mais adiante que, mesmo dentro da área de excitação na saída dos LSCs ( $\mathrm{d}=0 \mathrm{~mm})$, a luz emitida por este polímero é eficientemente convertida para comprimentos de onda de menor energia. Este fenômeno faz com que as coordenadas CIE para posições da luz de excitação próximas à saída dos LSCs estejam alteradas, ou seja, mais deslocadas para cores de menor comprimento de onda (azul-amarelo). Na realidade, estas coordenadas para $d=0 \mathrm{~mm}$ deveriam iniciar na região azul-verde. Estes aspectos serão discutidos a seguir para o caso dos LSCs contendo interface metálica. 


\subsubsection{LSCs com uma interface metálica}

Diferentemente dos anteriores, os $\mathrm{LSC}_{\mathrm{CM}}$ estudados nessa seção possuem uma interface metalizada. Utilizamos as três soluções contendo diferentes concentrações poliméricas da seção anterior em que a deposição ("cast") sobre vidro resultou nos LSC SM. $_{\text {. }}$ Três conversores com diferentes concentrações de cromóforos foram obtidos: LSC $_{\mathrm{CM}}$ $(4,4,4,3,5), \operatorname{LSC}_{\mathrm{CM}}(6,6,6,5,7)$ e $\operatorname{LSC}_{\mathrm{CM}}(8,8,8,6,10)$. De acordo com a seção 3.2.4, uma camada de metal foi depositada sobre estes filmes com a posterior remoção desse substrato. Assim, a emissão proveniente de uma das faces dos $\mathrm{LSC}_{\mathrm{CM}}$ pode ser observada através de medidas de luminescência lateral de um guia de PMMA. Estes apresentavam espessura ativa da ordem de $30 \mu \mathrm{m}$ contendo metal em uma das interfaces e ar na outra, como pode ser visto no esquema da Figura 30a. A maneira como os $\mathrm{LSC}_{\mathrm{CM}}$ foram fixados e o posicionamento da fibra óptica segue o mesmo padrão apresentado na Figura 29b e Figura 29c e discutidos na seção 4.3.1.

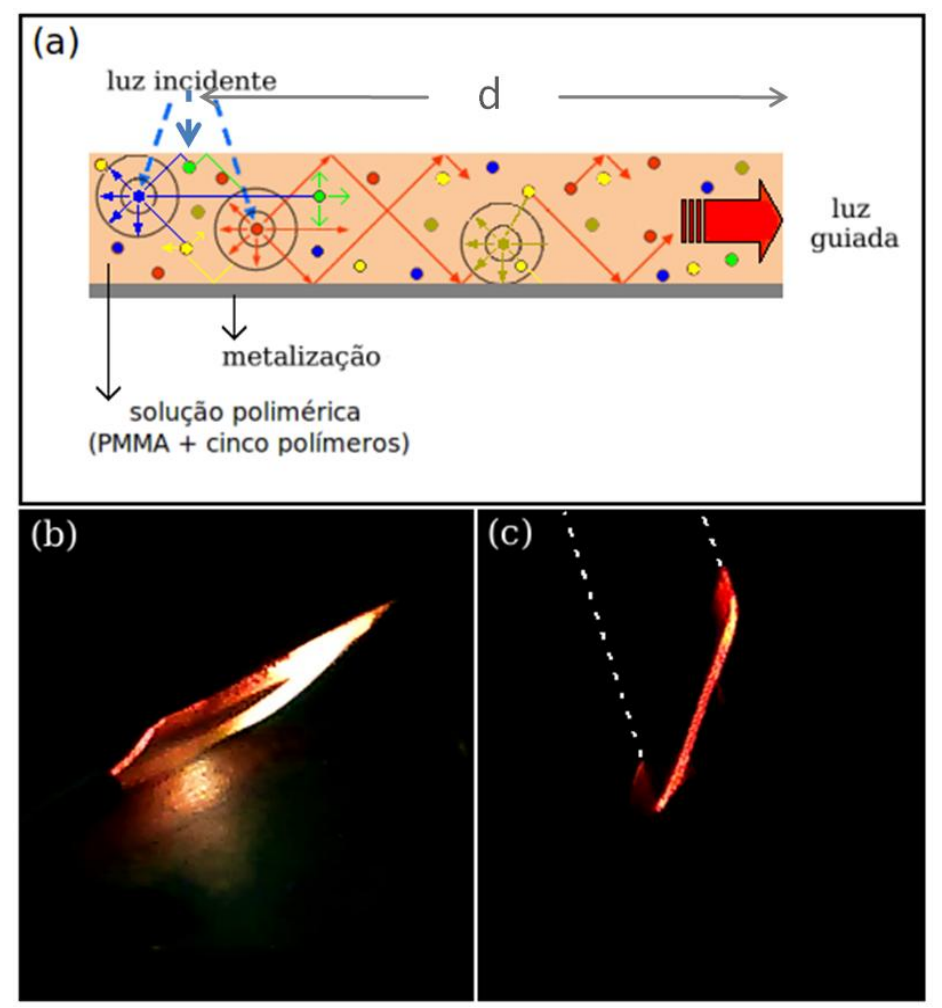

Figura 30 - (a) representação esquemática do $\mathrm{LSC}_{\mathrm{CM}}$ avançado, (b) e (c) destacam a emissão lateral característica da SP utilizada para o $\operatorname{LSC}_{\mathrm{CM}}(6,6,6,5,7)$. 
Os espectros da emissão lateral com a dependência da distância $d$ entre a área da luz de excitação em $350 \mathrm{~nm}$ e a saída lateral (Figura 31c) do $\operatorname{LSC}_{\mathrm{CM}}(6,6,6,5,7)$ podem ser observados na Figura 31a. Como nos LSCs $_{\text {SM }}$ a emissão provinda do polímero ADS-329BE no ultravioleta (ver Figura 31b) está ausente devido a alta eficiência de conversão de comprimento de onda na região espectral de 400 a $450 \mathrm{~nm}$. Além disso, a luz emitida em alta energia é praticamente convertida para a região de emissão envolvendo transições vibracionais do MEH-PPV já nos primeiros milímetros do LSC. Pode-se observar que a emissão sofre uma forte redução entre 400 e $500 \mathrm{~nm}$ nos primeiros seis milímetros $(d=6 \mathrm{~mm})$ do guia de onda, onde a (luz guiada) emissão é praticamente convertida na emissão vermelha. É importante observar que o MEH-PPV praticamente não absorve no comprimento de onda de excitação de 350 nm (ver Figura 22) Devido à metalização presente em uma das faces dos concentradores a eficiência em conversão de comprimento de onda aumenta significativamente. Isto porque o sistema AR/filme/METAL faz com que o feixe de luz emitido seja melhor guiado ao longo do LSC através de múltiplas reflexões nas duas interfaces contendo metal e ar.

A cada espectro da Figura 31a foi associada uma coordenada CIE no diagrama cromáticomostrado na Figura 31d em função da distância $d$. O mesmo procedimento foi adotado para os concentradores com diferentes concentrações de cromóforos: $\operatorname{LSC}_{\mathrm{CM}}(4,4,4,3,5)$ e $\mathrm{LSC}_{\mathrm{CM}}$ $(8,8,8,6,10)$. Os pontos $d=0 \mathrm{~mm}$ encontram-se na região verde-amarelo. Pode-se ver que, para poucos milímetros da saída, a luz emitida por todas as moléculas excitadas em $350 \mathrm{~nm}$ já é convertida para a região do vermelho. Pode-se ver que a borda do diagrama cromático é alcançada em $d=12 \mathrm{~mm}$ para a amostra $\operatorname{LSC}_{\mathrm{CM}}(4,4,4,3,5)$ de menor concentração de polímeros e em $d=8 \mathrm{~mm}$ para o $\operatorname{LSC}_{\mathrm{CM}}(8,8,8,6,10)$ de maior concentração. Nesse caso, a cor da luz na saída é quase um vermelho puro.

Outro fenômeno importante, é que as coordenadas CIE continuam se deslocando para o vermelho na borda do diagrama com o aumento de $d$. Isto significa que o comprimento de onda da luz que se propaga dentro do LSC, continua sendo convertido, mesmo tendo alcançado os comprimentos de onda da molécula de mais baixa energia, no caso o MEH-PPV, que emite na região do laranja-vermelho (550-600 nm). Isto se deve à cauda de absorção na região de baixa energia originária principalmente do MEH-PPV (ver Figura 29), que continua reabsorvendo para grandes valores de $d$ (caminho ótico maior), apesar da luz ter se desacoplado energeticamente das outras moléculas. 

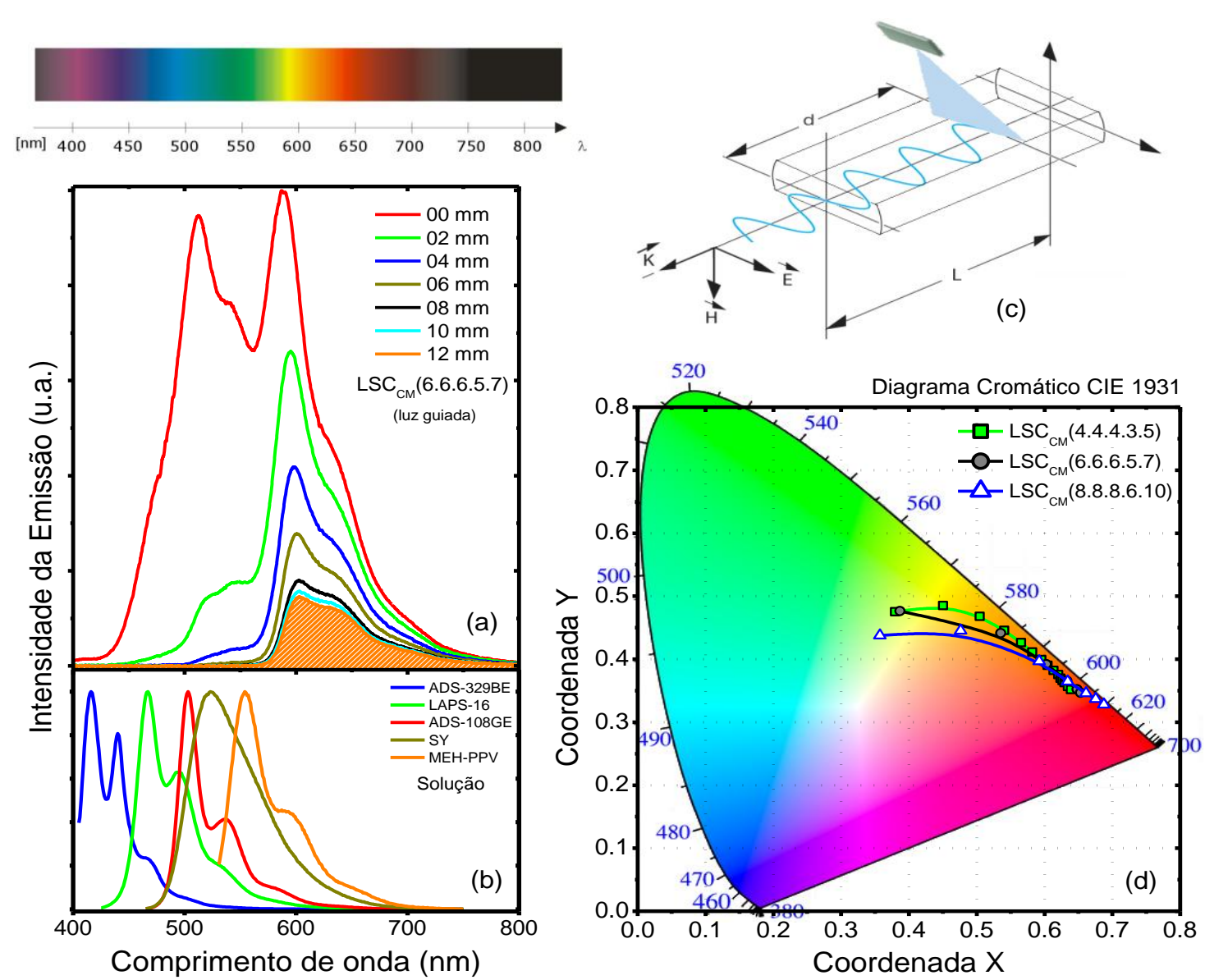

Figura 31 - (a) Espectros de luminescência em função da distância lateral d da saída do guia. (b) Espectros de luminescência dos cinco polímeros que compõe o conversor de comprimento de ondas que emitem em uma vasta região espectral.(c) Emissão lateral para um conversor evidenciando a distância $d$ de excitação. (d) Representação do conversor em que uma luz incidente Deslocamento das coordenadas CIE em um diagrama cromático 1931 para $\operatorname{LSC}_{\mathrm{CM}}(4,4,4,3,5), \operatorname{LSC}_{\mathrm{CM}}(6,6,6,5,7) \mathrm{e}$ $\operatorname{LSC}_{\mathrm{CM}}(8,8,8,6,10)$ respectivamente em vermelho (quadrado), preto (círculo) e azul (triângulo). A distância da luz incidente aumenta com relação ao maior caminho ótico da esquerda para a direita. (Colocar ponto inicial e final $\mathrm{d}=\mathrm{o}$ e $\mathrm{d}=12 \mathrm{~mm}$ no diagrama CIE)

A Figura 32 ilustra melhor os processos ópticos e as perdas ao longo dos LSCs. Essa figura mostra a dependência da intensidade da luminescência medida em $630 \mathrm{~nm}$ em função da posição da luz de excitação $d$ em relação à saída dos LSCs de mais baixa e mais alta concentração, ou seja, $\operatorname{LSC}_{\mathrm{CM}}(4,4,4,3,5)$ e $\operatorname{LSC}_{\mathrm{CM}}(8,8,8,6,10)$. Emissões nesse comprimento de onda se situam na região vibracional do MEH-PPV e não sofrem efeito do processo de conversão. Por isso, medidas realizadas em $630 \mathrm{~nm}$ são adequadas para se analisar as perdas ao longo dos LSCs, pois correspondem aos fótons que sobreviveram a todo o processo de conversão nesse sistema. 


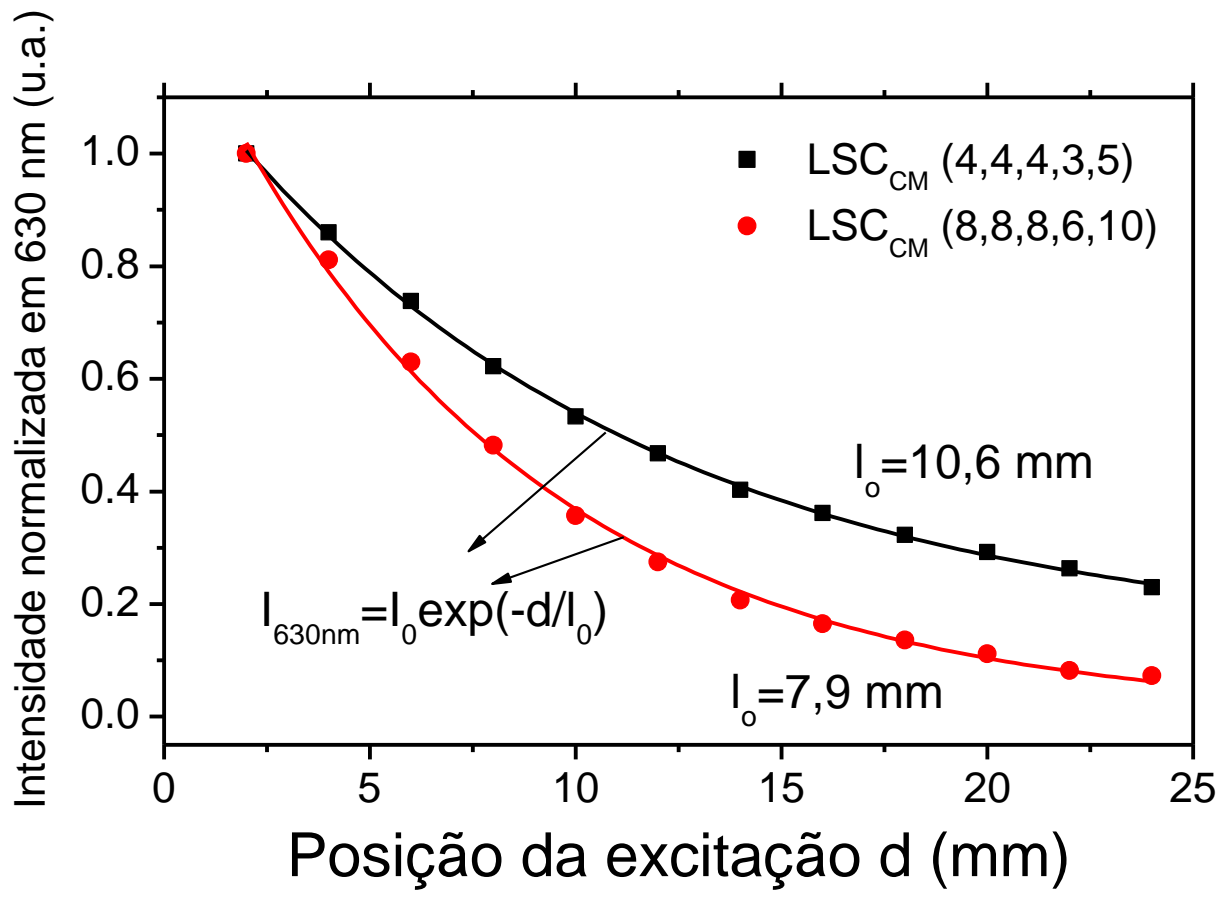

Figura 32 - Dependência da intensidade da luminescência medida em $630 \mathrm{~nm}$ em função da posição da luz de excitação $d$ em relação à saída dos LSCs de mais baixa e mais alta concentrações, ou seja, LSC $_{\mathrm{CM}}$ $(4,4,4,3,5)$ e $\operatorname{LSC}_{\mathrm{CM}}(8,8,8,6,10)$.

Pode-se ver na Figura 32 que a intensidade da luz na saída dos LSCs decai na forma de uma exponencial simples com a distância $d$, do tipo $\exp \left(-d / l_{o}\right)$, onde $l_{o}$ é uma distância típica. Este tipo de decaimento único indica que somente as perdas relacionadas a fótons não guiados (aqueles re-emitidos em ângulos menores que o ângulo crítico $\theta_{c}=\operatorname{sen}^{-1}(1 / n)=42^{\circ}$ ) estão ocorrendo nos LSCs preparados nesse trabalho. É interessante notar que o decaimento é maior para concentrações mais altas. Isto é explicado pelo fato da maior ocorrência de eventos relacionados às reabsorções e re-emissões nessas amostras. A distância $l_{o}$ avaliada pelo decaimento exponencial (ver Figura 32), é a mesma para o comprimento no qual os fótons convertidos se desacoplam das moléculas, mesmo para emissões/absorções em altas energias ou para a qual a borda do diagrama cromático tenha sido alcançada (ver Figura 31d). Nessa distância, as perdas de fótons é de $62 \%$. Conversores mais otimizados, por exemplo, com materiais que tornam o índice de refração maior nos guias irão reduzir substancialmente essas perdas. Algumas perdas por re-emissão podem ser reduzidas a 30\% para o índice de refração do guia igual a $2(7,18,19)$.

A Figura 33 compara o deslocamento das coordenadas CIE no diagrama cromático para conversores de comprimento de onda contendo a mesma concentração polimérica, mas com metal refletor $\left(\operatorname{LSC}_{\mathrm{CM}}(8,8,8,6,10)\right)$ e sem metal $\left.\operatorname{LSC}_{\mathrm{SM}}(8,8,8,6,10)\right)$ em uma das 
interfaces. Pode-se ver que o $\mathrm{LSC}_{\mathrm{CM}}$ é mais eficiente na conversão do comprimento de onda (maior deslocamento no diagrama cromático para uma mesma distância $d$ ). Quando comparamos a eficiência entre os LSCs com e sem metalizações alguns fatores devem ser levados em consideração, dos quais, de forma mais específica, problemas relacionados ao escape de luz do guia como nos casos em que não existem metalizações em suas interfaces refletoras. Isto faz com que parte da luz passe do LSC $(n=1.49)$ para o substrato de vidro $(\mathrm{n}=1.38)$, esta é guiada parcialmente por este e depois retorna sem ser reabsorvida. Isso faz com que o processo de reabsorção/re-emissão seja pouco efetivo ao longo do comprimento do $\mathrm{LSC}_{\mathrm{SM}}$.

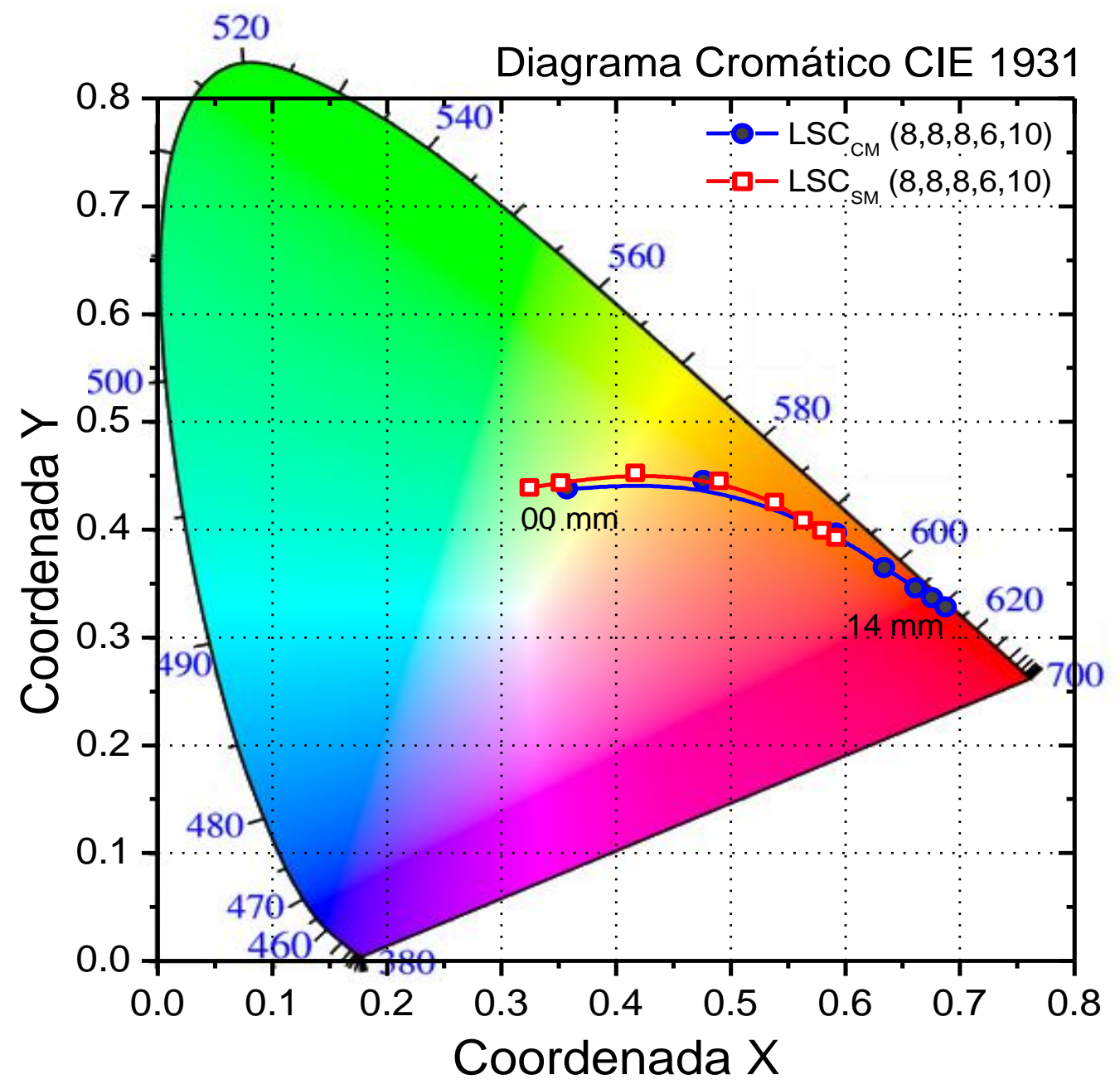

Figura 33 - Coordenadas CEI em um diagrama cromático 1931 para $\operatorname{LSC}_{\mathrm{CM}}(8,8,8,6,10)$ e $\operatorname{LSC}_{\mathrm{SM}}(8,8,8,6,10)$ respectivamente em azul (círculo) e vermelho (quadrado). 


\subsection{Emissão lateral com variação da excitação}

Até agora foram feitos estudos dos LSCs com comprimento de onda de excitação fixa em $350 \mathrm{~nm}$ no ultravioleta. Vimos na seção anterior que uma fonte de perda está associada ao escape dos fótons emitidos em ângulos menores que $\theta_{c}$. Ensaios a respeito do comportamento da emissão lateral em relação à variação do comprimento de onda de excitação foram realizados com o objetivo de: esclarecer possíveis processos que gerariam perdas intermolecurlares durante os processos de reabsorção e emissão devido a processos não radiativos; Avaliar a existencia de processos de transferência de energia entre moléculas que possibilitaria a migração para centros não radiativos $(54,88,89)$.

$\mathrm{Na}$ Figura 34 é apresentada a dependência da intensidade normalizada da luminescência lateral com a variação do comprimento de onda de excitação para o $\operatorname{LSC}_{\mathrm{SM}}(8,8,8,6,10)$, bem como a comparacão com o espectro de absorbância correspondente. $\mathrm{O}_{\operatorname{LSC}}(8,8,8,6,10)$ foi escolhido devido a sua alta eficiência de conversão. A posição da luz de excitação foi tomada em $d=30 \mathrm{~mm}$ de modo a permitir conversão completa. O comprimento de onda da luz de excitação variou de 350 a $550 \mathrm{~nm}$ em intervalos de $50 \mathrm{~nm}$. Este intervalo de comprimentos de onda permite excitar todas os polímeros presentes no LSC. Em primeiro lugar, a forma de linha dos espectros de luminescência na saída do LSC não depende do comprimento de onda de excitação e, portanto, o processo de conversão independe da molécula que está sendo excitada. Toda a energia é convertida para a região de emissão vibracional do MEH-PPV independente de onde a excitação é originada. Em segundo lugar, a intensidade da luminescência na saída do LSC segue o mesmo perfil do espectro de absorção, ou seja, a intensidade na saída é proporcional à densidade de estados de todas as moléculas conjugadas presentes na região de excitação e que é a mesma ao longo do filme de PMMA. Este resultado indica que eventuais perdas intermoleculares e intramoleculares (por processos de transferência de energia) são desprezíveis para os valores de concentração utilizados. Perdas por estes processos em qualquer polímero no interior do LSC geraria um desvio entre a intensidade da luminescência no experimento de excitação variável e o espectro de absorbância. 


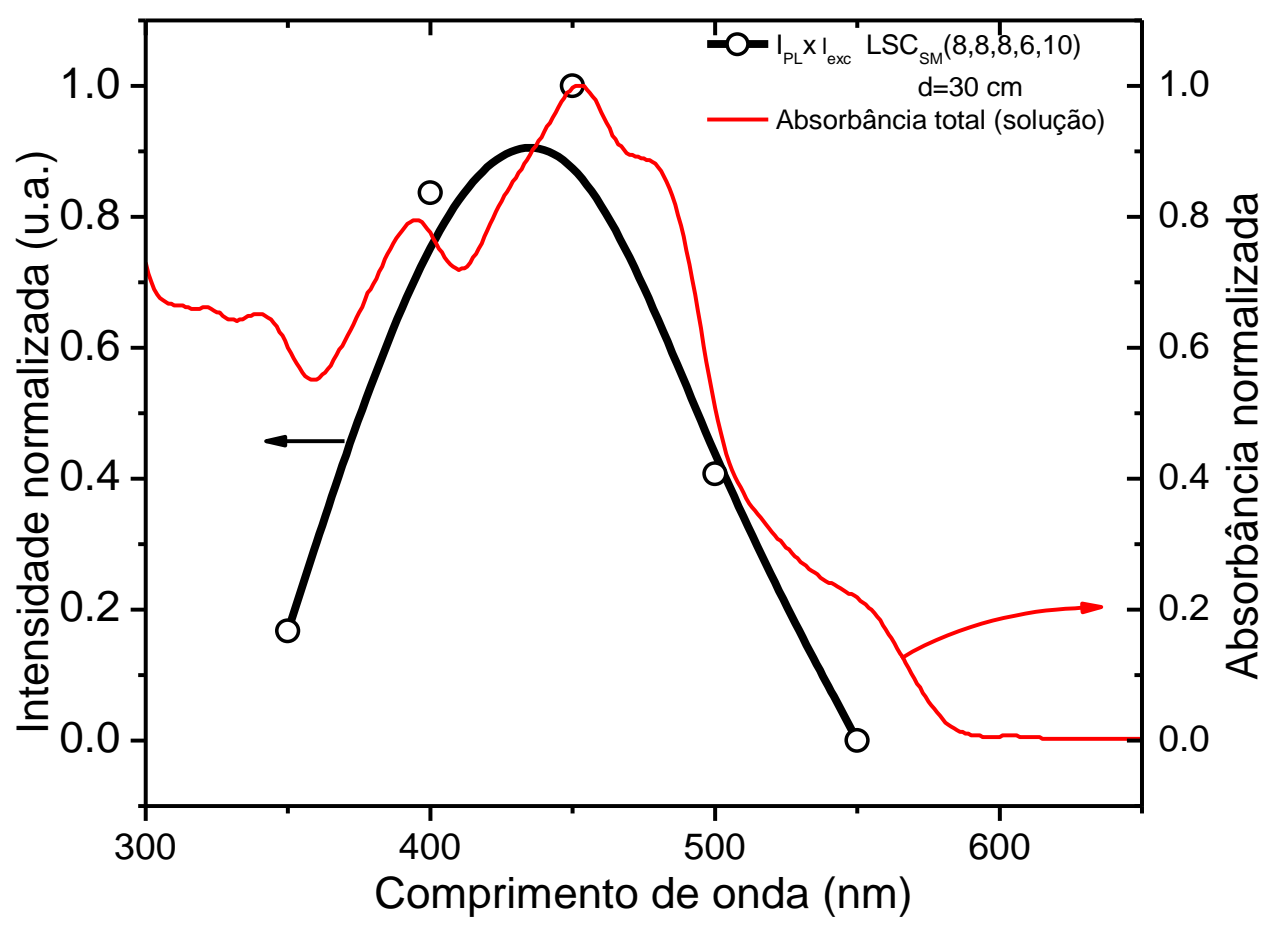

Figura 34 - Intensidade normalizada da luminescência lateral com a variação do comprimento de onda de excitação para o $\operatorname{LSC}_{S M}(8,8,8,6,10)$ comparada com o espectro de absorbância da solução.

Como comprovação da capacidade destes dispositivos em converter comprimentos de onda na região de absorção dos LSCs produzidos neste trabalho, a Figura 35 mostra o espectro de uma lâmpada espectral de mercúrio que emite entre 220 e 1100 nm medido na saída do $\operatorname{LSC}_{\mathrm{CM}}(8,8,8,6,10)$. O espectro da lâmpada possui estruturas espectrais do mercúrio (picos estreitos) superpostos à emissão larga de um corpo cinza. Esta luz espectral foi obtida colocando o monocromador do fluorímetro na posição de comprimento de onda zero. Nesse caso, a rede de difração do mesmo funcionou como um espelho para todos os comprimentos de onda emitidos pela lâmpada. Além disso, a posição da área de excitação foi para d=30 mm. Para comparação, a figura também mostra os espectros de absorbância e emissão normal, também medido na saída do mesmo dispositivo.

Podemos ver que todos os comprimentos de onda abaixo de aproximadamente $600 \mathrm{~nm}$ são absorvidos pelo LSC. Este comprimento de onda corresponde ao ponto em que não há mais absorção. Comprimentos de onda maiores que $600 \mathrm{~nm}$ passam pelo mesmo sem ser absorvidos guiados pelas reflexões totais nas interfaces. Estes fótons foram acoplados ao guia através de possíveis espalhamentos por imperfeições nas duas interfaces do LSC. Pode-se dizer que o LSC absorve toda a luz na região espectral abaixo de $600 \mathrm{~nm}$ e converte todos esses comprimentos de onda em luz emitida na faixa espectral em torno de $600 \mathrm{~nm}$. 


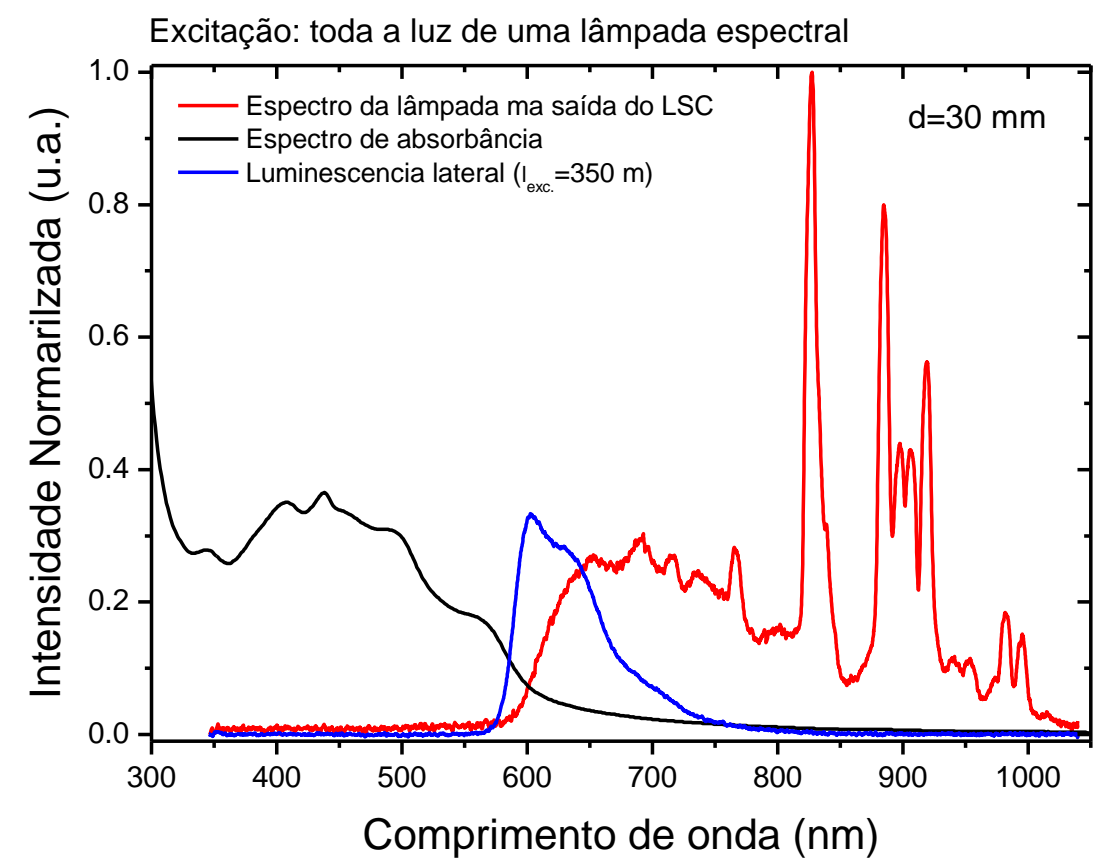

Figura 35 - Caráter de conversão para o $\operatorname{LSC}_{\mathrm{CM}}(8,8,8,6,10)$ observado através da emissão lateral com a incidência de luz branca na superfície do dispositivo em comparação com a emissão normal para o mesmo.

\subsection{Caracterização dos LSCs através da emissão normal}

Na seção 4.3 vimos que a luminescência dos polímeros que emitem em alta energia (como é o caso do ADS-329BE que emite em $400 \mathrm{~nm}$ ) é convertida para comprimentos de onda menores mesmo para a luz de excitação posicionada nas proximidades da saída do LSC $(d=0 \mathrm{~mm})$. Assim, é interessante estudar as propriedades da luz emitida perpendicular ao plano deste dispositivo, ou seja, a emissão normal que resulta da mesma área de excitação e que propaga ao longo de uma distância típica de $30 \mu \mathrm{m}$, que é a espessura do LSC. Esta espessura corresponde exatamente ao caminho livre $\ell$ de propagação do fóton entre duas absorções. Isto significa que o fóton tem a probabilidade de sofrer apenas uma absorção ao propagar nessa direção. Assim, os experimentos de emissão normal a seguir permitem observar a presença dos polímeros de mais alta energia nos LSCs fabricados, uma vez que na emissão lateral a luminescência correspondente a estes polímeros não aparece nos espectros de emissão. 


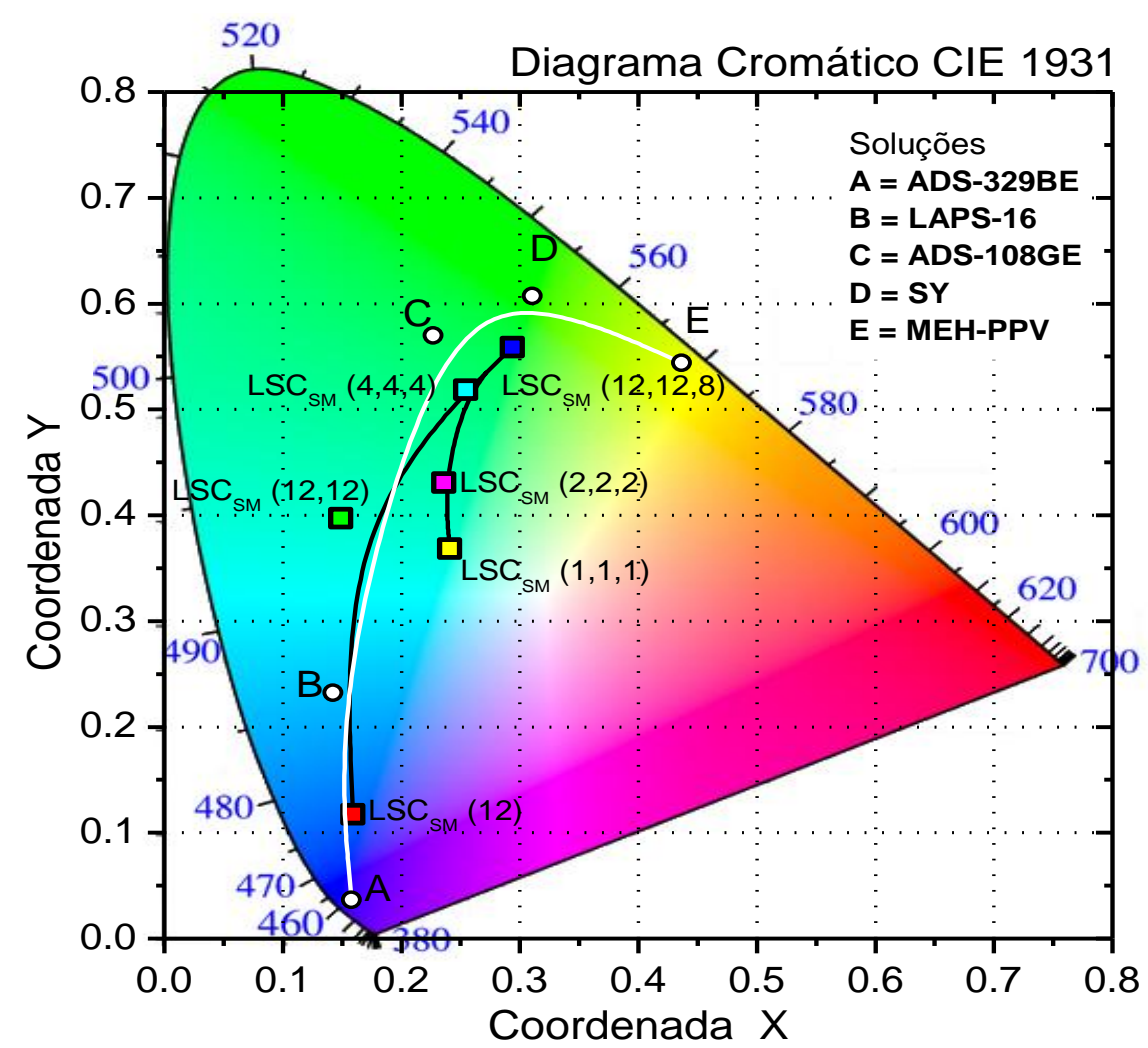

Figura 36 - Coordenadas CEI para a emissão normal para os $\operatorname{LSC}_{\mathrm{CM}}(12), \operatorname{LSC}_{\mathrm{CM}}(12,12), \operatorname{LSC}_{\mathrm{CM}}(12,12,8)$, $\operatorname{LSC}_{\mathrm{CM}}(1,1,1), \operatorname{LSC}_{\mathrm{CM}}(2,2,2)$ e $\mathrm{LSC}_{\mathrm{CM}}(4,4,4)$ (pontos coloridos). Os pontos brancos de A a $\mathrm{E}$ correspondem às coordenadas no diagrama CIE obtidos de espectros obtidos a partir de soluções de tolueno contendo um único polímero.

A Figura 36 compara as coordenadas no diagrama CIE dos espectros obtidos a partir de soluções de tolueno contendo um único polímero (pontos brancos no intervalo A - E) e espectros de emissão normal de filmes de PMMA contendo: apenas o polímero ADS-329BE (quadrado vermelho LSC $_{\mathrm{CM}}$ (12)); o ADS-329BE e o LAPS-16 (quadrado verde $\mathrm{LSC}_{\mathrm{CM}}$ $(12,12))$; o ADS-329BE, o LAPS-16 e o SY (quadrado azul escuro $\operatorname{LSC}_{\mathrm{CM}}(12,12,8)$ ); bem como estes três últimos polímeros nas concentrações $4 \mathrm{C}_{\mathrm{o}}$ (quadrado azul claro $\mathrm{LSC}_{\mathrm{CM}}$ $(4,4,4)) ; 2 \mathrm{C}_{\mathrm{o}}$ (quadrado em rosa $\operatorname{LSC}_{\mathrm{CM}}(2,2,2)$ ) e $\mathrm{C}_{\mathrm{o}}$ (quadrado amarelo $\operatorname{LSC}_{\mathrm{CM}}(1,1,1)$ ).

A diferença entre as coordenadas $\mathrm{CIE}$ do $\operatorname{LSC}_{\mathrm{CM}}$ (12) contendo apenas o polímero ADS-329BE e a sua solução em tolueno se deve às mudanças espectrais devido a interações desse polímero com a matriz de PMMA e com o solvente. Quando se adicionam os polímeros LAPS-16 e SY para formar os conversores $\operatorname{LSC}_{\mathrm{CM}}(12,12)$ e $\operatorname{LSC}_{\mathrm{CM}}(12,12,8)$, respectivamente, vemos que este último (quadrado azul escuro) se aproxima da solução em tolueno do polímero de mais baixa energia (o SY, ponto D). Isto ocorre mesmo para uma menor concentração de $\mathrm{SY}\left(8 \mathrm{C}_{\mathrm{o}}\right)$ no filme do que os outros dois componentes $\left(12 \mathrm{C}_{\mathrm{o}}\right)$. Este fato indica que existe uma conversão eficiente de comprimento de onda, mesmo quando o 
caminho percorrido pelos fótons emitidos se encontra dentro do comprimento do livre caminho médio do fóton $\ell$, ou seja, condição de se ter apenas a probabilidade de um só processo de reabsorção/re-emissão, como mostra a Figura 37. Os valores espectrais para o livre caminho do fóton nessa figura foram obtidos dos espectros de absorbância dos filmes tratados na Figura 36 que possuem espessura em torno de $30 \mu \mathrm{m}$. O livre caminho do fóton varia de três a cinco vezes com a incorporação sucessiva dos polímeros nos $\operatorname{LSC}_{\mathrm{CM}}(12)$, $\operatorname{LSC}_{\mathrm{CM}}(12,12)$ e $\operatorname{LSC}_{\mathrm{CM}}(12,12,8)$ devido à forte superposição dos estados energéticos dos mesmos. Pode-se ver que a amostra $\operatorname{LSC}_{\mathrm{CM}}(12,12,8)$ possui $\ell$ da ordem da espessura do filme de PMMA na região espectral entre 370 e $450 \mathrm{~nm}$. O livre caminho do fóton aumenta com a diminuição da concentração dos polímeros nas amostras $\operatorname{LSC}_{\mathrm{CM}}(1,1,1), \operatorname{LSC}_{\mathrm{CM}}(2,2,2)$ e $\operatorname{LSC}_{\mathrm{CM}}(4,4,4)$.

Processos intermoleculares equivalentes de transferência de energia poderiam produzir a mesma conversão de comprimento de onda, porém estes processos seriam fortemente reduzidos nas concentrações poliméricas utilizadas de $12 \mathrm{C}_{\mathrm{o}}=0,02 \mathrm{~g} / \mathrm{l}$.

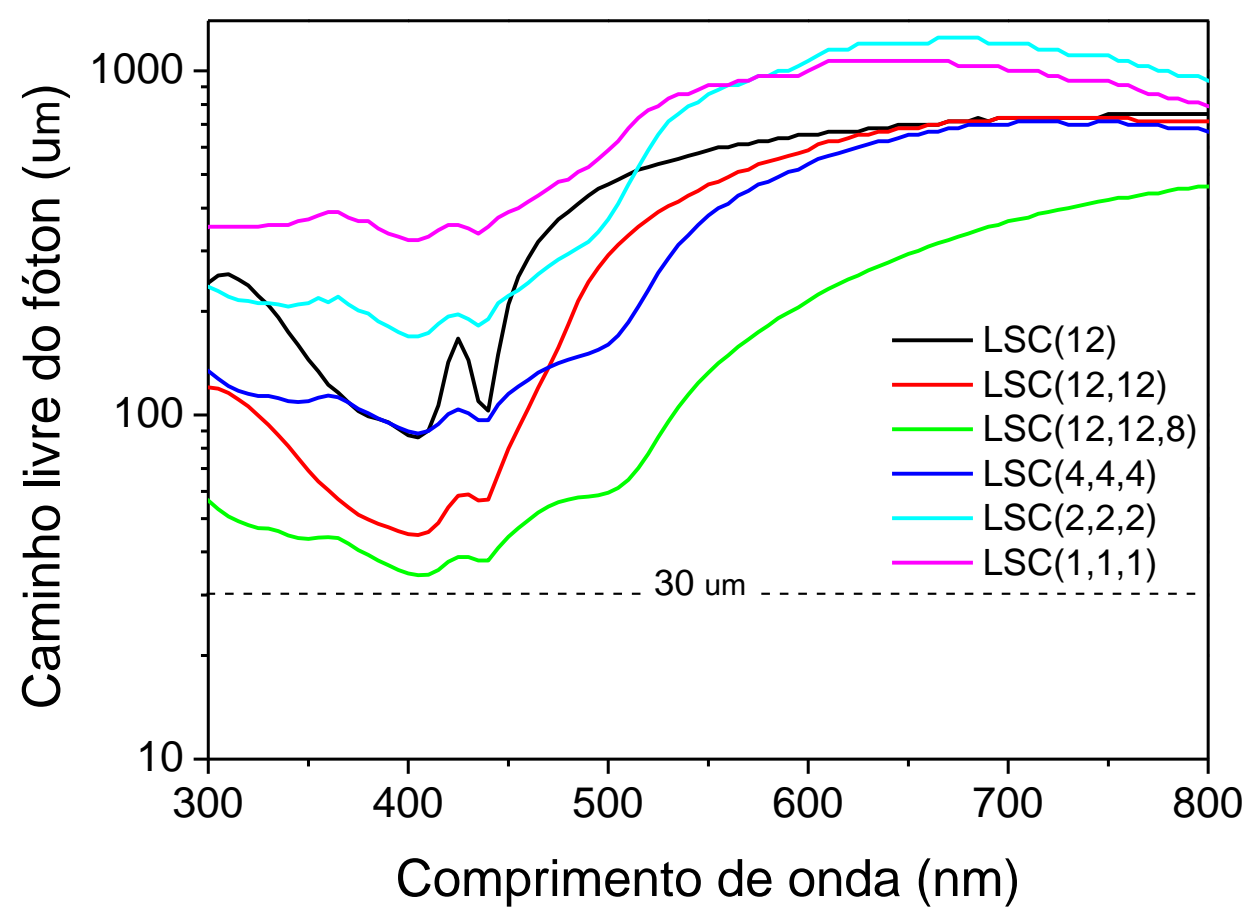

Figura 37 - Caminho livre do fóton nos LSCs estudados na Figura 36. As espessuras desses dispositivos são de $30 \mu \mathrm{m}$.

É interessante notar que as coordenadas CIE se deslocam mais para regiões de mais altas energias quando a concentração de polímeros no conversor é reduzida (diminuída). Nessas condições, estamos aumentando o livre caminho médio do fóton $\ell$ para valores 
maiores que a espessura do $\operatorname{LSC}(\sim 30 \mu \mathrm{m})$. Assim, para concentrações ainda menores, o deslocamento das coordenadas CIE para regiões de maiores energias indica que os processos de conversão por reabsorção/re-emissão estão sendo suprimidos $(\ell>>30 \mu m)$. Nessas condições, os fótons emitidos na direção normal atravessam a espessura do filme sem serem reabsorvidos e re-emitidos. É importante notar que, no experimento, a luz não é coletada exatamente na direção normal e sim dentro de um ângulo sólido através da lente do equipamento. Deste modo, fótons coletados podem propagar ao longo de uma distância maior que $30 \mu \mathrm{m}$, aumentando a probabilidade de serem reabsorvidos.

A Figura 38a compara os espectros de emissão normal dos LCS utilizados para se calcular as coordenadas CIE da Figura 36. A escala logarítmica para o eixo das ordenadas foi utilizada para dar ênfase às pequenas intensidades. Pode-se observar que a emissão em torno de $440 \mathrm{~nm}$ do polímero de maior lacuna de energia, o ADS-329BE (ver amostra $\operatorname{LSC}_{\mathrm{CM}}(12)$ ), quase que desaparece com a introdução do polímero LAPS-16 na amostra $\operatorname{LSC}_{\mathrm{CM}}(12,12)$. É interessante notar que a emissão deste último decai com a incorporação do polímero que emite no amarelo-laranja em torno de $540 \mathrm{~nm}$, o SY. Isto demonstra a presença de uma eficiente conversão para os fótons propagando na direção normal. Para as concentrações utilizadas $\left(12 \mathrm{C}_{\mathrm{o}}\right)$, o livre caminho médio do fóton $\ell$ é da ordem da espessura dos LSCs, o que aumenta a probabilidade de processos de reabsorção/re-emissão nessas amostras. Além disso, a emissão no amarelo-laranja do SY (com máximo em torno de $540 \mathrm{~nm}$ ) cai com a diminuição da concentração (amostras $\operatorname{LSC}_{\mathrm{CM}}(4,4,4), \operatorname{LSC}_{\mathrm{CM}}(2,2,2)$ e $\operatorname{LSC}_{\mathrm{CM}}(1,1,1)$ ), indicando que esses processos são suprimidos devido ao aumento de $\ell$. Pode-se observar que a emissão do polímero de maior energia (o ADS-329BE) volta a aparecer em torno de $440 \mathrm{~nm}$, o que reforça esta hipótese.

Até o momento não foram considerados processos de transferência de energia nos LSCs. No entanto, as emissões normais podem dar uma indicação desses processos para as amostras contendo alta concentração polimérica. Este efeito pode ser visto na dependência da intensidade da emissão normal em função da concentração polimérica (Figura 38b). Uma dependência linear com a concentração de polímeros nos LSCs é esperada se processos de transferência de energia estiverem ausentes. Este comportamento linear pode ser visto para baixas concentrações no gráfico de intensidade versus concentração. No entanto, o comportamento sublinear que aparece para concentrações poliméricas altas $\left(12 \mathrm{C}_{\mathrm{o}}\right)$ indica uma saturação da emissão devido da introdução de processos não radiativos com o aumento da concentração molecular. 


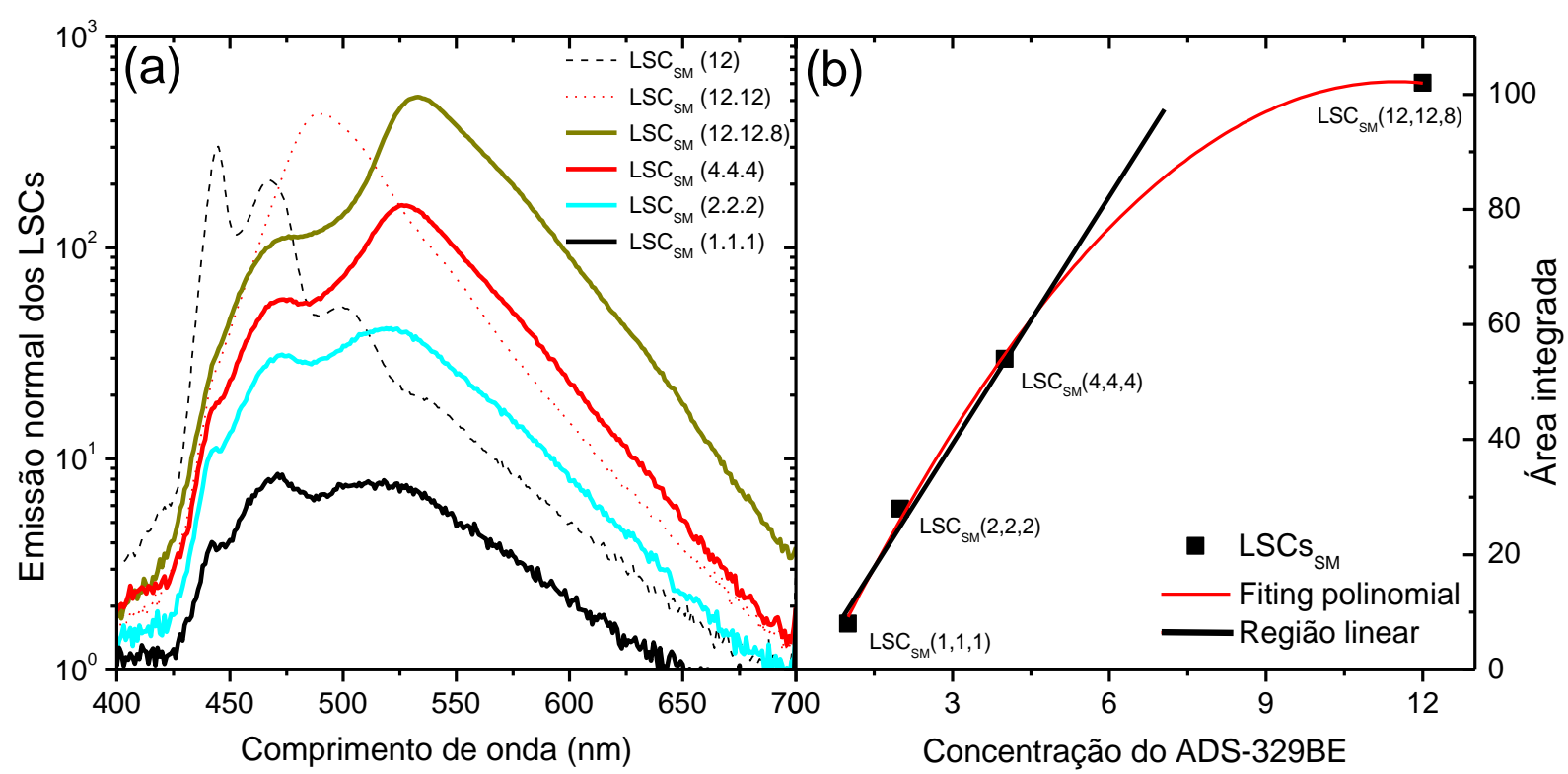

Figura 38 - (a) Emissão normal com a variação da concentração em cinco LSCs. (b) Representa a área integrada dos espectros de (a) em função da concentração polimérica nos LSCs.

Quando comparamos dispositivos com diferentes concentrações, devemos ficar atentos para o aumento das possibilidades de ocorrerem transferência de energia intercadeia para distâncias moleculares inferiores a $80 \AA$ (54, 88-90). O aumento da concentração polimérica na matriz de PMMA pode gerar agregados moleculares devido à segregação de fase entre a matriz e os polímeros luminescentes. Estes agregados favorecem o processo de transferência de energia que, por sua vez, aumenta a probabilidade de encontrar centros não radiativos através da migração do estado molecular excitado. Este fator decorrente do aumento da concentração nos LSCs e influencia na eficiência de emissão dos mesmos, como pode ser observado na Figura 38b. Este experimento mostra que processos de transferência de energia podem estar competindo com processos de reabsorção/re-emissão na conversão de comprimento de onda nos LSCs contendo concentração poliméricas maiores que $5 \mathrm{C}_{0}$. 


\subsection{LSCs de alta energia}

Levando em consideração uma possível aplicação destes dispositivos em conjunto com células solares, surge a necessidade da obtenção de LSCs sintonizáveis ou que tenham como característica a absorção em regiões de menores comprimentos de onda. Isso porque é interessante sintonizar o comprimento de onda na saída lateral nos LSCs para as características de absorção máxima de um outro dispositivo acoplado, uma célula solar por exemplo, que opere basicamente no visível. Além disso, o espectro da radiação solar possui elevada incidência na região que compreende desde o ultravioleta próximo até o infravermelho próximo. Levando em conta este espectro podemos adicionar centros luminescentes com bandas de absorção características de modo a aproveitar ao máximo a energia proveniente da radiação incidente e convertê-la para um comprimento de onda específico.

Utilizamos os mesmos $\operatorname{LSC}_{\mathrm{SM}}(12), \operatorname{LSC}_{\mathrm{SM}}(12,12)$ e $\operatorname{LSC}_{\mathrm{SM}}(12,12,8)$ estudados na seção anterior para o estudo da emissão lateral sintonizável. Estes LSCs são compostos dos três polímeros luminescentes, o ADS-329BE, LAPS-16 e SY diluídos em uma matriz planar de PMMA. Caracterizações quanto à alteração da emissão lateral com a variação da posição da excitação foram realizadas através de ensaios de fotoluminescência. O comprimento de onda de excitação utilizado nesse experimento foi de $350 \mathrm{~nm}$.

O deslocamento das coordenadas CIE no diagrama cromático pode ser observado na Figura 39a em função da distância $d$ da saída dos dispositivos. É interessante notar que as coordenadas CIE do $\operatorname{LSC}_{\mathrm{SM}}(12)$ contendo apenas o ADS-329BE já sofre significante deslocamento para regiões de baixas energias para $d=0 \mathrm{~mm}$ quando comparamos com as coordenadas da emissão normal (Figura 36). As coordenadas se deslocam para baixas energias (região azul-amarelado) com o aumento da distância $d$ da saída do dispositivo. Este deslocamento se deve às múltiplas reabsorções/re-emissões ao longo do guia na região espectral onde a cauda da absorção penetra na emissão. Esta região espectral corresponde a uma baixa densidade molecular e a um alto caminho livre para o fóton emitido (200-500 $\mu \mathrm{m}$, ver Figura 37). As mudanças espectrais responsáveis pelo deslocamento no diagrama cromático são mostradas na Figura 39b. O espectro do ADS-329BE em solução de tolueno é também usado para comparação. Pode-se ver que as transições de fônon zero em $415 \mathrm{~nm}$, bem como aquelas envolvendo um fônon em torno de $438 \mathrm{~nm}$ e dois fônons em $475 \mathrm{~nm}$ são 
fortemente reabsorvidas já na saída do $\operatorname{LSC}(d=0 \mathrm{~mm})$. Os fótons são convertidos para regiões de mais baixa energia através de processos de relaxação interna e múltiplas reabsorções/reemissões. É importante notar que as perdas na região de alta energia são bem maiores que as dos LSCs multipoliméricos apresentados na seção 4.3.2 devido ao maior índice de refração do PMMA.
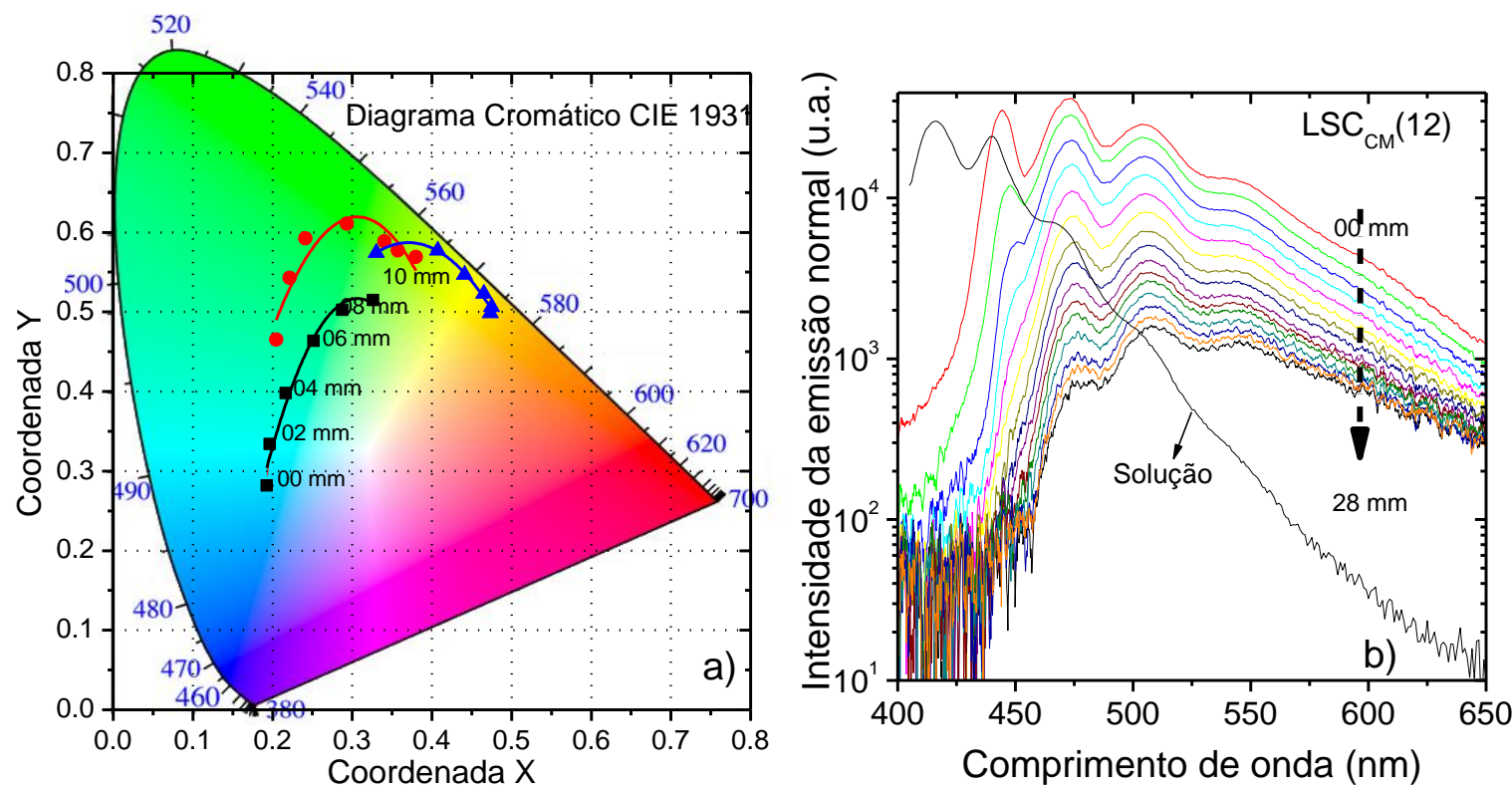

Figura 39 - (a) Coordenadas CEI em um diagrama cromático 1931 para $\operatorname{LSC}_{\mathrm{CM}}(12)$, $\operatorname{LSC} \mathrm{CM}_{\mathrm{CM}}(12,12)$ e $\operatorname{LSC}_{\mathrm{CM}}(12,12,8)$ respectivamente em preto (quadrado), vermelho (círculo) e azul (triângulo). (b) Mudanças espectrais responsáveis pelo deslocamento $\operatorname{LSC}_{\mathrm{CM}}(12)$ no diagrama cromático comparadas em escala logarítmica com o espectro do ADS-329BE em solução.

As coordenadas CIE se deslocam ainda mais para baixas energias com a adição do LAPS-16 e SY na matrix de PMMA e alcançam a borda do diagrama cromático na região de cores mais puras do amarelo-laranja através da emissão do SY no $\operatorname{LSC}_{\mathrm{CM}}(12,12,8)$. Os espectros de excitação na Figura 24 mostram que o SY não é excitado no comprimento de onda de $350 \mathrm{~nm}$ o que demonstra mais uma vez o forte caráter de conversão de comprimento de onda dos LSCs produzidos nesse trabalho.É importante evidenciar que os LCSs propostos neste trabalho, apesar de comportarem como um filtro de cor que absorve abaixo de um comprimento de onda característico e transmitir totalmente acima do mesmo, eles possuem a propriedade de converter parte da energia absorvida em um comprimento de onda de mais baixa energia através de processos fotofísicos. Esse processo de conversão se procede através da propagação do fóton ao longo de distâncias muito maiores que o caminho livre do fóton na matriz. Esta proposta é atual e ainda apresenta pontos em aberto que merecem estudos mais detalhados visando aplicação em dispositivos no futuro. 


\section{Conclusões e perspectivas futuras}

As atividades deste trabalho foram dedicadas à preparação e caracterização de guias de onda planares híbridos a base de materiais poliméricos emissores de luz embebidos em uma matriz inerte transparente. O objetivo principal seria obter um guia de onda luminescente que tivesse emissão com características a) de interferência presentes em uma cavidade ótica do tipo Fabri-Perot e b) de conversão de comprimento de onda de LSC, visando utilização em sensoriamento ótico e em concentradores solares para células solares de ultima geração.

Aqui, optamos pela utilização de uma matriz de polimetacrilato (PMMA) e de cinco polímeros com propriedades de emissão e absorção em uma larga faixa espectral entre 350 e $600 \mathrm{~nm}$. Estes polímeros serviram para acoplar a radiação luminosa incidente ao interior do guia através da absorção eficiente e da posterior emissão por parte dos polímeros. Processos óticos distintos foram responsáveis para obter características de interferências na emissão lateral para guias de onda planares com espessura entre 0,6 e $3 \mu \mathrm{m}$ e de conversão de comprimento de onda em LSCs preparados a partir de filmes com espessura de $30 \mu \mathrm{m}$.

A escolha da solução polimérica utilizada na preparação dos guias de onda foi de fundamental importância para o desenvolvimento do presente estudo. A concentração do PMMA e dos polímeros luminescentes nessa matriz foi determinada a partir de metodologia desenvolvida neste trabalho. A concentração de cada polímero foi tal que o livre caminho médio do fóton (obtido por meio de medidas de absorbância) no guia de onda fosse da ordem da espessura do guia. Além disso, o processo de secagem lenta da solução polimérica precursora foi desenvolvido ao longo destes estudos e foi essencial para a obtenção de filmes 'cast' de alta homogeneidade e qualidade ótica.

Guias de onda com caracterizados por sua geometria restrita (espessura entre 0,6 e 3 $\mu \mathrm{m})$ apresentam emissão lateral constituída por padrões de interferência resultantes de múltiplas reflexões internas ao longo dos filmes luminescentes e da emissão rasante à superfície do guia. Simulações demonstraram que estas emissões possuem padrões de interferência do tipo Fabri-Perot, que são extremamente sensíveis à geometria (espessura) e a qualidade ótica do guia. A emissão lateral é composta por modos TE e TM características de cavidades óticas com picos de emissão extremamente estreitos (largura de $3 \mathrm{~nm}$ ) e intensos ao longo de toda a faixa espectral dos polímeros que compõem o guia. Esses modos 
correspondem aos únicos comprimentos de onda dessa larga emissão que se acoplam com o guia de onda como resultado de interferências construtivas e destrutivas.

Já guias de onda espessos (largura de $30 \mu \mathrm{m}$ ) apresentaram características de um conversor de comprimento de onda ou LSC. A luz absorvida é convertida em luz de baixo comprimento de onda e alta pureza espectral. Este fenômeno não depende do comprimento de onda da luz de excitação incidente. As propriedades óticas foram analisadas em termos de suas emissões laterais (ao longo do plano) e normal (perpendicular ao plano) e do deslocamento das respectivas coordenadas CIE em um diagrama cromático em função da posição da luz de excitação ao longo do guia. Esta conversão é obtida através de sucessivos processos de re-absorção, relaxação interna e re-emissões ao longo do guia de onda. Por fim, a luz convertida é direcionada para uma das faces laterais do guia.

Neste trabalho foram estudados dois concentradores, um com interface vidro/PMMA/ar e outro com metal/PMMA/ar. O uso de baixas concentrações das moléculas utilizadas foi necessário para evitar possíveis formações de agregados quando altas concentrações de PMMA são utilizadas na preparação dos filmes. O escape dos fótons nas interfaces para ângulos menores que o ângulo crítico $\left(\theta_{\mathrm{c}}=\operatorname{sen}^{-1}(1 / \mathrm{n})\right)$ foram as maiores fontes de perdas nos LSCs estudados. Processos de transferência de energia estão presentes nos LSCs com alta concentração polimérica e podem ser evidência de separação de fase e, conseqüente formação de agregados poliméricos neste sistema. Esse efeito deve ser otimizado para a aplicação dos LSCs como dispositivos em futuros dispositivos. 


\section{Referências}

1 BAILEY, S.T.; LOKEY, G.E.; HANES, M.S.; SHEARER, J.D.M.; MCLAFFERTY, J.B.; BEAUMONT, G.T.; BASELER, T.T.; LAYHUE, J.M.; BROUSSRD, D.R.; ZHANG, Y.Z.; WITTMERSHAUS, B.P. Optimized excitation energy transfer in a three-dye luminescent solar concentrator. Solar Energy Materials and Solar Cells, v. 91, n. 1, p. 67-75, 2007.

2 SCHMITT, K.; OEHSE, K.; SULZ, G.; HOFFMANN, C. Evanescent field sensors based on tantalum pentoxide waveguides - a review. Sensors, v. 8, n. 2, p. 711-738, 2008.

3 SHAYANI, R.A.; OLIVEIRA, M.A.G.; CAMARGO, I.M.T. Comparação do custo entre energia solar fotovoltaica e fontes convencionais. In: CONGRESSO BRASILEIRO DE PLANEJAMENTO ENERGÉTICO, 2006. Brasilia-DF. Anais... Brasilia-DF: UnB, 2006. Disponível em: $\langle$ http://engenharia.shayani.net/Comparacao_Custo_Energia_Solar_FV.pdf $>$. Acesso em: 21/05/2010.

4 SHOLIN, V.; OLSON, J.D.; CARTER, S.A. Semiconducting polymers and quantum dots in luminescent solar concentrators for solar energy harvesting. Journal of Applied Physics, v. 101, n. 12, p. 123114, 2007.

5 WEBER, W.H.; LAMBE, J. Luminescent greenhouse collector for solar radiation. Applied Optics, v. 15, n. 10 , p. $2299-2300,1976$.

6 CHATTEN, A.J.; BARNHAM, K.W.J.; BUXTON, B.F.; EKINS-DAUKES, N.J.; MALIK, M.A. Quantum dot solar concentrators. Semiconductors, v. 38, n. 8, p. 909-917, 2004.

7 VAN SARK, W.G.J.H.M.; BARNHAM, K.W.J.; SLOOFF, L.H.; CHATTEN, A.J.; BÃCHTEMANN, A.; MEYER, A.; MCCORMACK, S.J.; KOOLE, R.; FARRELL, D.J.; BOSE, R.; BENDE, E.E.; BURGERS, A.R.; BUDEL, T.; QUILITZ, J.; KENNEDY, M.; MEYER, T.; DE MELLO DONEGÃ, C.; MEIJERINK, A.; VANMAEKELBERGH, D. Luminescent solar concentrators - a review of recent results. Optics Express, v. 16, n. 26, p. 21773-21792, 2008.

8 BRUHWILER, D.; DIEU, L.Q.; CALZAFERRI, G. Nanochannel materials for quantum solar energy conversion devices. Chimia, v. 61, n. 12, p. 820-822, 2007.

9 KITTIDACHACHAN, P.; DANOS, L.; MEYER, T.J.J.; ALDERMAN, N.; MARKVART, T. Photon collection efficiency of fluorescent solar collectors. Chimia, v. 61, n. 12, p. 780-786, 2007. 
10 BENNISTON, A.C.; HARRIMAN, A. Artificial photosynthesis. Materials Today, v. 11, n. 12, p. 26-34, 2008.

11 FANG, Y. Non-invasive optical biosensor for probing cell signaling. Sensors, v. 7, n. 10, p. 23162329, 2007.

12 FAN, X.D.; WHITE, I.M.; SHOPOUA, S.I.; ZHU, H.Y.; SUTER, J.D.; SUN, Y.Z. Sensitive optical biosensors for unlabeled targets: a review. Analytica Chimica Acta, v. 620, n. 1-2, p. 8-26, 2008.

13 HU, C.Y.; ZHENG, H.Z.; ZHANG, J.D.; ZHANG, H.; YANG, F.H.; ZENG, Y.P. Mode splitting in photoluminescence spectra of a quantum-dot-embedded microcavity. Applied Physics Letters, v. 82 , n. 5, p. 665-667, 2003.

14 VALENTA, J.; LALIC, N.; LINNROS, J. Electroluminescence of single silicon nanocrystals. Applied Physics Letters, v. 84, n. 9, p. 1459-1461, 2004.

15 PACHOLSKI, C.; SARTOR, M.; SAILOR, M.J.; CUNIN, F.; MISKELLY, G.M. Biosensing using porous silicon double-layer interferometers: reflective interferometric Fourier transform spectroscopy. Journal of the American Chemical Society, v. 127, n. 33, p. 11636-11645, 2005.

16 LIN, V.S.Y.; MOTESHAREI, K.; DANCIL, K.P.S.; SAILOR, M.J.; GHADIRI, M.R. A porous silicon-based optical interferometric biosensor. Science, v. 278, n. 5339, p. 840-843, 1997.

17 GONÇALVES, V.C. Síntese e caracterização de derivados do politiofeno para utilização em sensores. 2010. 160 p. Tese (Doutorado) - Instituto de Física de São Carlos, Universidade de São Paulo, São Carlos - SP, 2010.

18 BATCHELDER, J.S.; ZEWAIL, A.H.; COLE, T. Luminescent solar concentrators .1. theory of operation and techniques for performance evaluation. Applied Optics, v. 18, n. 18, p. 3090-3110, 1979.

19 BATCHELDER, J.S.; ZEWAIL, A.H.; COLE, T. Luminescent solar concentrators .2. experimental and theoretical-analysis of their possible efficiencies. Applied Optics, v. 20, n. 21, p. 3733-3754, 1981.

20 TRIVINHO-STRIXINO, C. S. ; PEREIRA, Ernesto Chaves ; GUIMARÃES, F. E. G. Active waveguides made from porous anodic alumina filled with luminescent polymers: an optical sensor proposition. In: INTERNATIONAL CONFERENCE ON ADVANCED MATERIALS.ICAM, 11, 2009. Rio de Janeiro,RJ. Proceedings.... Rio de Janeiro: IUMRS, 2009. v.1, p.545.

21 AGNARSSON, B.; HALLDORSSON, J.; ARNFINNSDOTTIR, N.; INGTHORSSON, S.; GUDJONSSON, T.; LEOSSON, K. Fabrication of planar polymer waveguides for evanescent-wave sensing in aqueous environments. Microelectronic Engineering, v. 87, n. 1, p. 56-61, 2010. 
22 JRADI, S.; SOPPERA, O.; LOUGNOT, D.J. Fabrication of polymer waveguides between two optical fibers using spatially controlled light-induced polymerization. Applied Optics, v. 47, n. 22, p. 3987-3993, 2008.

23 ICHIHASHI, Y.; HENZI, P.; BRUENDEL, M.; MOHR, J.; RABUS, D.G. Polymer waveguides from alicyclic methacrylate copolymer fabricated by deep-UV exposure. Optics Letters, v. 32, n. 4, p. 379-381, 2007.

24 DE LUCA, S.; RENDINA,Ivo; MORETTI, Luigi; TUNDO, S. ROSSI; ANDREA, M. Smart optical sensors for chemical substances based on porous silicon technology. Washington, DC, ETATS-UNIS: Optical Society of America, 2004.

25 WUN, A.W.; SNEE, P.T.; CHAN, Y.; BAWENDI, M.G.; NOCERA, D.G. Non-linear transduction strategies for chemo/biosensing on small length scales. Journal of Materials Chemistry, v. 15, n. 2728, p. 2697-2706, 2005.

26 PELANT, I.; OSTATNICKY, T.; VALENTA, J.; LUTEROVA, K.; SKOPALOVA, E.; MATES, T.; ELLIMAN, R.G. Waveguide cores containing silicon nanocrystals as active spectral filters for silicon-based photonics. Applied Physics B-Lasers and Optics, v. 83, n. 1, p. 87-91, 2006.

27 LUTEROVA, K.; CAZZANELLI, M.; LIKFORMAN, J.P.; NAVARRO, D.; VALENTA, J.; OSTATNICKY, T.; DOHNALOVA, K.; CHEYLAN, S.; GILLIOT, P.; HONERLAGE, B.; PAVESI, L.; PELANT, I. Optical gain in nanocrystalline silicon: comparison of planar waveguide geometry with a non-waveguiding ensemble of nanocrystals. Optical Materials, v. 27, n. 5, p. 750-755, 2005.

28 CHOI, C.K.; MARGRAVES, C.H.; JUN, S.I.; ENGLISH, A.E.; RACK, P.D.; KIHM, K.D. Optoelectric cellular biosensor using optically transparent indium tin oxide (ITO) electrodes. Sensors, v. 8, n. 5, p. 3257-3270, 2008.

29 VOROS, J.; RAMSDEN, J.J.; CSUCS, G.; SZENDRO, I.; DE PAUL, S.M.; TEXTOR, M.; SPENCER, N.D. Optical grating coupler biosensors. Biomaterials, v. 23, n. 17, p. 3699-3710, 2002.

30 BROUWER, H.J. Semiconducting polymers for light-emitting diodes and lasers. Netherlands: Grafisch bedrijf Ponsen \& Looijen BV Wageningen, 1966. 135 p.

31 CHIANG, C.K.; FINCHER, C.R.; PARK, Y.W.; HEEGER, A.J.; SHIRAKAWA, H.; LOUIS, E.J.; GAU, S.C.; MACDIARMID, A.G. Electrical-conductivity in doped polyacetylene. Physical Review Letters, v. 39, n. 17, p. 1098-1101, 1977.

32 BLYTHE, A.R.; BLOOR, D. Electrical properties of polymers. 2nd ed. Cambridge ; New York: Cambridge University Press, 2005. 480 p. 
33 YU, L. Solitons \& polarons in conducting polymers. Singapore: World Scientific, 1988. 772 p.

34 KITTEL, C. Introduction to solid state physics. 8th ed. Hoboken, NJ: Wiley, 2005. 680 p.

35 HAGLER, T.; PAKBAZ, K.; VOSS, K.; HEEGER, A. Enhanced order and electronic delocalization in conjugated polymers oriented by gel processing in polyethylene. Physical Review B, v. 44, n. 16, p. 8652-8666, 1991.

36 YANG, S. Bandgap calculations for conjugated polymers. Synthetic Metals, v. 141, n. 1-2, p. 171177, 2004.

37 PICHLER, K.; HALLIDAY, D.A.; BRADLEY, D.D.C.; BURN, P.L.; FRIEND, R.H.; HOLMES, A.B. Optical spectroscopy of highly ordered poly(P-Phenylene Vinylene). Journal of Physics Condensed Matter, v. 5, n. 38, p. 7155-7172, 1993.

38 RAKOVIC, D.; KOSTIC, R.; GRIBOV, L.A.; DAVIDOVA, I.E. Theoretical-study of the vibrational-spectra in Poly(Rho-Phenylene Vinylene). Physical Review B, v. 41, n. 15, p. 1074410746, 1990.

39 CHANDROSS, M.; MAZUMDAR, S.; JEGLINSKI, S.; WEI, X.; VARDENY, Z.V.; KWOCK, E.W.; MILLER, T.M. Excitons in poly(para-phenylenevinylene). Physical Review B, v. 50, n. 19, p. 14702-14705, 1994.

40 FACETO, A.D. Simulação dos processos de migração e relexação energética em sistemas orgânicos pi-conjugados emissores de luz. 2007. 115p. Dissertação (Mestrado em Física) - Instituto de Física de São Carlos, Universidade de São Paulo, São Carlos, SP, 2007.

41 VARDENY, Z.; EHRENFREUND, E.; BRAFMAN, O.; NOWAK, M.; SCHAFFER, H.; HEEGER, A.J.; WUDL, F. Photogeneration of confined soliton pairs (Bipolarons) in polythiophene. Physical Review Letters, v. 56, n. 6, p. 671-674, 1986.

42 PAKBAZ, K.; LEE, C.H.; HEEGER, A.J.; HAGLER, T.W.; MCBRANCH, D. Nature of the primary photoexcitations in poly(Arylene-Vinylenes). Synthetic Metals, v. 64, n. 2-3, p. 295-306, 1994.

43 RAUSCHER, U.; BASSLER, H.; BRADLEY, D.D.C.; HENNECKE, M. Exciton versus band description of the absorption and luminescence spectra in Poly(Para-Phenylenevinylene). Physical Review B, v. 42, n. 16, p. 9830-9836, 1990.

44 GRAGE, M.M.L.; WOOD, P.W.; RUSECKAS, A.; PULLERITS, T.; MITCHELL, W.; BURN, P.L.; SAMUEL, I.D.W.; SUNDSTROM, V. Conformational disorder and energy migration in MEHPPV with partially broken conjugation. Journal of Chemical Physics, v. 118, n. 16, p. 7644-7650, 2003. 
45 SOOS, Z.G.; SCHWEIZER, K.S. Absorption-spectrum of flexible conjugated polymers - the weakdisorder limit. Chemical Physics Letters, v. 139, n. 2, p. 196-200, 1987.

46 SCHWEIZER, K.S. Configurational dependence of the optical-properties of pi-conjugated polymers .1. strong disorder limit. Journal of Chemical Physics, v. 85, n. 7, p. 4181-4193, 1986.

47 GAILBERGER, M.; BASSLER, H. Dc and transient photoconductivity of Poly(2-Phenyl-1,4Phenylenevinylene). Physical Review B, v. 44, n. 16, p. 8643-8651, 1991.

48 FRANKEVICH, E.L.; LYMAREV, A.A.; SOKOLIK, I.; KARASZ, F.E.; BLUMSTENGEL, S.; BAUGHMAN, R.H.; HORHOLD, H.H. Polaron-pair generation in Poly(Phenylene Vinylenes). Physical Review B, v. 46, n. 15, p. 9320-9324, 1992.

49 SCHEIDLER, M.; LEMMER, U.; KERSTING, R.; KARG, S.; RIESS, W.; CLEVE, B.; MAHRT, R.F.; KURZ, H.; BASSLER, H.; GOBEL, E.O.; THOMAS, P. Monte Carlo study of picosecond exciton relaxation and dissociation in poly(phenylenevinylene). Physical Review B, v. 54, n. 8, p. 5536-5544, 1996.

50 KERSTING, R.; LEMMER, U.; MAHRT, R.F.; LEO, K.; KURZ, H.; BASSLER, H.; GOBEL, E.O. Femtosecond energy relaxation in pi-conjugated polymers. Physical Review Letters, v. 70, n. 24, p. 3820-3823, 1993.

51 FRIEND, R.H.; BRADLEY, D.D.C.; TOWNSEND, P.D. Photoexcitation in Conjugated Polymers. Journal of Physics D - Applied Physics, v. 20, n. 11, p. 1367-1384, 1987.

52 PARKER, C.A. Photoluminescence of solutions with applications to photochemistry and analytical chemistry. New York, NY: Elsevier Pub. Co., 1968. 544 p.

53 PHILLIPS, D.; ROBERTS, A.J. Photophysics of synthetic polymers. Northwood, Middlesex, England: Science Reviews, 1982. 171 p.

54 MAIA, F.C.B. Correlação entre polarização da luminescência e orientação molecular em polímeros conjugados.2006. 142p. Dissertação (Mestrado em Física) - Instituto de Física de São Carlos, Universidade de São Paulo, São Carlos, SP, 2006.

55 VALEUR, B. Molecular fluorescence: principles and applications. Weinheim ; New York: Wiley-VCH, 2002. 387 p.

56 MEER, B.W.V.D.; COKER, G.; CHEN, S.Y.S. Resonance energy transfer : theory and data. New York: VCH, 1994. 177 p. 
57 WILMOT, D.W.; SCHINELL.ER Optical waveguides formed by proton irradiation of fused silica. Journal of the Optical Society of America, v. 56, n. 10, p. 1434, 1966.

58 WEI, D.T.Y.; LEE, W.W.; BLOOM, L.R. Quartz optical waveguide by ion-implantation. Applied Physics Letters, v. 22, n. 1, p. 5-7, 1973.

59 SHUBERT, R.; HARRIS, J.H. Optical surface waves on thin films and their application to integrated data processors. IEEE Transactions on Microwave Theory and Techniques, v. 16, $\mathrm{n}$. 12, p. 1048, 1968.

60 OSTROWSK.DB; JACQUES, A. Formation of optical waveguides in photoresist films. Applied Physics Letters, v. 18, n. 12, p. 556-557, 1971.

61 GOELL, J.E.; STANDLEY, R.D. Sputtered glass waveguide for integrated optical circuits. Bell System Technical Journal, v. 48, n. 10, p. 3445, 1969.

62 TIEN, P.K. Modes of propagating light waves in thin deposited semiconductor films. Applied Physics Letters, v. 14, n. 9, p. 291, 1969.

63 HALL, D.; YARIV, A.; GARMIRE, E. Optical guiding and electro-optic modulation in GaAs epitaxial layers. Optics Communications, v. 1, n. p. 403-405, 1970.

64 IZAWA, T.; KIMURA, T.; NAKAGOME, H. Optical waveguides formed by electrically induced migration of ions in glass plates. IEEE Journal Of Quantum Electronics, v. 8, n. 6, p. 545-546, 1972.

65 TAYLOR, H.F. Fabrication of single-crystal semiconductor optical waveguides by solid-state diffusion. Applied Physics Letters, v. 21, n. 3, p. 95, 1972.

66 PITT, C.W.; WALPITA, L.M. Optical waveguiding in Langmuir films. Electronics Letters, v. 12, n. 18 , p. $479,1976$.

67 HENRY, C.H.; BLONDER, G.E.; KAZARINOV, R.F. Glass waveguides on silicon for hybrid optical packaging. Journal of Lightwave Technology, v. 7, n. 10, p. 1530-1539, 1989.

68 GRIFFITHS, D.J. Introduction to electrodynamics. 3rd ed. Upper Saddle River, N.J.: Prentice Hall, 1999. 576 p.

69 SIPE, J.E.; STEGEMAN, G.I. Comparison of normal mode and total field analysis techniques in planar integrated-optics. Journal of the Optical Society of America, v. 69, n. 12, p. 1676-1683, 1979. 
70 NGUYEN, T.Q.; WU, J.J.; DOAN, V.; SCHWARTZ, B.J.; TOLBERT, S.H. Control of energy transfer in oriented conjugated polymer-mesoporous silica composites. Science, v. 288, n. 5466, p. 652-656, 2000.

71 HUANG, G.S.; WU, X.L.; YANG, L.W.; SHAO, X.F.; SIU, G.G.; CHU, P.K. Dependence of blue-emitting property on nanopore geometrical structure in Al-based porous anodic alumina membranes. Applied Physics a-Materials Science \& Processing, v. 81, n. 7, p. 1345-1349, 2005.

72 PENZKOFER, A.; HOLZER, W.; TILLMANN, H.; HORHOLD, H.H. Leaky-mode emission of luminescent thin films on transparent substrates. Optics Communications, v. 229, n. 1-6, p. 279-290, 2004.

73 CHAN, S.; LI, Y.; ROTHBERG, L.J.; MILLER, B.L.; FAUCHET, P.M. Nanoscale silicon microcavities for biosensing. Materials Science \& Engineering C-Biomimetic and Supramolecular Systems, v. 15, n. 1-2, p. 277-282, 2001.

74 FOWLES, G.R. Introduction to modern optics. 2nd ed. New York: Dover Publications, 1989. $328 \mathrm{p}$.

75 HUNSPERGER, R.G. Integrated optics. 6th ed. New York, NY: Springer New York, 2009. 513 p.

76 KHRIACHTCHEV, L.; RASANEN, M.; NOVIKOV, S. Efficient wavelength-selective optical waveguiding in a silica layer containing Si nanocrystals. Applied Physics Letters, v. 83, n. 15, p. 3018-3020, 2003.

77 DUAN, X.F.; HUANG, Y.; AGARWAL, R.; LIEBER, C.M. Single-nanowire electrically driven lasers. Nature, v. 421, n. 6920, p. 241-245, 2003.

78 AGARWAL, R.; BARRELET, C.J.; LIEBER, C.M. Lasing in single cadmium sulfide nanowire optical cavities. Nano Letters, v. 5, n. 5, p. 917-920, 2005.

79 KINDERMAN, R.; SLOOFF, L.H.; BURGERS, A.R.; BAKKER, N.J.; BUCHTEMANN, A.; DANZ, R.; VAN ROOSMALEN, J.A.M. I-V Performance and stability study of dyes for luminescent plate concentrators. Journal of Solar Energy Engineering, v. 129, n. 3, p. 277, 2007.

80 GREEN, M.A. Third generation photovoltaics : advanced solar energy conversion. Berlin ; New York: Springer, 2003. $160 \mathrm{p}$.

81 LUQUE, A.; MARTÍ, A. Increasing the efficiency of ideal solar cells by photon induced transitions at intermediate levels. Physical Review Letters, v. 78, n. 26, p. 5014-5017, 1997. 
82 BARNHAM, K.; MARQUES, J.L.; HASSARD, J.; O'BRIEN, P. Quantum-dot concentrator and thermodynamic model for the global redshift. Applied Physics Letters, v. 76, n. 9, p. 1197-1199, 2000.

83 LUQUE, A.; MARTI, A.; BETT, A.; ANDREEV, V.; JAUSSAUD, C.; VANROOSMALEN, J.; ALONSO, J.; RAUBER, A.; STROBL, G.; STOLZ, W. Fullspectrum: a new PV wave making more efficient use of the solar spectrum. Solar Energy Materials and Solar Cells, v. 87, n. 1-4, p. 467479, 2005.

84 PENG, X.G.; SCHLAMP, M.C.; KADAVANICH, A.V.; ALIVISATOS, A.P. Epitaxial growth of highly luminescent $\mathrm{CdSe} / \mathrm{CdS}$ core/shell nanocrystals with photostability and electronic accessibility. Journal of the American Chemical Society, v. 119, n. 30, p. 7019-7029, 1997.

85 INDAC I.N.P.D.D.A.-. Tudo sobre acrílico. 2010.Disponivel em: $<$ http://www.indac.org.br/ $>$. Acesso em: 20/04/2010.

86 TOZONI, J.R.; GUIMARAES, F.E.G.; ATVARS, T.D.Z.; NOWACKI, B.; AKCELRUD, L.; BONAGAMBA, T.J. De-aggregation of polyfluorene derivative by blending with a series of poly(alkyl methacrylate)s with varying sidegroup sizes. European Polymer Journal, v. 45, n. 8, p. 2467-2477, 2009.

87 JONES, S.; FONDA, G.R. Quantum efficiencies and optical properties of phosphors. Journal of the Optical Society of America, v. 43, n. 4, p. 336-336, 1953.

88 BORGES, C.A.M. Processos radiativos e não radiativos em polímeros conjugados emissores de luz. 2001. 124 p. Dissertação (Mestrado em Física) - Instituto de Física de São Carlos, Universidade de São Paulo, São Carlos, SP, 2001.

89 FAVARIM, H.R. Estudo dos processos fotofísicos em heteroestruturas orgânicas que utilizam chaveamento de luz por fotoalinhamento molecular. 2006. 126p. Dissertação (Mestrado em Física) - Instituto de Física de São Carlos, Universidade de São Paulo, São Carlos, SP, 2006.

90 FAVARIM, H.R.; SPADACIO, D.; FACETO, A.D.; ZUCOLOTTO, V.; OLIVEIRA, O.N.; GUIMARAES, F.E.G. Energy-modulated heterostructures made with conjugated polymers for directional energy transfer and carrier confinement. Advanced Functional Materials, v. 17, n. 15, p. 2862-2868, 2007. 